\title{
Microeconomic Evidence of Creative Destruction in Industrial and Developing Countries
}

\author{
By Eric Bartelsman, John Haltiwanger and Stefano Scarpetta ${ }^{1}$
}

\begin{abstract}
In this paper we provide an analysis of the process of creative destruction across 24 countries and 2-digit industries over the past decade. We rely on a newly assembled dataset that draws from different micro data sources (business registers, census, or representative enterprise surveys). The novelty of our approach is in the harmonization of firm-level data across countries, which enables international comparisons and the identification of country-specific factors as opposed to sector and time effects. All countries display a massive reallocation of resources, with the entry and exit of many firms in all markets, the failure of many newcomers and the expansion of successful ones. This process of creative destruction affects productivity directly by reallocating resources toward more productive uses, but also indirectly through the effects of increased market contestability. There are also large differences across groups of countries. While entry and exit rates are fairly similar across industrial countries, post-entry performance differs markedly between Europe and the United States, a potential indication of the importance of barriers to firm growth as opposed to barriers to entry. Transition economies show an even more impressive process of creative destruction and, those that have progressed the most toward a market economy show better outcomes from this process. Finally, Mexico shows large firm dynamics with many new firms entering the battle but also many failing rapidly, while Argentina resembles Continental Europe with smaller flows and less impressive post-entry growth of successful firms.

JEL classification: L11, G33, D92,
\end{abstract}

Keywords: entry, exit, survival, firm size, productivity, micro data

1. Respectively: Free University Amsterdam and Tinbergen Institute; University of Maryland, U.S. Census Bureau, and NBER; The World Bank. We are grateful to the World Bank for financial support of this project and to Karin Bouwmeester, Helena Schweiger and Victor Sulla for excellent research assistance. The views expressed in this paper are those of the authors and should not be held to represent those of the World Bank or its countries. 


\section{Introduction}

A rapidly growing number of studies provide evidence of heterogeneity in firm behavior, even within narrowly-defined industries or markets (see Caves, 1998; Bartelsman and Doms, 2000; and Ahn, 2000 for surveys). In all countries studied, there is evidence that the population of firms undergo significant changes over time, both through resource reallocation between existing firms and the process of firm entry and exit. For the study of productivity, the role of within-firm productivity growth $v s$. the productivity growth induced by the reallocation of resources from less productive to more productive businesses has been the focus of much recent research (see, e.g., Olley and Pakes (1996), Griliches and Regev (1995) and Foster, Haltiwanger and Krizan $(2001,2002))$. The impact of changing patterns of international trade on an economy is increasingly viewed through these lenses, with evolving trade relations changing the market structure and mix of businesses (e.g. Helpman, Melitz, and Yeaple, 2004). At the same time, the substantial churning of firms, along with the reallocation of labor across continuing firms, implies that workers and firms incur significant search and other adjustment costs (see, e.g., Mortensen and Pissarides, 1999; and Caballero and Hammour, 2000). The efficiency of an economy in dealing with such reallocation is important not only for the productivity dynamics of the economy, but also for the dynamics of the labor market and in particular of unemployment. For all of these reasons, firm-level dynamics appear to be crucial for the relative success of developed economies and also for the trajectories of transition and emerging economies as they develop and open up markets (see Eslava et. al., 2004; Roberts and Tybout, 1997; Aw, Chung and Roberts, 2002; and Brown and Earle, 2004 for studies on Latin America, East Asia and transition economies, respectively).

Much useful work on these issues has proceeded on a country-by-country basis, using firm-level datasets for a specific country. But there also is a clear interest and need to combine data from multiple countries. This allows in principle an assessment of how much of the observed dynamism at the micro level is due to industry-specific technological factors and market characteristics, and how much is the result of different institutional and policy settings that influence firm behavior and competitive forces in each market. In this paper, we do not specifically address the role of policy and institutions. Instead, we conduct exploratory data analysis exercises of the panel dataset exploiting the variation across countries, industries and time. The dataset, constructed through 'distributed micro-data analysis' as described in detail in Bartelsman, Scarpetta, and Haltiwanger (2004), includes indicators built up from (confidential) micro-level sources available to researchers in each of the countries included. ${ }^{2}$

We present evidence on the process of creative destruction in a selection of industrialized and developing economies. We focus on the distribution of firm size over time, the frequency and size of firm entry and exit, and the evolution of the (size) distribution of firms by entry-cohort. Further, we analyze the sources of productivity growth at the industry and aggregate levels. We look at the contribution of firm entry and exit to productivity growth as well as at the contribution coming from the reallocation of resources across existing firms. Overall, we provide a comprehensive picture of the magnitude, characteristics and effectiveness of the creative

2. The approach to collecting and constructing harmonized firm-level data in this project differs from projects like the ICA project that use the same survey instrument in a number of countries. A discussion of the advantages and disadvantages of the alternative approaches as well as the relationship on key findings from the ICA dataset vs. the type of firm-level data used here is provided in Haltiwanger and Schweiger (2004). Recent papers that have used the ICA data to study firm performance include Bastos and Nasir (2004), Dollar et. al. (2003), HallwardDriemeier et al. (2003). 
destruction process and, by exploiting the different dimensions of our data, we make the first attempt at understanding the sources of the observed variations across countries and industries. Our country dataset includes 24 economies over a period covering most of the past decade; ten industrial countries, five Central and Eastern European countries in transition, and nine emerging economies in Latin America and East Asia. These countries differ significantly along different dimensions including the underlying economic conditions and the policy and institutional settings.

The remainder of the paper is organized as follows. In Section 2, we briefly review the recent theory on the reasons behind firms' heterogeneity and the importance of experimentation and learning by doing. In this section, we also discuss how policy and institutional settings may influence firm heterogeneity. We argue that different policy settings may influence firm behavior in multiple ways and that several firm-level indicators are needed to assess how the different policy choices ultimately affect economic efficiency. In Section 3, we provide a brief description of the data for 24 industrial, transition and emerging economies. We then turn to the empirical evidence. In Section 4 we first present the distribution of firms by size; we then document the magnitude and key features of firm dynamics (entry and exit of firms) and, finally, we study post entry performance of different cohorts of new firms. In Section 5 we analyze the effectiveness of creative destruction for productivity growth. We distinguish between the productivity contribution coming from the process of creative destruction (entry and exit of firms) to that stemming from within-firm efficiency improvements and reallocation of resources across incumbents. In the final section, we draw some preliminary conclusions and propose a research agenda to start exploring the links between policy and firm dynamics.

\section{Firm heterogeneity, market structure and institutions}

\section{Stylized Facts}

Over the past two decades, evidence has mounted suggesting sizable heterogeneity of firms across different interrelated dimensions, size, growth, market shares, life cycle etc. In particular, some regularities have been found in the growing empirical literature, including (see e.g. Sutton, 1997; Pakes and Ericson, 1998, Geroski, 1995 for surveys): ${ }^{3}$

1. Size and growth: The probability of survival tends to increase with firm (or plant) size; but, conditional on survival, the proportional rate of growth of a firm is decreasing in size (see Evans 1987a, 1987b; Dunne et al. 1988, 1989).

2. The firm life cycle: For any given size of firm, the proportional rate of growth is smaller the older the firm, but its survival probability is greater (see Foster et al. 2001; and the survey of post entry performance of firms in the International Journal of Industrial Organization, 1995).

3. Shakeouts: The number of producers in a given market tends first to rise to a peak, and later to fall to some lower level. Entry rates tend to be higher for more recent industries but tend to decline as the industry matures (Klepper and Graddy, 1990; Klepper and Simons, 1993; Geroski, 1995).

3. Amongst others, see Aghion and Howitt (1992) and Caballero and Hammour (1994, 1996). Foster, Haltiwanger and Krizan (2001), Caves (1998) and Bartelsman and Doms (2000) offer further discussion of this literature. 
4. Churning: There is a high pace of the reallocation of outputs and inputs across businesses that (i) is largely within narrowly defined sectors; (ii) differs substantially across sectors and firm characteristics (e.g., much more churning amongst young and small businesses); and (iii) where entry and exit of businesses account for a substantial fraction of the variation and the positive correlation between gross entry rates and gross exit rates across industries helps account for the differences in churning rates across sectors (e.g. Geroski, 1995, Ahn, 2000 and Davis and Haltiwanger, 1999 for surveys of the literature).

5. Reallocation and Productivity: The pattern of reallocation is far from random. In well-developed market economies, the evidence is overwhelming that the pattern of reallocation is productivity enhancing. Accounting exercises show that a large fraction of total factor productivity and labor productivity growth at the industry level is accounted for by the reallocation of outputs and inputs from less productive to more productive businesses (see e.g. Olley and Pakes, 1996, Griliches and Regev, 1995, and Foster, Haltiwanger and Krizan, 2001, 2002).

\section{Why are firms so heterogeneous?}

These statistical regularities depict a story whereby entrant firms start business with a different initial size reflecting differences in their own perceived ability. Because of the inherent uncertainty in their potentials, even an entrant who is very successful, ex post, tends to begin with a smaller size at the initial stage of his life. This provides an explanation why small and young survivors show rapid growth. Competition continuously separates winners and losers with unsuccessful firms exiting the market relatively rapidly, and successful survivors growing and adapting. The accumulation of experience and assets, in turn, strengthens survivors and lowers the likelihood of failure.

Several theories have been developed to explain these observed patterns of firm dynamics survival and growth. They generally relate to the process of 'creative destruction' (usually ascribed to Joseph Schumpeter). The distinguishing element of Schumpeter's theory from 'standard' theories of firm behavior is that it recognizes heterogeneity amongst producers and that the continual shift in the composition of the population of firms through entry, exit, expansion and contraction is essential in developing and creating new processes, products and markets.

The first two regularities are consistent with one class of models of firm learning process, the passive learning model of Jovanovic (1982). In his model, a sequence of firms that do not know their own potential profitability enters the market. Only after entry does the firm start to learn about the distribution of its own profitability based on noisy information from realized profits. By continually updating such learning, the firm decides to expand, contract, or to exit. One of the main implications of this model is that smaller and younger firms should have higher and more variable growth rates.

Cabral (1995 and 2003) offers an alternative theoretical explanation for the observed negative relation between firm size and growth (the so called Gibrat's law). His model assumes that firms must incur a sunk cost in building production capacity. Since small entrants have a higher probability of exit than large firms, it is optimal for them to invest more gradually, and thus experience higher growth rates if successful, than larger entrants. Cabral also suggests that financial constraints are an alternative for sunkness of capacity and technology investment. Since cash constraints are expected to be less binding after start up, cash constrained start-ups should expect higher-than-average growth rates. 
Jovanovic and MacDonald (1994) propose a model that is consistent with the observed shakeout of firms as product markets mature. They postulate that at the beginning firms all use a common technology, but over time a new technology emerges which offers low unit costs but higher level of output per firm. The transition to the new technology involves a shakeout of first generation firms, and the survival of a smaller number of firms which employ the new largerscale technology. Klepper (1996) combines a stochastic growth process for firms who enter by developing some new products, with the idea that each firm spends some fixed amount to lower its unit costs. Assuming some imperfection in capital markets and inertia in sales, larger firms will invest more on fixed costs for product innovation, and over time tend to displace smaller firms generating the shakeout.

The presence of high turbulence in most markets is consistent with the active learning model developed by Ericson and Pakes (1995). ${ }^{4}$ In their model, a firm explores its economic environment actively and invests to enhance its profitability under competitive pressure from both within and outside the industry. Its potential and actual profitability changes over time in response to the stochastic outcomes of the firm's own investment, and those of other actors in the same market. The firm grows if successful, shrinks or exits if unsuccessful.

Vintage models of technological change also offer possible explanations for the observed regularities in firm dynamics and performance. These models stress that new technology is often embodied in new capital which often requires a retooling process in existing plants (see e.g. Solow, 1960; Cooper, Haltiwanger and Power, 1997). Related to this idea are models (e.g. Caballero and Hammour, 1994; Mortensen and Pissarides, 1994; Campbell, 1997) that emphasize the potential role of entry and exit: if new technology can be better harnessed by new firms, productivity growth will be dependent upon the entry of new units of production that displace outpaced establishments. Moreover, the existence of sunk costs implies that new firms using the "state-of-the-art" production technology coexist with older and less productive firms generating the observed heterogeneity.

In this paper, we look at harmonized firm-level data for several industrial, transition and developing countries to seek confirmation of the statistical regularities highlighted in previous studies and to assess the possible sources of firm heterogeneity exploiting cross sectoral and well as cross-country variations. As such, this is the first paper, to our knowledge, to exploit a crosscountry sample beyond industrialized countries.

\section{The Role of Market Structure and Institutions}

It is tempting at first glance to hypothesize that countries -- and/or sectors -- where the creative destructive process is distorted in some manner will have less churning and lower productivity levels and productivity growth rates. Indeed, it is not hard to take extreme versions of the models discussed in the prior section and generate just this prediction. That is, making entry and exit (and adjustment more generally) prohibitively costly via distorted market structure and institutions will lead to a reduced pace of churning and lower productivity (see, e.g., Davis and Haltiwanger, 1999 for the illustration of this prediction in a calibration exercise using an extreme example where all reallocation is shutdown). Taken literally, this prediction can be tested by examining the variation by country, sector and year in our harmonized data and relating

4. Various empirical papers have attempted to identify passive and active learning processes. For example, using US data, Pakes and Ericson (1998) claim that manufacturing firms are more consistent with the active learning model whilst retailing firms are more consistent with the passive learning model. 
such variation to country, sector and year variations in institutions. Even more simply, the immediate temptation is to test this prediction implicitly by examining the rank ordering of firm turnover and productivity dynamics across countries and to match that rank ordering up with priors about the rank ordering of market structure and institutions across countries.

However, further reflections suggest that the predictions regarding distortions in market structure and institutions are in fact not so clear. The reason is that distortions may affect the reallocation dynamics on different margins in a variety of ways. For example, artificially high barriers to entry will lead to reduced firm turnover and to a less efficient allocation of resources. But given the high barrier to entry (and in turn the implied ability of marginal incumbents to increase survival probabilities), the average productivity of entrants will rise while the average productivity of incumbents and exiting businesses will fall. Similar predictions apply to policies that subsidize incumbents and/or restrict exit in some fashion. The point is that institutional distortions might yield a larger gap in productivity between entering and exiting businesses.

Alternatively, some types of distortions in market structure and institutions might make the entry and exit process less rational (i.e., less driven by market fundamentals but more by random factors). Such randomness may be associated with either a higher or lower pace of churning. Pure randomness would, in principle, increase the pace of churning but the random factors might be correlated with other factors (e.g., firm size) and thus the impact would be to distort the relationship between churning and such factors with less clear predictions on the overall pace of churning. In any event, such randomness would imply less systematic differences between entering, exiting and incumbent businesses - in the extreme when all entry and exit is random there should be no differences between entering, exiting and incumbent businesses.

Another related problem is that a business climate that encourages more market experimentation might have a larger long run contribution but a smaller short run contribution from the creative destruction process. That is, the greater market experimentation may be associated with more risk and uncertainty in the short run so that it is only after the trial and error process of the experimentation has worked its way out (through learning and selection effects) that the productivity payoff is realized. Thus, a business climate that encourages market experimentation might have a lower short run contribution from entry and exit but a higher long run contribution from entry and exit.

In short, the gap between the productivity of entering and exiting businesses is not by itself sufficient to gauge the contribution or efficiency of the creative destruction process. In addition, different types of distortions might be acting simultaneously in a country. It might be that different policies act to subsidize incumbents (preferential treatment for incumbents), other policies artificially increase the barriers to entry (poorly functioning financial markets and/or regulatory barriers), while other policies make exit more random for some types of businesses (e.g., poorly functioning financial markets for young and small businesses). As such, there might be too little churning on some dimensions and too much on others, the gap between entering and exiting businesses might be too large on some margins and too small on others.

All of these remarks suggest the need for both caution and creativity in using the firm demographic and productivity dynamic statistics that we analyze below. On the one hand, even this brief discussion makes clear that simple cross country comparisons on specific dimensions may be misleading or inadequate. On the other hand, this discussion suggests that creativity needs to be used to examine the connection between the churning and productivity dynamics along multiple dimensions. In like fashion, this discussion helps make clear why it is likely important to exploit variation beyond simple country variation but instead exploit variation on 
additional dimensions like sector and size using difference-in-differences (e.g., exploiting differences in the cross-industry variation across countries).

As will become clear in our discussion of the data in the next section, limitations in the data in different dimensions across countries and compromises that were made to generate 'comparable' data, may hamper analysis of certain questions and generally suggest caution in interpreting simple cross country differences. We now turn to a discussion of the data.

\section{A new dataset of firm-level data from industrial and developing countries}

The dataset used in the study was collected in various stages. Most recently, the firm-level project organized by the World Bank collected indicators for 14 countries (Estonia, Hungary, Latvia, Romania, Slovenia; Argentina, Brazil, Chile, Colombia, Mexico, Venezuela, Indonesia, South Korea and Taiwan.(China)) An earlier OECD study collected indicators based on information on firms from: Canada, Denmark, Germany, Finland, France, Italy, the Netherlands, Portugal, United Kingdom and United States.

These projects made use of a common analytical framework and the data analysis and collection was conducted by active experts in each of the countries. ${ }^{5}$ The framework involves the harmonization, to the extent possible, of key concepts (e.g. entry, exit, or the definition of the unit of measurement) as well as the definition of common methodologies for studying firm-level data. The methodology for collecting the country/industry/time panel dataset built up from underlying micro-level datasets has been referred to as 'distributed micro-data analysis' (Bartelsman 2004). A detailed technical description of the dataset may be found in Bartelsman, Haltiwanger and Scarpetta (2004).

The distributed micro-data analysis was conducted for two separate analytical themes. The first set of analyses gathered data relating to firm demographics, such as entry and exit, jobs flows, size distribution and firm survival. The second theme gathered indicators of movements of firms and resources related to productivity, such as productivity contributions of entry/exit and other measures of resource reallocation. The synthetic indicators used in the analysis for these two themes are discussed in details in Box 1.

The analysis of firm demographics is based on business registers, census, social security databases, or employment-based register containing information on both establishments and firms (see Table 1). Data for the analysis of productivity growth come more frequently from business surveys. Using these data, time-series indicators on firm demographics were generated for

5. In addition to the authors of this paper, the researchers involved in the distributed micro-data analysis network for the various projects are: John Baldwin (Canada); Tor Erickson (Denmark); Seppo Laaksonen, Mika Maliranta, and Satu Nurmi (Finland); Bruno Crépon and Richard Duhautois (France); Thorsten Schank (Germany); Fabiano Schivardi (Italy); Karin Bouwmeester, Ellen Hoogenboom and Robert Sparrow (the Netherlands); Pedro Portugal Dias (Portugal); Ylva Heden (Sweden); Jonathan Haskel, Matthew Barnes, and Ralf Martin (United Kingdom); Ron Jarmin and Javier Miranda (United States); Gabriel Sánchez (Argentina), Marc Muendler and Adriana Schor (Brazil), Andrea Repetto (Chile), Maurice Kugler (Colombia and Venezuela), David Kaplan (Mexico), John Earle (Hungary and Romania), Mihails Hazans (Latvia), Raul Eamets and Jaan Maaso (Estonia), Mark Roberts (Korea, Indonesia and Taiwan (China)), Milan Vodopivec (Slovenia). 
disaggregated sectors for each country. The classification into about 40 sectors (roughly the 2digit level detail of ISIC Rev3) coincides with the OECD Structural Analysis (STAN) database. ${ }^{6}$

The other set of indicators in the dataset concerns productivity and its components. The data sources used for the analysis of productivity differ from those used for firm demographics in many countries. For productivity measures, data are needed on output, employment and possibly other productive inputs such as intermediate materials and capital services. Using these source data, indicators are calculated on labor productivity by industry and year, and on the decomposition of productivity growth into within-firm and reallocation components (see below).

\section{Box 1 Main indicators available in the firm-level database}

The use of annual data on firm dynamics implies a significant volatility in the resulting indicators. In order to limit the possible impact of measurement problems, it was decided to use definitions of continuing, entering and exiting firms on the basis of three (rather than the usual two) time periods. Thus, the tabulations of firm demographics contained the following variables:

Entry: The number of firms entering a given industry in a given year. Also tabulated, where available, was the number of employees in entering firms. Entrant firms (and their employees) were those observed as (out, in, in) the register in time $\left(\mathrm{t}_{-1}, \mathrm{t}, \mathrm{t}_{+1}\right)$.

Exit: The number of firms that leave the register and the number of people employed in these firms. Exiting firms were those observed as (in, in, out) the register in time $\left(\mathrm{t}_{-1}, \mathrm{t}, \mathrm{t}+1\right)$.

One-year firms: The number of firms and employees in those firms that were present in the register for only one year. These firms were those observed as (out, in, out) the register in time $\left(t_{-1}, t, t_{+1}\right)$.

Continuing firms: The number of firms and employees that were in the register in a given year, as well as in the previous and subsequent year. These firms were observed as (in, in, in) the register in time $\left(\mathrm{t}_{-1}, \mathrm{t}, \mathrm{t}_{+1}\right)$.

The above indicators were split into 8 firm-size classes including the class of firms without employees. ${ }^{7}$ The data thus allow detailed comparisons of firm-size distributions between industries and countries.

Firm survival: available data allow to track entering firms over time, This allows to calculate survival probabilities over the initial life of firms and to assess their changes in employment over time.

Decomposition of productivity growth: The database includes different types of productivity decomposition for manufacturing industries and some service industries. Depending on the availability of output and input measures, productivity data are available in the database with reference to labor productivity, multifactor productivity using either gross output or value added as the indicator of output (see Bartelsman et al. 2004 for more details). In this paper, the analysis is limited to labor productivity, generally defined as deflated gross output per worker. Firm level nominal values of output are deflated at the industry level

6. See www.oecd.org/data/stan.htm

7. For the OECD countries there are only 6 groups, with the groups between 1 and 20 combined and the groups between 100 and 500 combined. 
Table 1. Data sources

\begin{tabular}{|c|c|c|c|c|c|c|c|}
\hline \multirow[b]{2}{*}{ Country } & \multicolumn{3}{|c|}{ Firm demographics and survival } & \multicolumn{3}{|c|}{ Labor productivity } & \multirow[b]{2}{*}{ Sectors } \\
\hline & Source & Period & Threshold & Source & Period & Threshold & \\
\hline Canada & Business register & $84-98$ & Emp $\geq 1$ & & & & All Economy \\
\hline Denmark & Business register & $81-94$ & $\mathrm{Emp} \geq 1$ & & & & All \\
\hline Finland & Business register & $88-98$ & $\mathrm{Emp} \geq 1$ & Census & $95-00$ to $97-02$ & & All \\
\hline France & Fiscal database & $89-97$ & $\begin{array}{l}\text { Turnover: } \\
\text { Man: Euro } 3.8 \mathrm{~m} \\
\text { Serv: Euro } 1.1 \mathrm{~m}\end{array}$ & Fiscal database & $85-90$ to $90-95$ & $\begin{array}{l}\text { Turnover: } \\
\text { Man: Euro } \\
3.8 \mathrm{~m} \\
\end{array}$ & All \\
\hline Germany (West) & Social security & $77-99$ & $E m p \geq 1$ & $\begin{array}{l}\text { Survey, pop. } \\
\text { weighted }\end{array}$ & $95-00$ to $97-02$ & & $\begin{array}{l}\text { All but civil } \\
\text { service, } \\
\text { self employed } \\
\end{array}$ \\
\hline Italy & Social security & $86-94$ & $E m p \geq 1$ & Survey & $82-87$ to $93-98$ & $\begin{array}{l}\text { Turnover: } \\
\text { Euro 5m }\end{array}$ & All \\
\hline Netherlands & Business register & $87-97$ & None & $\begin{array}{l}\text { Survey, pop. } \\
\text { weighted }\end{array}$ & $94-99$ to $1996-01$ & & Private Business \\
\hline Portugal & $\begin{array}{l}\text { Employment- } \\
\text { based register }\end{array}$ & $83-98$ & $E m p \geq 1$ & $\begin{array}{l}\text { Employment- } \\
\text { based register }\end{array}$ & $86-91 \& 89-94$ & & $\begin{array}{l}\text { All but public } \\
\text { administration }\end{array}$ \\
\hline United Kingdom & Business register & $80-98$ & $E m p \geq 1$ & $\begin{array}{l}\text { Survey, pop. } \\
\text { weighted }\end{array}$ & $95-00 \& 96-01$ & & Manufacturing \\
\hline USA & Business register & $88-97$ & Emp $\geq 1$ & Census & $87-92$ to $92-97$ & Emp $>1$ & Private businesses \\
\hline Argentina & $\begin{array}{l}\text { Register, based on } \\
\text { Integrated System } \\
\text { of Pensions }\end{array}$ & $95-02$ & $E m p \geq 1$ & $\begin{array}{l}\text { Annual Industrial } \\
\text { Survey. INDEC }\end{array}$ & $90-95$ to $96-01$ & $\begin{array}{l}\text { Emp } \geq 9 \& \\
\$ 2 \mathrm{~m} \\
\text { threshold }\end{array}$ & $\begin{array}{l}\text { Firm } \\
\text { demographics = } \\
\text { all; productivity = } \\
\text { manufacturing }\end{array}$ \\
\hline Brazil & Census & 96-01 & & $\begin{array}{l}\text { Annual Industrial } \\
\text { Survey }\end{array}$ & $1997-2001$ & $\begin{array}{l}\text { Emp } \geq 30+ \\
\text { sample of } \\
10-29\end{array}$ & Manufacturing \\
\hline Chile & $\begin{array}{l}\text { Annual Industry } \\
\text { Survey (ENIA) }\end{array}$ & $79-99$ & Emp. $\geq 10$ & $\begin{array}{l}\text { Annual Industry } \\
\text { Survey (ENIA) }\end{array}$ & $80-85$ to $94-99$ & Emp. $\geq 10$ & Manufacturing \\
\hline Colombia & $\begin{array}{l}\text { Annual } \\
\text { Manufacturing } \\
\text { survey (EAM) } \\
\end{array}$ & $82-98$ & Emp. $\geq 10$ & $\begin{array}{l}\text { Annual } \\
\text { Manufacturing } \\
\text { survey (EAM) } \\
\end{array}$ & $82-86$ to $94-98$ & Emp. $\geq 10$ & Manufacturing \\
\hline Estonia & Business Register & $95-01$ & $E m p \geq 1$ & Business register & $95-00$ to $96-01$ & $E m p \geq 1$ & All \\
\hline Hungary & $\begin{array}{l}\text { Fiscal register } \\
(\mathrm{APEH})\end{array}$ & $92-01$ & $E m p \geq 1$ & $\begin{array}{l}\text { Fiscal register } \\
(\mathrm{APEH})\end{array}$ & $92-96$ to $97-01$ & Emp $>1$ & All \\
\hline Indonesia & $\begin{array}{l}\text { Manufacturing } \\
\text { survey }\end{array}$ & $90-95$ & Emp. $\geq 10$ & $\begin{array}{l}\text { Manufacturing } \\
\text { survey }\end{array}$ & $90-95$ & Emp. $\geq 10$ & Manufacturing \\
\hline Korea (Rep.) & Census & $\begin{array}{l}83-93(3 \\
\text { years })\end{array}$ & $E m p \geq 5$ & Census & $88 \& 93$ & $E m p \geq 5$ & Manufacturing \\
\hline Latvia & Business register & $96-02$ & Emp $\geq 1$ & Business register & 96-01 97-02 & $E m p \geq 1$ & All \\
\hline Mexico & Social security & $85-01$ & $E m p \geq 1$ & & & & All \\
\hline Romania & Business register & $92-01$ & Emp $\geq 1$ & Business register & $95-98$ to $96-99$ & Emp $\geq 1$ & All \\
\hline Slovenia & Business register & $92-01$ & $E m p \geq 1$ & Business register & $92-97$ to $97-01$ & Emp $>1$ & All \\
\hline Taiwan (China) & Census & $\begin{array}{l}86-91(2 \\
\text { years })\end{array}$ & $E m p \geq 1$ & Census & $86-91$ to $91-96$ & $E m p \geq 1$ & Manufacturing \\
\hline Venezuela & $\begin{array}{l}\text { Annual Industrial } \\
\text { Survey }\end{array}$ & $95-00$ & $\begin{array}{l}\text { Emp } \geq 15, \text { sample } \\
\text { of smaller }\end{array}$ & $\begin{array}{l}\text { Annual Industrial } \\
\text { Survey }\end{array}$ & $95-99$ to $96-00$ & $E m p \geq 5$ & Manufacturing \\
\hline
\end{tabular}




\section{Assessing the process of creative destruction}

\section{The distribution of firms by size: sector specialization or framework conditions}

The first step in our analysis of creative destruction is to look at the distribution of firm by size across countries and industries. Firm size is an important dimension in our analysis for several reasons. As discussed above, small firms seem to be affected by greater churning, but also have greater potential for expansion. Thus, a distribution of firms skewed toward small units may imply higher entry and exit, but also greater post entry growth of successful firms. Alternatively, it may point to a sectoral specialization of the given country towards newer industries, where churning tends to be larger and more firms experiment with different technologies. However, as for all our firm-level indicators, any observed difference in one single indicator - like firm size -- cannot, per se, be taken to indicate differences in the magnitude or characteristics of creative destruction. The distribution of firm by size is likely to be influenced by the overall dimension of the internal market - especially for non-tradeables - as well as the business environment in which firms operate that can discourage firm expansion (see below). So, the analysis of firm size should be taken as one of the aspects that together with the others on firm demographics and the productivity decomposition will enable to identify a coherent story about cross-country differences in creative destruction.

It should be stressed at the outset that our analysis is affected by the different thresholds used on firm size. For most countries the data cover all firms with at least one employee. But the cutoff size is 5 employees in South Korea and Venezuela (with a random sample of smaller), ${ }^{8} 10$ employees in Chile, Colombia and Indonesia. Second, even amongst the countries for which data cover all firms with at least one employee, data may be at the establishment level instead of the plant level, and the definition of both may vary across countries. Third, data for some countries are based on other selection criteria, which might induce some bias in the results which cannot be determined a priori (e.g. in France data exclude firms with a turnover below a given threshold). Finally, from a sectoral perspective, community services and utilities are more difficult to compare, given the important role of the public sector, whose coverage changes from country to country, and of regulation in these sectors.

Table 2 suggests that in all countries the population of firms is dominated by micro units (with less than 20 employees). ${ }^{9}$ They account for at least 80 percent of the total firm population. Their share in total employment is much lower and ranges from less than 15 percent in some transition economies (e.g. Romania) -- which still reflects the presence of large (formerly or still) state-owned firms inherited from the central plan period -- to less than 20 percent in the United States and around 30 percent or more in some small European economies. ${ }^{10}$

8. However, the enterprise survey in Venezuela is representative of all firms with at least 15 employees, and only includes a random sample of firms below this threshold. In our analysis, we have used the data for Venezuela with reference to firms with 20+ employees, given the lack of coverage for the lover size classes.

9. For proper comparability, the Table excludes all countries for which the size threshold is 5 or 10 employees instead of one.

10. The Table reports the share of firms with fewer than 20 employees over the total number of firms or total employment for the countries for which we have all firms with at least 1 employee. 
Table 2. Small firms across broad sectors and countries, 1990s (firms with fewer than 20 employees as a percentage of total)

\begin{tabular}{|c|c|c|c|c|c|c|c|c|}
\hline & \multicolumn{4}{|c|}{ Firms } & \multicolumn{4}{|c|}{ Employment* } \\
\hline & $\begin{array}{l}\text { Total } \\
\text { economy }\end{array}$ & \begin{tabular}{|l|} 
Non- \\
Agriculture \\
Business \\
Sector (1) \\
\end{tabular} & Manufacturing & \begin{tabular}{|l} 
Total \\
services
\end{tabular} & $\begin{array}{l}\text { Total } \\
\text { economy }\end{array}$ & \begin{tabular}{|l|} 
Non- \\
Agriculture \\
Business \\
Sector (1) \\
\end{tabular} & Manufacturing & \begin{tabular}{|l} 
Total \\
services
\end{tabular} \\
\hline \multicolumn{9}{|l|}{ Industrial countries } \\
\hline Denmark & 91.3 & 89.5 & 76.6 & 92.3 & 32.7 & 31.1 & 17.6 & 35.0 \\
\hline France & 82.1 & 82.3 & 77.9 & 82.0 & 15.9 & 16.0 & 19.9 & 13.6 \\
\hline Italy & 93.8 & 93.8 & 88.6 & 96.0 & 35.9 & 39.6 & 31.3 & 36.4 \\
\hline Netherlands & 96.3 & 96.5 & 88.3 & 97.1 & 31.8 & 36.8 & 18.3 & 32.9 \\
\hline Finland & 93.6 & 92.7 & 85.4 & 95.3 & 29.5 & 32.7 & 13.5 & 39.1 \\
\hline West Germany & 89.6 & 85.8 & 83.3 & 0.0 & 25.8 & 23.8 & 16.6 & 0.0 \\
\hline Portugal & 89.2 & 88.9 & 75.3 & 93.8 & 32.2 & 31.4 & 18.9 & 42.9 \\
\hline UK & & & 81.3 & & & & 12.4 & \\
\hline USA & 88.0 & 88.0 & 72.6 & 88.7 & 18.4 & 19.3 & 6.7 & 19.9 \\
\hline \multicolumn{9}{|l|}{ Latin America } \\
\hline Mexico & 90.1 & 90.0 & 82.8 & 92.2 & 23.2 & 24.5 & 13.9 & 28.5 \\
\hline Argentina & 90.0 & 89.4 & 82.1 & 91.2 & 27.7 & 27.7 & 21.3 & 27.7 \\
\hline \multicolumn{9}{|l|}{ Transition economies } \\
\hline Slovenia & 87.7 & 88.0 & 71.6 & 93.1 & 13.4 & 13.5 & 5.1 & 26.0 \\
\hline Hungary & 84.4 & 85.5 & 71.1 & 90.8 & 16.0 & 16.4 & 8.8 & 23.6 \\
\hline Estonia & 80.6 & 81.3 & 64.6 & 87.1 & 22.8 & 22.6 & 11.5 & 34.2 \\
\hline Latvia & 87.7 & 87.7 & 87.8 & 87.6 & 24.7 & 24.8 & 26.9 & 24.2 \\
\hline Romania & 90.9 & 91.5 & 77.1 & 95.6 & 12.9 & 12.8 & 4.2 & 31.6 \\
\hline \multicolumn{9}{|l|}{ East Asia } \\
\hline Korea $^{2}$ & & & 57.0 & & & & 11.1 & \\
\hline Taiwan & & & 82.5 & & & & 26.6 & \\
\hline
\end{tabular}

* Share of Employment with less than 20 employees

(1) This aggregates excludes agriculture (ISIC 1-5) and community services (ISIC3: 75-79)

(2) In Korea, data cover firms with 5 or more employees.

Average firm size in aggregate manufacturing or business services in some countries may largely result from a specialization towards industries with a small efficient scale. To assess the role of sectoral specialization versus within sector differences we need a more disaggregated analysis based on a shift-and-share decomposition. The idea behind this technique is to determine how much of the overall deviation of average size from a given benchmark (in our case the crosscountry average) is due to country specialization in sectors with different underlying technological and size characteristics and how much to the fact that average size within sectors tends to be different from that of the benchmark. For example, it could be that overall larger size of manufacturing in the United States is mostly due to the fact that the United States has a productive structure specialized in sectors with large size. The decomposition exploits the following identity: $\bar{s}_{j}=\sum_{i} \omega_{i j} s_{i j}$, where $\bar{s}_{j}$ is the average firm size in manufacturing in country $j, \quad s_{i j}$ is the average firm size in sub-sector $i$ and $\omega_{i j}$ is the share of firms in sub-sector $i$ with respect to the total number of firms in manufacturing. Define now $\bar{s}$ as the overall mean in manufacturing across countries and $\bar{\omega}_{i}$ as the share of overall number of firms in sub-sector $j$. Then the difference between country $j$ and overall mean can be decomposed as follows:

$$
\begin{aligned}
\bar{s}_{j}-\bar{s}=\sum_{i} \omega_{i j} s_{i j}-\sum_{i} \bar{\omega}_{i} \bar{s}_{i}= & \sum_{i}\left(\omega_{i j}-\bar{\omega}_{i}\right) \bar{s}_{i}+\sum_{i}\left(s_{i j}-\bar{s}_{i}\right) \bar{\omega}_{i i}+\sum_{i}\left(s_{i j}-\bar{s}_{i}\right)\left(\omega_{i j}-\bar{\omega}_{i}\right)= \\
& =\Delta_{\omega}+\Delta_{\mathrm{S}}+\Delta_{\omega \mathrm{S}}
\end{aligned}
$$

The first term accounts for differences in the sectoral composition of firms, the second for cross-country differences in firm size within each sector and the last an interaction term, 
which can be interpreted loosely as an indicator of covariance: if it is positive, size and sectoral compositions deviate from the benchmark in the same direction.

The decomposition (Table 3) suggests that within-sector differences generally play the most important role in explaining differences in overall size across countries: this component is much larger (in absolute terms) that the sectoral composition in many countries. ${ }^{11}$ The withinindustry size component is particularly large in the United States, confirming the idea that a larger internal market tends to promote larger firms, but also in some transition economies (Slovenia and especially Romania) where some very large firms of the central-plan period have survived during the transition. However, the sectoral composition also play an important role - similar to the within sector component - in some small European countries such as Denmark and Portugal but also in a relatively larger country like France and an emerging economy like Mexico. These results suggest that both the size structure and the sectoral composition should be controlled for when analyzing firms dynamics and its effects on aggregate performance.

Table 3. Shift and share analysis of the determinants of firm size

\begin{tabular}{|c|c|c|c|c|}
\hline \multicolumn{5}{|c|}{ contribution coming from differences in: } \\
\hline & & Average & Interaction & \\
\hline Country & $\begin{array}{c}\text { Sectoral } \\
\text { composition }\end{array}$ & $\begin{array}{l}\text { Size of } \\
\text { Firms }\end{array}$ & $\begin{array}{c}\text { between sectoral } \\
\text { comp. and size }\end{array}$ & Total \\
\hline Denmark & 0.14 & -0.03 & -0.09 & 0.01 \\
\hline France & 0.08 & -0.05 & -0.05 & -0.02 \\
\hline Italy & -0.02 & -0.17 & -0.01 & -0.20 \\
\hline Netherlands & 0.01 & -0.13 & -0.04 & -0.16 \\
\hline Finland & -0.02 & -0.05 & -0.02 & -0.09 \\
\hline Portugal & -0.05 & -0.04 & 0.02 & -0.07 \\
\hline UK & -0.01 & -0.02 & -0.03 & -0.06 \\
\hline USA & 0.00 & 0.42 & -0.07 & 0.34 \\
\hline Canada & 0.01 & 0.03 & -0.02 & 0.01 \\
\hline Brazil & 0.00 & -0.08 & -0.01 & -0.09 \\
\hline Mexico & 0.06 & -0.06 & -0.02 & -0.02 \\
\hline Argentina & 0.04 & -0.14 & -0.02 & -0.12 \\
\hline Slovenia & 0.01 & 0.30 & -0.07 & 0.24 \\
\hline Hungary & 0.01 & 0.14 & -0.02 & 0.12 \\
\hline Estonia & -0.03 & 0.07 & 0.02 & 0.06 \\
\hline Latvia & -0.03 & -0.20 & 0.04 & -0.20 \\
\hline Romania & 0.08 & 0.97 & -0.36 & 0.68 \\
\hline Korea & 0.04 & 0.12 & 0.02 & 0.18 \\
\hline Taiwan & 0.03 & -0.14 & -0.03 & -0.14 \\
\hline
\end{tabular}

The decomposition also suggests that the sectoral composition and differences within sectors are not highly correlated: the interaction term is negative in most cases, and the sign of the sectoral composition and within sector terms is equal in only a few cases. These results do not support the hypothesis that if a country has an institutional setting that favors a certain size structure, say large firms, it is also characterized both by large firms within sector and a sectoral specialization tilted towards productions naturally characterized by large firms (Davis and Henrekson, 1999).

11. In a sensitivity analysis, we have also replicated the decomposition for the sample of OECD countries and the non-OECD countries (including also Hungary and Mexico) separately. The results are broadly unchanged in the two sub-samples. Moreover, we have replicated the decomposition at a finer level of sectoral disaggregation and again the results are broadly unchanged. 
It is also interesting to look at the dispersion of firm by size within each sector of the economy and to see whether cross-country differences in the dispersion differ across sectors of the economy. Table 4 presents coefficient of variation of firm size, normalized by the overall cross-country coefficient of variation. ${ }^{12}$ If technological factors were predominant in determining the heterogeneity of firm size across countries, we should find that the values in the country columns in Table 3 to be concentrated around one. If, on the contrary, the size differences were explained mainly by national factors inducing a consistent bias within sectors, then we would expect the countries with an overall value above (below) the average (i.e. in the "Total" category) to be characterized by values generally above (below) one in the sub-sectors. The first element emerging from the table is that there are clear sectoral patterns which persist across countries. Service sector activities display greater within-industry dispersion in firm size. This is due to the higher degree of aggregation of most service sectors compared with manufacturing and to the fact that in most service industries small businesses coexist with large multi-plant enterprises. Within manufacturing, high-tech industries (electrical equipment, motor vehicles) have a greater dispersion in firm size than other more traditional manufacturing activities.

From a country perspective, industrial economies seem to have a greater dispersion in firm size, within each sector, than the other countries. And within the industrial countries, the United States show a much larger dispersion in firm size, even controlling for the greater average size of firms: in total manufacturing the dispersion in the US is double that in the average of industrial countries (even controlling for differences in average size) and the differences are even larger in some high-tech industries such as those related to the information and communication technology (ICT). Amongst transition economies, the transport sector still accounts for much of the overall variation being characterized by the presence of old state-owned firms together with new private (and generally smaller) ventures, while in the emerging economies of Latin America and especially East Asia the within-sector dispersion in firm size tend to be smaller than in the industrial countries. Still, it is interesting that every country but Finland has at least one sector with greater dispersion than the cross-country average and every country but the U.S. has at least one sector (and typically many) with less dispersion than the cross-country average.

All in all, overall differences in average firm size are largely driven by within-sector differences, although in some countries sectoral specialization also plays a significant role. Smaller countries tend to have a size distribution skewed towards smaller firms, but the average size of firms as well as the dispersion within and across countries do not map precisely with the overall dimension of the domestic market. The United States tend to have larger firms and wider dispersion within most industries. Other industrial countries, including France, UK, Portugal, also have relatively larger shares of large firms, but not necessarily large dispersion in firm size within industries. Significant differences are also found across emerging and transition economies. While some common patterns can be identified amongst transition economies and can be easily linked to remaining elements of the central plan period, no single factor can be brought to explain the observed cross-country differences in the other countries. Overall, these results point to the possible influence of differences in business environment conditions in shaping firm characteristics and the degree of heterogeneity of firms in the economy and further encourage us to continue our journey into the firm level analysis.

12. We use the coefficient of variation because the dispersion of size across industries or countries is not independent from the average size: sectors (or countries) with larger size also tend to display higher standard deviations. 
Table 4 Within-industry coefficient of variation of firm size

\begin{tabular}{|c|c|c|c|c|c|c|c|c|c|c|c|}
\hline & $\begin{array}{l}\text { cross-country } \\
\text { average }\end{array}$ & Mexico & Slovenia & Hungary & Korea & Taiwan & Estonia & Brazil & Latvia & Romania & Argentina \\
\hline \multicolumn{12}{|l|}{ Sectors } \\
\hline Total economy & 12.4 & 0.94 & 0.52 & 1.09 & 0.45 & 0.47 & 0.48 & 0.63 & 0.66 & 1.60 & 0.77 \\
\hline Agriculture, Hunting, Forestry And Fishing & 6.3 & 1.46 & 0.47 & 0.38 & & & 0.39 & & & 0.86 & 0.62 \\
\hline Mining And Quarrying & 5.7 & 0.71 & 0.60 & 0.56 & & & 0.84 & 1.62 & 0.39 & & 0.67 \\
\hline total manufacturing & 7.5 & 0.78 & 0.49 & 0.66 & 0.74 & 0.77 & 0.40 & 1.04 & 0.64 & 1.29 & 0.68 \\
\hline Food Products, Beverages And Tobacco & 5.8 & 1.08 & 0.33 & 0.56 & 0.56 & 2.40 & 0.39 & 1.56 & 1.18 & & 0.94 \\
\hline Textiles, Textile Products, Leather And Footwear & 4.0 & 1.06 & 0.89 & 0.68 & 1.06 & 0.83 & 0.63 & 1.74 & 0.91 & & 1.17 \\
\hline Wood And Products Of Wood And Cork & 3.2 & 1.02 & 0.81 & 0.92 & 1.09 & 1.07 & 0.63 & 1.07 & 1.23 & & 1.28 \\
\hline Publishing, Printing And Reproduction Of Recorded Media & 5.9 & 0.64 & 0.73 & 0.71 & 0.46 & 0.74 & 0.37 & 0.99 & 0.62 & 2.23 & 0.62 \\
\hline Coke, Refined Petroleum Products And Nuclear Fuel & 2.7 & 0.63 & 0.67 & 1.09 & 0.97 & & 0.37 & 1.22 & 0.30 & 0.44 & 1.87 \\
\hline Chemicals And Chemical Products & 4.4 & 0.81 & 0.66 & 0.96 & 0.62 & 1.54 & 0.54 & 1.04 & 0.44 & 0.93 & 0.73 \\
\hline Rubber And Plastics Products & 3.9 & 0.72 & 1.34 & 0.76 & 0.75 & 1.13 & 0.41 & 0.99 & 0.50 & 1.45 & 0.69 \\
\hline Other Non-Metallic Mineral Products & 4.2 & 1.16 & 0.56 & 0.70 & 0.67 & 0.73 & 0.42 & 0.95 & 0.76 & 0.80 & 0.84 \\
\hline Basic Metals & 4.6 & 1.19 & 0.45 & 0.66 & 1.11 & 0.60 & 0.24 & 1.75 & 0.23 & 0.95 & 1.57 \\
\hline Fabricated Metal Products, Except Machinery And Equipment & 3.7 & 1.12 & 1.09 & 0.86 & 1.11 & 0.81 & 0.49 & 1.23 & 0.68 & 1.17 & 0.73 \\
\hline Machinery And Equipment, N.E.C. & 4.7 & & 0.67 & 0.83 & 0.93 & 0.65 & 0.47 & 1.09 & 0.87 & 0.96 & 0.52 \\
\hline Office, Accounting And Computing Machinery & 5.3 & & 0.27 & 0.77 & 0.49 & 0.77 & 0.22 & 0.79 & 0.46 & 0.90 & 0.25 \\
\hline Electrical Machinery And Apparatus, Nec & 5.1 & & 0.60 & 1.35 & 0.59 & 1.00 & 0.62 & 1.19 & 0.28 & 0.70 & 0.53 \\
\hline Radio, Television And Communication Equipment & 5.3 & & 0.54 & 0.67 & 1.09 & & 0.85 & 0.84 & 0.65 & 0.66 & 0.85 \\
\hline Medical, Precision And Optical Instruments & 5.1 & & 0.78 & 0.79 & 0.62 & 0.45 & 0.49 & 0.72 & 0.83 & 0.62 & 0.40 \\
\hline Motor Vehicles, Trailers And Semi-Trailers & 6.6 & 0.61 & 0.46 & 0.57 & 1.24 & 0.69 & 0.37 & 1.51 & 0.15 & 0.49 & 0.88 \\
\hline Other Transport Equipment & 5.6 & 0.79 & 0.39 & 0.48 & 1.33 & 1.18 & 0.50 & 1.24 & 0.31 & 0.43 & 0.63 \\
\hline Manufacturing Nec; Recycling & 4.1 & 1.18 & 0.63 & 0.63 & 1.04 & 0.70 & 0.79 & 0.97 & 0.50 & 1.04 & 0.52 \\
\hline Electricity, Gas And Water Supply & 5.8 & 1.69 & 0.26 & 0.43 & & & 1.15 & & 0.52 & 1.10 & 0.84 \\
\hline Construction & 5.0 & 0.81 & 0.75 & 0.67 & & & 0.36 & & 0.89 & 1.09 & 0.87 \\
\hline Services & 15.9 & 0.95 & 0.64 & 1.50 & & & 0.39 & & 0.55 & 2.33 & 0.72 \\
\hline --bus sector services & 17.1 & 0.69 & 0.62 & 1.42 & & & 0.37 & & 0.51 & 2.23 & 0.63 \\
\hline Wholesale And Retail Trade; Restaurants And Hotels & 10.0 & 0.79 & 0.55 & 0.68 & & & 0.23 & & 0.47 & 0.80 & 1.04 \\
\hline Transport And Storage And Communication & 15.8 & 0.64 & 0.71 & 1.25 & & & 0.44 & & 0.92 & 1.65 & 0.76 \\
\hline Finance, Insurance, Real Estate And Business Services & 11.8 & 1.19 & 0.58 & 0.95 & & & 0.25 & & 0.59 & 0.45 & 0.73 \\
\hline Community Social And Personal Services & 9.3 & 1.92 & 0.41 & 0.62 & & & 0.23 & & 0.85 & 1.11 & 1.25 \\
\hline
\end{tabular}

\begin{tabular}{|c|c|c|c|c|c|c|c|c|c|c|}
\hline & $\begin{array}{l}\text { cross-country } \\
\text { average }\end{array}$ & Industrial & Other countries & France & Italy & Netherlands & Finland & Portugal & UK & USA \\
\hline \multicolumn{11}{|l|}{ Sectors } \\
\hline Total economy & 12.4 & 1.19 & 0.87 & & 1.69 & 1.35 & 0.31 & 0.68 & & 2.36 \\
\hline Agriculture, Hunting, Forestry And Fishing & 6.3 & 1.23 & 0.81 & 2.07 & 0.56 & 0.48 & & 0.66 & & 1.92 \\
\hline Mining And Quarrying & 5.7 & 1.31 & 0.68 & 1.26 & 1.24 & 0.97 & 0.31 & 0.52 & & 3.55 \\
\hline total manufacturing & 7.5 & 1.28 & 0.74 & 1.04 & 2.18 & 1.19 & 0.49 & 0.48 & 1.03 & 2.83 \\
\hline Food Products, Beverages And Tobacco & 5.8 & 1.14 & 0.85 & 0.77 & 1.51 & 0.86 & 0.42 & 0.51 & 0.82 & 2.96 \\
\hline Textiles, Textile Products, Leather And Footwear & 4.0 & 1.04 & 0.96 & 0.67 & 0.93 & 0.98 & 0.55 & 0.67 & 1.15 & 2.32 \\
\hline Wood And Products Of Wood And Cork & 3.2 & 1.01 & 0.99 & 0.74 & 0.81 & 0.87 & 0.74 & 0.87 & 1.18 & 1.76 \\
\hline Publishing, Printing And Reproduction Of Recorded Media & 5.9 & 1.15 & 0.86 & 0.59 & 2.33 & 0.73 & 0.66 & 0.48 & 0.74 & 2.46 \\
\hline Coke, Refined Petroleum Products And Nuclear Fuel & 2.7 & 1.26 & 0.77 & 0.90 & 1.61 & 0.89 & 0.43 & 0.75 & 1.53 & 2.71 \\
\hline Chemicals And Chemical Products & 4.4 & 1.24 & 0.78 & 1.50 & 1.11 & 0.90 & 0.65 & 0.66 & 0.93 & 2.70 \\
\hline Rubber And Plastics Products & 3.9 & 1.11 & 0.90 & 0.83 & 1.82 & 0.64 & 0.48 & 0.49 & 0.95 & 2.52 \\
\hline Other Non-Metallic Mineral Products & 4.2 & 1.21 & 0.81 & 1.03 & 1.27 & 0.91 & 0.59 & 0.64 & 1.05 & 2.81 \\
\hline Basic Metals & 4.6 & 1.20 & 0.84 & & 2.50 & 1.59 & 0.72 & 0.57 & 0.82 & 1.63 \\
\hline Fabricated Metal Products, Except Machinery And Equipment & 3.7 & 1.04 & 0.97 & & 0.80 & 0.91 & 0.59 & 0.77 & 0.96 & 2.10 \\
\hline Machinery And Equipment, N.E.C. & 4.7 & 1.19 & 0.77 & 1.02 & 1.45 & 0.54 & 0.68 & 0.44 & 1.06 & 2.88 \\
\hline Office, Accounting And Computing Machinery & 5.3 & 1.46 & 0.53 & & 2.00 & 1.49 & 0.58 & 0.20 & 1.16 & 3.63 \\
\hline Electrical Machinery And Apparatus, Nec & 5.1 & 1.22 & 0.74 & 1.28 & 1.35 & 0.78 & 0.67 & 1.01 & 0.99 & 2.21 \\
\hline Radio, Television And Communication Equipment & 5.3 & 1.25 & 0.69 & 1.26 & 1.86 & 2.21 & 0.48 & 0.58 & 1.38 & 2.07 \\
\hline Medical, Precision And Optical Instruments & 5.1 & 1.27 & 0.68 & 1.64 & 1.06 & 1.00 & 0.68 & 0.65 & 0.95 & 2.68 \\
\hline Motor Vehicles, Trailers And Semi-Trailers & 6.6 & 1.46 & 0.58 & 0.76 & 2.76 & 0.94 & 0.52 & 0.54 & 1.47 & 3.48 \\
\hline Other Transport Equipment & 5.6 & 1.44 & 0.59 & 1.16 & 1.74 & 1.88 & 1.00 & 0.70 & 1.61 & 2.57 \\
\hline Manufacturing Nec; Recycling & 4.1 & 1.19 & 0.82 & 1.46 & 0.77 & 1.66 & 0.55 & 0.51 & 0.96 & 2.66 \\
\hline Electricity, Gas And Water Supply & 5.8 & 1.09 & 0.91 & 0.52 & 3.14 & 0.26 & 0.44 & 0.73 & & 1.68 \\
\hline Construction & 5.0 & 1.21 & 0.80 & 1.12 & 1.39 & 1.03 & 0.43 & 1.07 & & 2.28 \\
\hline Services & 15.9 & 0.94 & 1.05 & 0.72 & 1.23 & 1.21 & 0.20 & 0.79 & & 1.83 \\
\hline --bus sector services & 17.1 & 1.06 & 0.95 & 0.68 & 1.53 & 1.48 & 0.18 & 0.79 & & 2.17 \\
\hline Wholesale And Retail Trade; Restaurants And Hotels & 10.0 & 1.35 & 0.68 & 0.93 & 0.96 & 1.17 & 0.21 & 0.49 & & 4.20 \\
\hline Transport And Storage And Communication & 15.8 & 1.10 & 0.91 & 0.31 & 1.85 & 1.81 & 0.30 & 0.82 & & 2.14 \\
\hline Finance, Insurance, Real Estate And Business Services & 11.8 & 1.26 & 0.76 & 0.89 & 1.85 & 2.31 & 0.23 & 0.85 & & 2.36 \\
\hline Community Social And Personal Services & 9.3 & 0.94 & 1.04 & 0.87 & 1.16 & 1.03 & & 0.50 & & 1.32 \\
\hline
\end{tabular}




\section{The creative destruction process: gross and net firm flows}

The second obvious step in our analysis is to look at the magnitude and characteristics of firm creation and destruction. Figure 1 shows entry and exit rates averaged over time (1989 onwards) for the business sector and for manufacturing. Confirming one of the key regularities highlighted in the previous literature, the Figure point to a high degree of turbulence in all countries. Many firms enter and exit most markets every year. Limiting the tabulations to firms with at least 20 employees to maximize the country coverage, total firm turnover (entry plus exit rates $)^{13}$ is in between 3-8 percent in most industrial countries and more than 10 percent in some of the transition economies. Extending the tabulations to also include micro units ( 1 to 19 employees) increases total turnover to between one-fifth and one-fourth of all firms. These data confirm previous findings that in all countries net entry (entry minus exit) is far less important than the gross flows of entry and exit that generate it. This suggests that the entry of new firms in the market is largely driven by a search process rather than augmenting the number of competitors in the market (a point also highlighted by Audretsch, 1995).

There are also interesting differences across countries. In transition economies firm entry largely out-paced firm exit, while more balanced patterns are found in other countries. Obviously this is related to the process of transition and is not sustainable over the longer run. Still it points to the fact that new firms not only displaced obsolete incumbents in the transition phase but also filled in new markets which were either nonexistent or poorly populated in the past. This is also reflected in the discrepancies between firm entry and exit across firm size. The Latin America region shows a wide variety of experiences: while Mexico, Chile (manufacturing) and Venezuela (manufacturing) show vigorous firm turnover, Colombia and especially Argentina show less turbulence, closer to the values observed in some Continental European countries.

Figure 1. Firm turnover rates in broad sectors, 1990s

Panel A: Manufacturing, firms with 20 or more employees

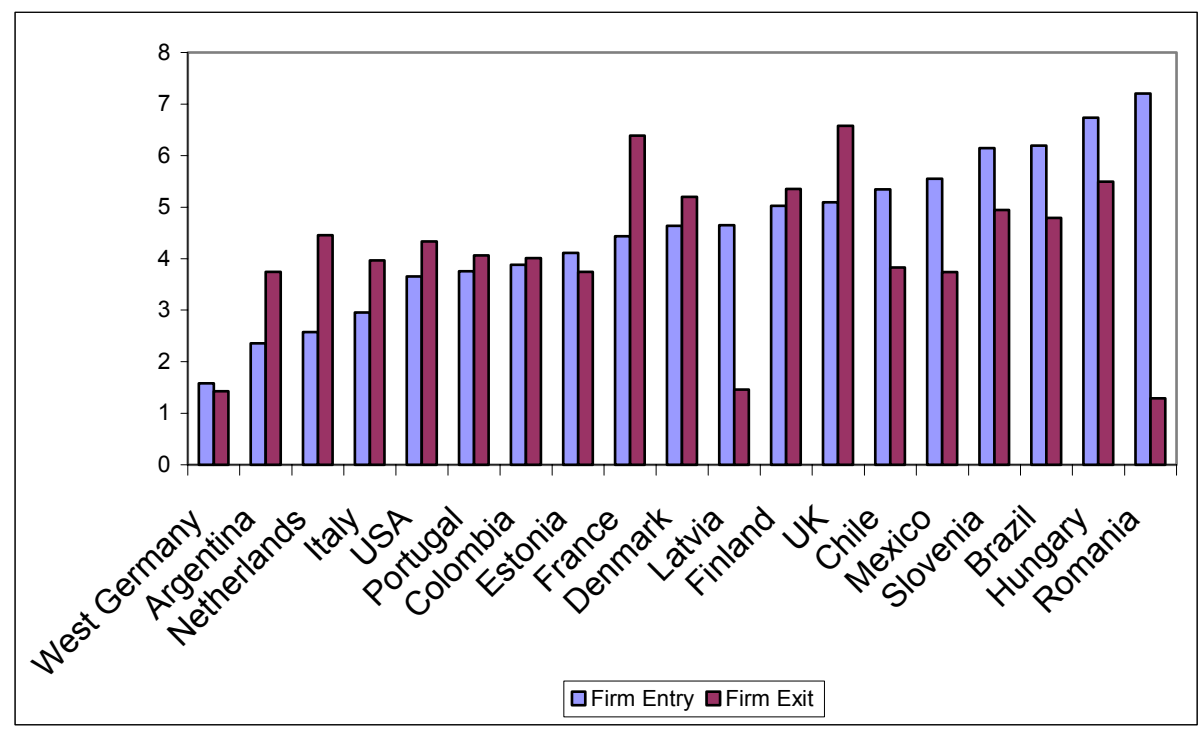

13. The entry rate is defined as the number of new firms divided by the total number of incumbent and entrants firms producing in a given year; the exit rate is defined as the number of firms exiting the market in a given year divided by the population of origin, i.e. the incumbents in the previous year. 
Panel B: Manufacturing, firms with at least 1 employee

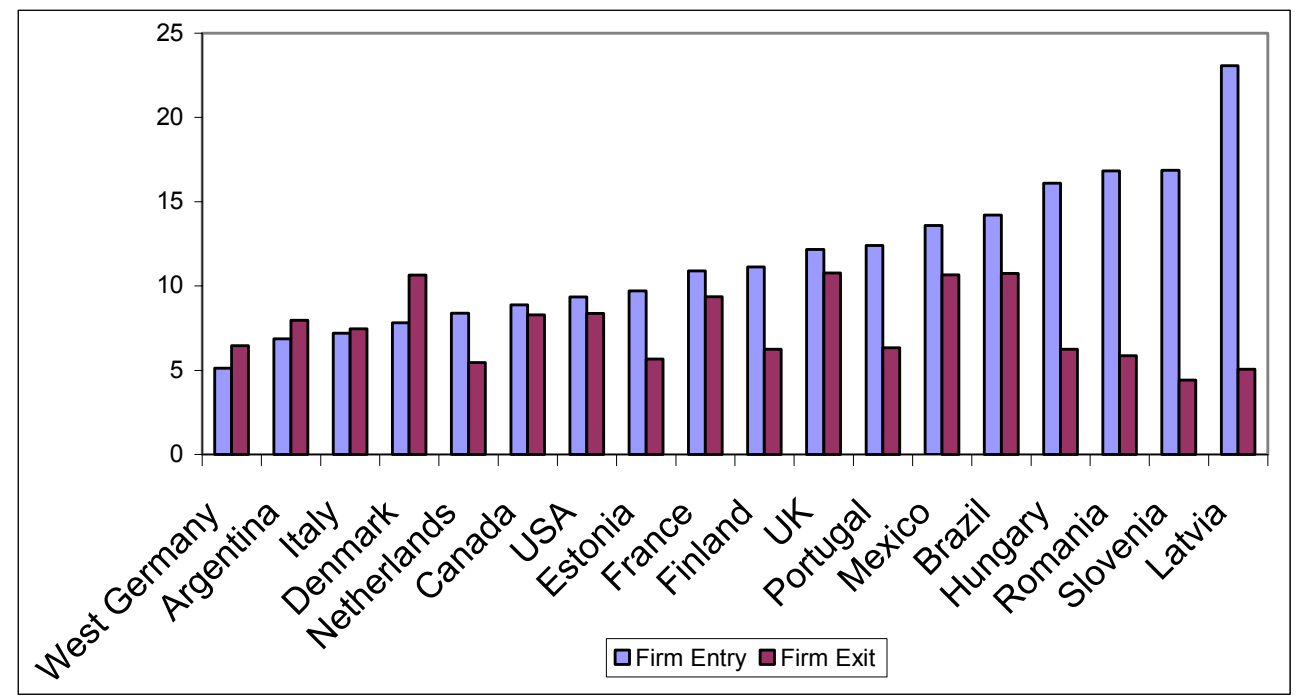

Panel C: Total business sector, firms 20 or more employees

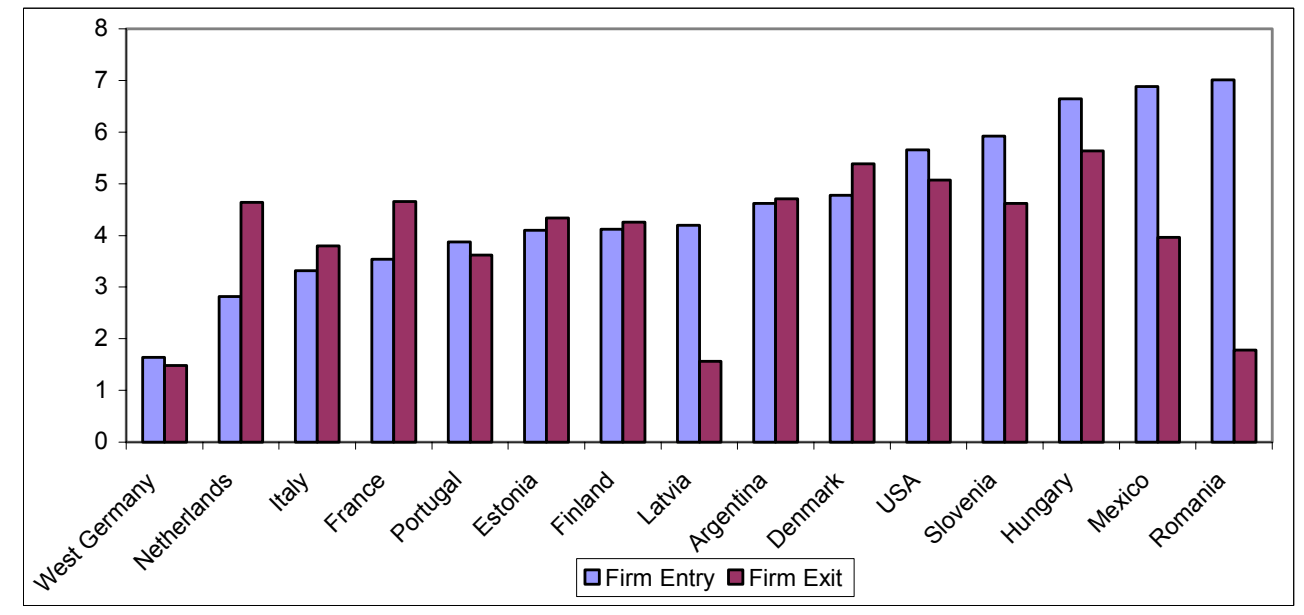

Panel D: Total business sector, firms with at least 1 employee

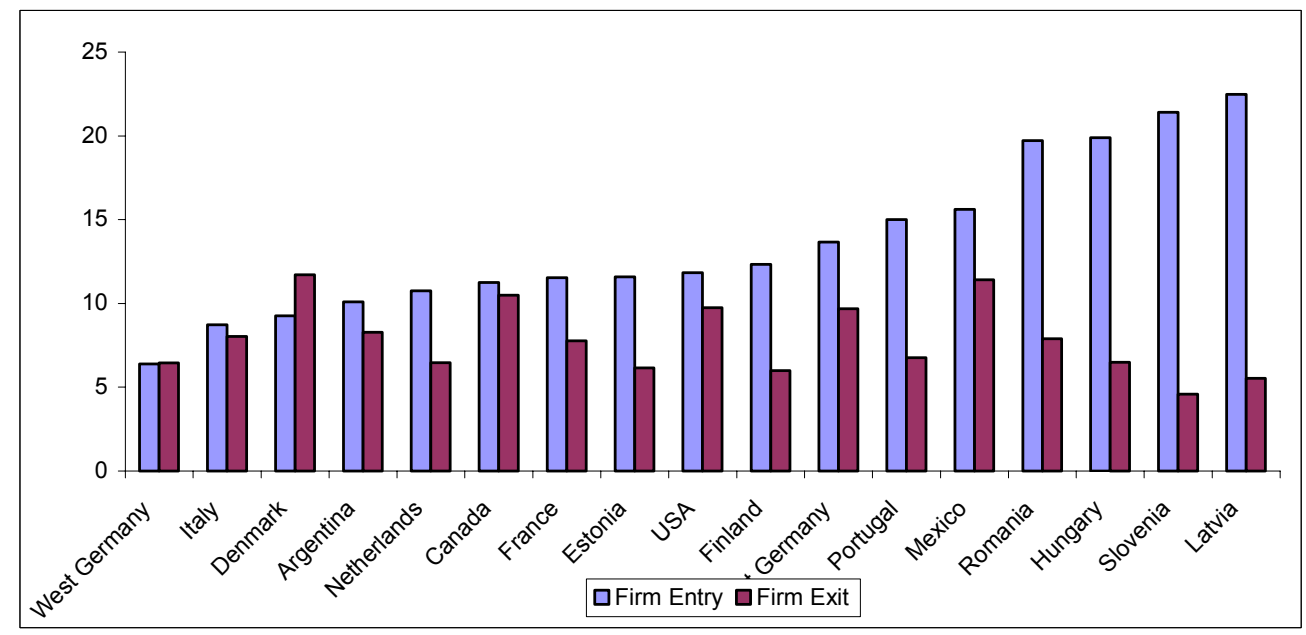


Data for the transition economies clearly show the role of market forces in shaping firm dynamics (Figure 2). At the beginning of their transition to a market economy, both gross and net firm flows were large compared to industrial and other emerging economies: in some of the transition economies a large fraction of firms were closed down and replaced by new small ventures, and this process accounted for more than 10 percent of total employment. As the transition moved forward gross and especially net flows declined to reach, at the end of the 1990 s, values fairly close to those observed in other countries.

Figure 2: The evolution of gross and net firm flows in transition economies, business sector Panel A: Gross firm flows
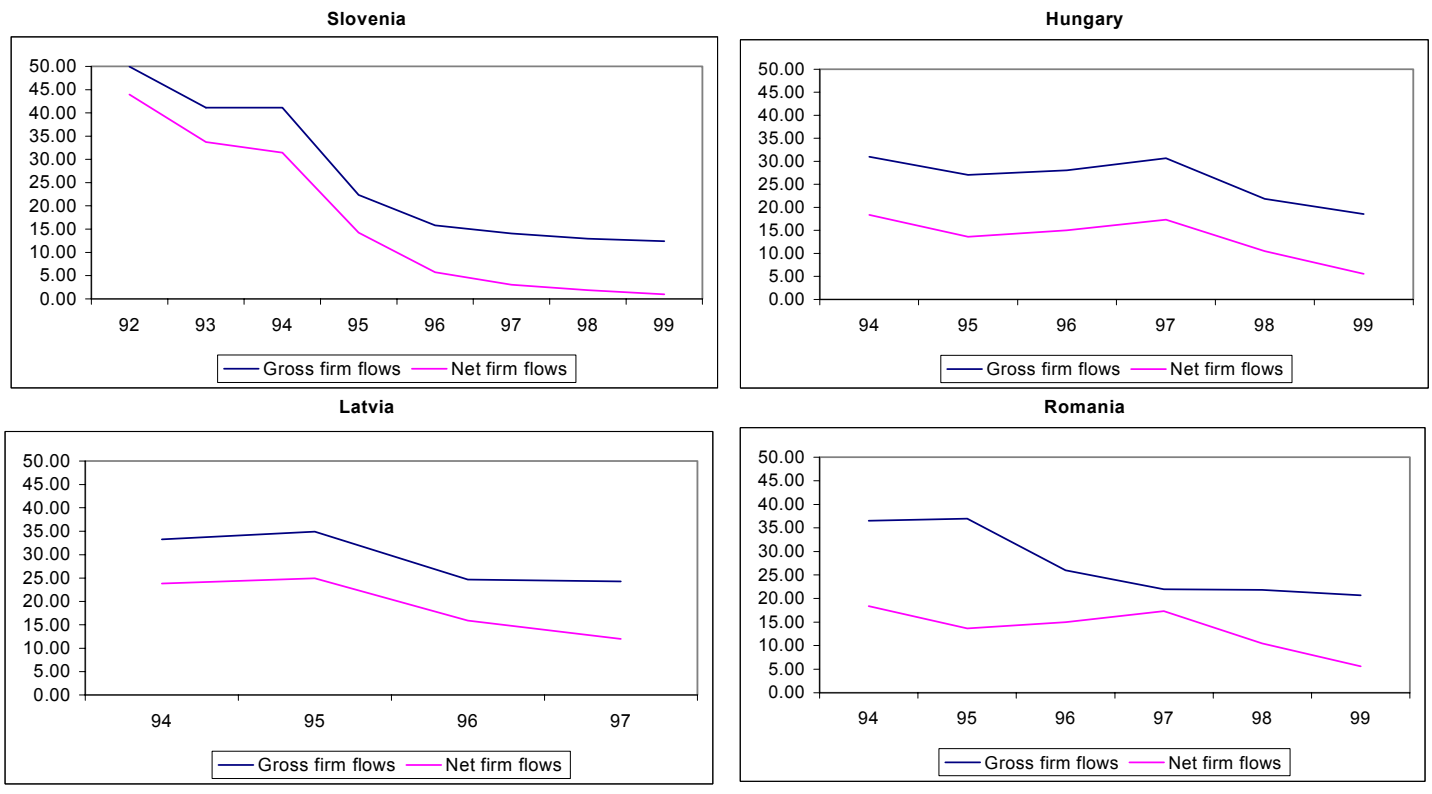

Panel B: Employment-weighted firm flows
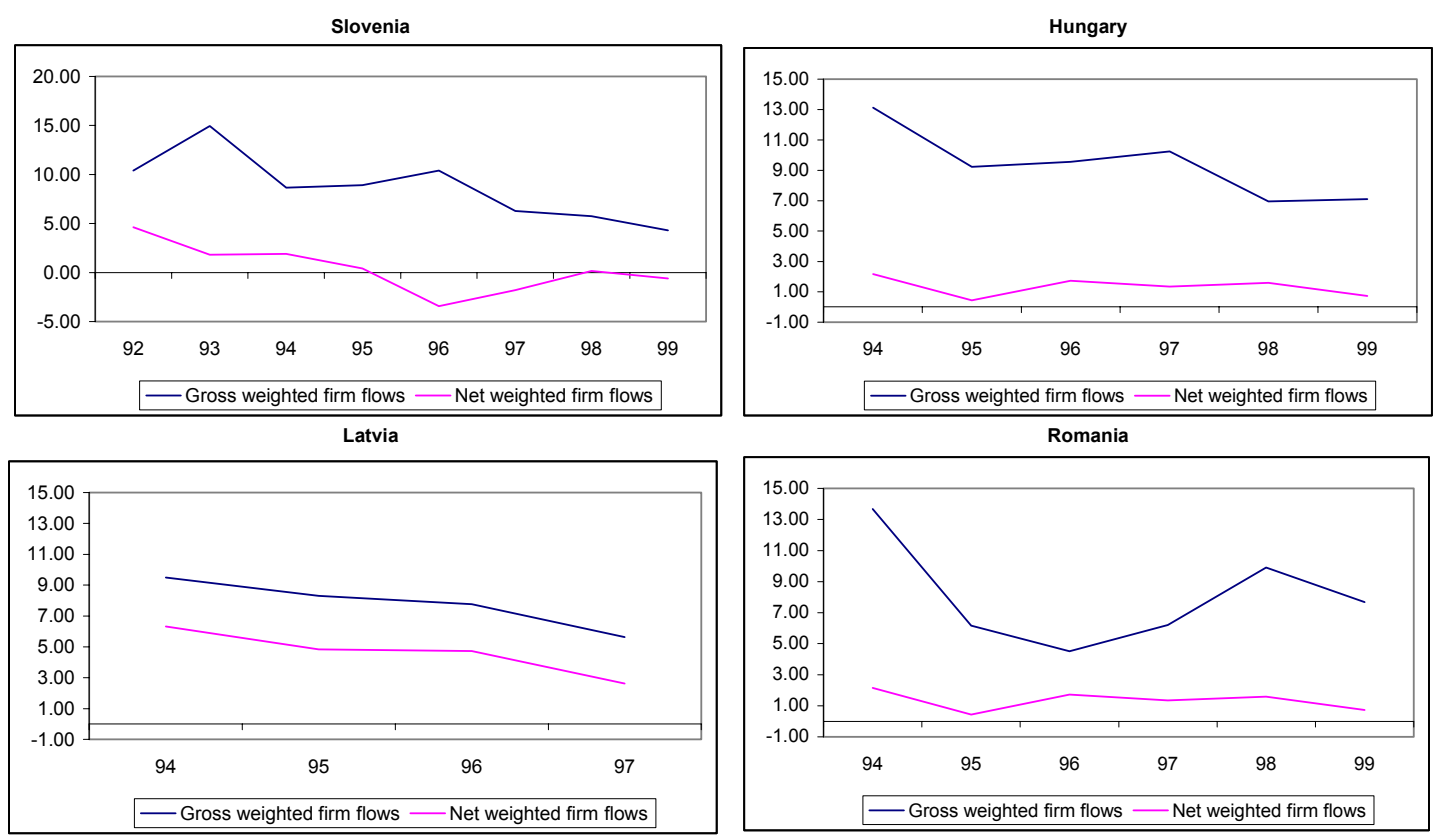
The high turnover rates amongst small firms suggest that the process of entry and exit of firms involves a proportionally low number of workers. Indeed, including all firms with at least 1 employee suggests that less than 10 percent of employment is, on average, involved in firm creation and destruction. The difference between un-weighted and employment-weighted firm turnover rates arises from the fact that both entrants and exiting firms are generally smaller than incumbents. For most countries, new firms are only 20 to 60 percent the average size of incumbents (Figure 3).

Figure 3. Relative firm size of entering and exiting firms relative to the average incumbent

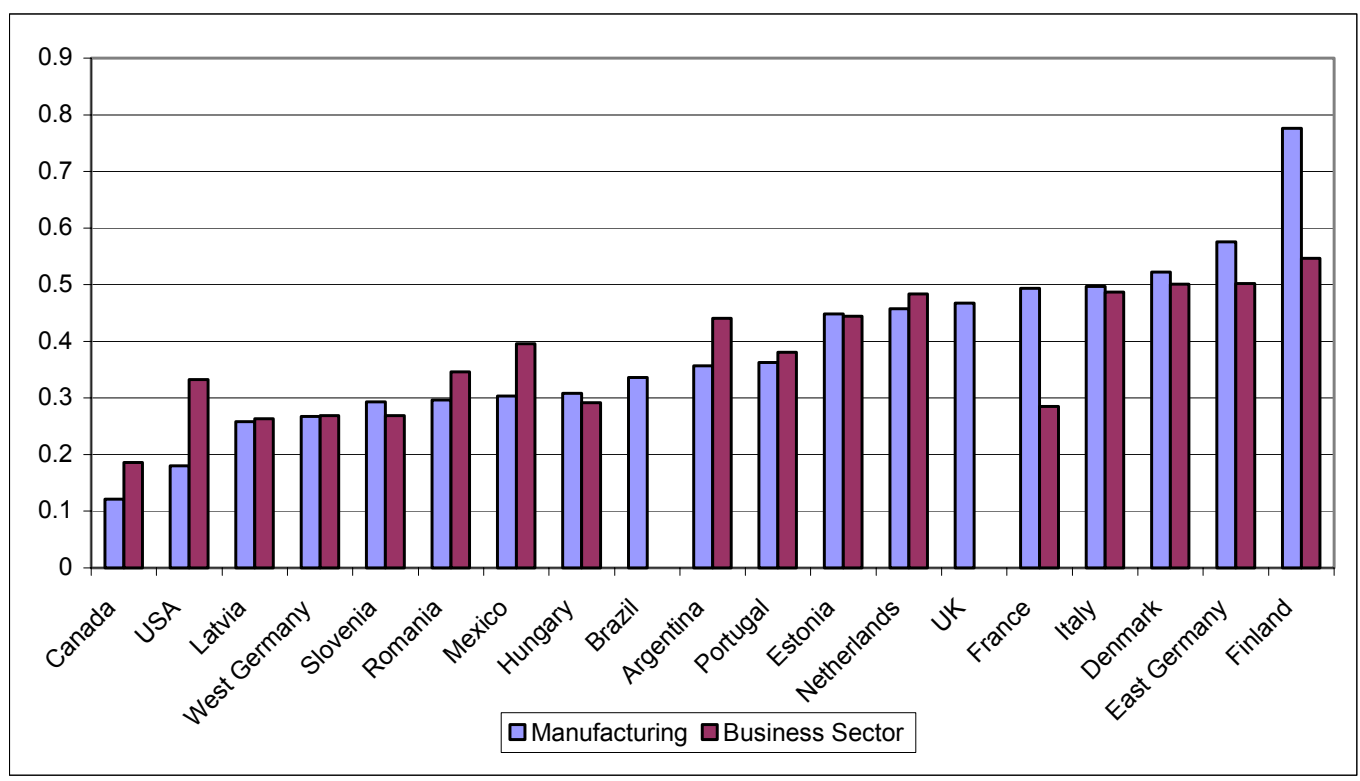

The small size of entrants relative to the average incumbents is driven by different factors across countries.

- In Canada and especially the United States the small relative size of entrant it reflects both the large size of incumbents (see above) and the small average size of entrants compared to that in most other countries (in the United States, about 2.5 employees in the total economy and about 5 in manufacturing). In other words, entrant firms are further away from the efficient size in the United States than in most other countries for which data are available. There are a number of different possible explanations for this. First, the larger market of the United States may partly explain the larger average size of incumbents. ${ }^{14}$ Second, the wider gap between entry size and the minimum efficient size in the United States may reflect economic and institutional factors, e.g. the relatively low entry and exit costs may increase incentives to start up relatively small businesses. We will return to this issue later.

- In the transition economies, new firms are substantially different from most of the existing firms that were drawn from the centrally-planned period. Indeed the net entry of firms (entry rate minus exit rate) is particularly large amongst micro units (20 or fewer

14. Geographical considerations may also affect the average size of firms: firms with plants spreading into different US states are recorded as single units, while establishments belonging to the same firm but located in different EU states are recorded as separate units. 
employees): during the centrally planned system there were relatively few of these micro firms which however exploded during the transition in most of business service activities.

Turnover rates vary significantly across sectors in each country. Table 5 presents the sectoral gross turnover rates (entry plus exit rates weighted by employment) normalized by the overall cross-country average. As before, if technological factors were predominant in determining the heterogeneity of firm dynamics across countries, we should find that the values in the country columns of Table 5 are concentrated around one. The first element to report is that the variability of turnover rates for the same industry across countries is comparable in magnitude to that across industry in each country. ${ }^{15}$ Turnover rates (especially if weighted by employment) are somewhat higher in the service sector (especially in trade) than in manufacturing. ${ }^{16}$ However, in most countries, some high-tech industries with rapid technological changes and market experimentation had relatively high entry rates in the 1990s (e.g. office, computing and equipments and radio, $T V$ and communication). Transition, but also emerging economies in Latin America tend to have greater firm churning than in the industrial countries, on average. This result is dominated by some sector dominated by few firms (e.g. fuel and petroleum) as well as some traditional activity (e.g. construction) but also some high-tech industry exposed to intense competition and FDI (e.g. radio, TV and communication).

It is also interesting to compare entry and exit rates across sectors to test two competing theories: one hypothesis is that entry and exit rates at the sectoral level are mostly driven by sectoral shocks. Sectors with positive profit shocks will have high entry and sectors with negative profit shocks will have high exit. If sectoral profit shocks are the predominant source of variation, then the cross-sectional correlation between entry and exit rates should be negative. Alternatively, entry and exit rates at the sectoral level might be driven by the within sector creative destruction process. A sector with a high dispersion of idiosyncratic shocks and/or low barriers to entry and exit will exhibit both high entry and high exit rates. If the creative destruction process is the predominant factor driving entry and exit, then the cross-sectional correlation of entry and exit should be positive.

In most of the industrial countries annual entry and exit rates are generally positively correlated across industries (Table 6), confirming previous evidence (e.g. Geroski, 1991a; Baldwin and Gorecki, 1991). And the correlations are particularly strong when the entry and exit rates are weighted by employment. The table also presents the correlations between the average entry and exit rates over the 1990s which account for the possibility that industry changes in entry and exit do not occur in the same year. Indeed, the correlations based on the average over the

15. Two sectors stand out as clear outliers: agriculture, where some countries have very high turnover rates in absolute and relative terms; and electricity, gas and water, where turnover is very low in some countries. This latter result is perhaps not surprising given that this industry is often dominated by public utilities.

16. In Italy and especially Finland, however, there appears to be only small differences in churning between manufacturing and services. In the case of Italy this is particularly evident for the employment-weighted turnover and likely reflects the small differences in average size of firms between manufacturing and services. For Finland, the high turnover in manufacturing is likely the result of major restructuring, which took place in the aftermath of the deep recession of the early 1990s. The lower turnover rate in the French service sector compared with that in manufacturing is likely to depend on the existence of a size threshold in the French data, which tends to be more binding in the service sector than in manufacturing. As an indication, the French data also suggest a higher average size of firms in the service sector than in manufacturing, in contrast with all other countries. 
decade tend to be even stronger. Perhaps not surprisingly, entry and exit rates are loosely or even negatively correlated in some of the transition economies where traditional manufacturing sectors are losing ground while new service sectors are expanding and in some emerging economies (Colombia and Venezuela) where, again, rapid structural changes have occurred in the period observed by the data.

These finding suggests that entries and exits are largely part of a creative destruction process in which entry and exit reflects within sector reallocation reflecting idiosyncratic differences across firms within sectors. ${ }^{17}$ Taken at face value, there are a few countries with negative correlations which might reflect a greater role for sectoral profitability shocks in those countries (and/or might reflect measurement error).

Table 5. Gross firm turnover across countries and sectors (employment-weighted flows)

\begin{tabular}{|c|c|c|c|c|c|c|c|c|c|c|c|c|}
\hline & $\begin{array}{l}\text { cross- } \\
\text { country } \\
\text { average }\end{array}$ & Industrial & $\begin{array}{c}\text { Other } \\
\text { countries }\end{array}$ & Denmark & France & Italy & Netherlands & Finland & $\begin{array}{c}\text { West } \\
\text { Germany }\end{array}$ & Portugal & UK & USA \\
\hline total economy & 8.1 & 0.95 & 1.08 & 1.26 & 0.86 & 1.06 & 1.24 & 1.47 & 0.48 & 1.15 & & 0.86 \\
\hline Agriculture, Hunting, Forestry And Fishing & 9.4 & 1.09 & 0.87 & 1.45 & 1.13 & 0.96 & 0.75 & & 0.99 & 1.63 & & 1.24 \\
\hline Mining And Quarrying & 7.1 & 0.87 & 1.21 & 0.80 & 1.48 & 1.40 & 0.47 & 1.78 & 0.13 & 0.98 & & 0.80 \\
\hline Total Manufacturing & 7.1 & 1.00 & 1.00 & 1.19 & 1.45 & 1.20 & 1.17 & 1.67 & 0.35 & 1.10 & 1.58 & 0.50 \\
\hline Food Products, Beverages And Tobacco & 6.8 & 1.08 & 0.90 & 1.63 & 2.21 & 1.47 & 1.41 & 1.34 & 0.48 & & 1.68 & 0.34 \\
\hline Textiles, Textile Products, Leather And Footwear & 8.3 & 1.02 & 0.97 & 1.37 & 1.34 & 1.23 & 1.47 & 1.30 & 0.41 & 1.14 & 1.47 & 0.85 \\
\hline Wood And Products Of Wood And Cork & 9.1 & 0.92 & 1.09 & 1.02 & 1.14 & 0.81 & 0.97 & 1.18 & 0.28 & 1.26 & 1.63 & 0.95 \\
\hline Publishing, Printing And Reproduction Of Recorded Media & 7.6 & 1.02 & 0.98 & 1.03 & 1.25 & 0.87 & 1.14 & 2.40 & 0.32 & 0.99 & 1.46 & 0.51 \\
\hline Coke, Refined Petroleum Products And Nuclear Fuel & 9.5 & 0.48 & 1.48 & & 1.74 & 1.55 & & 0.10 & 0.44 & & & 0.12 \\
\hline Chemicals And Chemical Products & 4.3 & 1.13 & 0.87 & 0.96 & 1.98 & 1.61 & 1.69 & 1.98 & 0.49 & 1.24 & & 0.41 \\
\hline Rubber And Plastics Products & 6.3 & 0.96 & 1.04 & 1.06 & 1.36 & 0.99 & 1.52 & 1.55 & 0.40 & 1.31 & & 0.65 \\
\hline Other Non-Metallic Mineral Products & 6.4 & 1.08 & 0.91 & 1.24 & 1.34 & 1.18 & 1.39 & 1.98 & 0.35 & 1.07 & 1.67 & 0.69 \\
\hline Basic Metals & 6.2 & 1.08 & 0.93 & 1.52 & & 2.28 & 0.12 & 1.25 & & 1.58 & 1.16 & 0.56 \\
\hline Fabricated Metal Products, Except Machinery And Equipment & 8.1 & 0.99 & 1.01 & & & 1.00 & 1.07 & 1.42 & & 1.11 & 1.44 & 0.59 \\
\hline Machinery And Equipment, N.E.C. & 7.8 & 0.87 & 1.13 & 0.74 & 0.96 & 0.91 & 0.84 & 1.29 & & & 1.37 & 0.45 \\
\hline Office, Accounting And Computing Machinery & 12.5 & 0.93 & 1.07 & & & 1.13 & 1.12 & 1.36 & & 3.96 & 1.52 & 0.18 \\
\hline Electrical Machinery And Apparatus, $\mathrm{Nec}$ & 6.8 & 1.12 & 0.88 & & 1.21 & 1.25 & 1.21 & 2.26 & & 0.68 & 1.60 & 0.42 \\
\hline Radio, Television And Communication Equipment & 9.0 & 0.88 & 1.13 & & 1.11 & 0.98 & 0.31 & 1.08 & & 1.37 & 1.40 & 0.43 \\
\hline Medical, Precision And Optical Instruments & 6.4 & 1.17 & 0.85 & & 1.39 & 1.18 & 1.14 & 1.42 & & 0.52 & 2.18 & 0.35 \\
\hline Motor Vehicles, Trailers And Semi-Trailers & 5.2 & 0.93 & 1.06 & & 1.09 & 0.73 & 2.68 & 1.65 & & 0.49 & 1.22 & 0.25 \\
\hline Other Transport Equipment & 9.7 & 1.01 & 0.99 & & 0.77 & 1.21 & 1.59 & 1.84 & & 1.50 & 1.37 & 0.11 \\
\hline Manufacturing Nec; Recycling & 9.0 & 0.90 & 1.10 & 1.02 & 1.51 & 1.00 & 0.69 & 1.16 & 0.40 & 0.79 & 1.53 & 0.72 \\
\hline Electricity, Gas And Water Supply & 5.7 & 1.04 & 0.94 & 0.18 & 1.72 & 5.16 & 2.96 & 1.23 & 0.13 & 0.02 & & 0.14 \\
\hline Construction & 11.7 & 0.87 & 1.19 & 1.07 & 0.96 & 1.02 & 0.63 & 1.26 & 0.44 & 0.94 & & 1.03 \\
\hline Services & 9.1 & 0.95 & 1.06 & 1.16 & 0.68 & 0.80 & 1.19 & 1.40 & & 1.10 & & 0.83 \\
\hline Market Services & 9.6 & 0.96 & 1.05 & 1.17 & 0.64 & 0.94 & 1.10 & 1.27 & & 1.06 & & 0.95 \\
\hline Wholesale And Retail Trade; Restaurants And Hotels & 10.5 & 0.91 & 1.11 & 1.05 & 0.78 & 0.98 & 0.78 & 1.07 & & 1.06 & & 0.89 \\
\hline Transport And Storage And Communication & 7.8 & 1.07 & 0.89 & 0.99 & 1.07 & 0.76 & 1.05 & 1.79 & 0.65 & 2.27 & & 0.72 \\
\hline Finance, Insurance, Real Estate And Business Services & 9.6 & 0.96 & 1.05 & 1.35 & 0.51 & 0.87 & 1.54 & 1.30 & & 0.72 & & 1.05 \\
\hline Community Social And Personal Services & 8.7 & 0.77 & 1.24 & 1.00 & 0.73 & 0.60 & 1.29 & & & 1.07 & & 0.53 \\
\hline
\end{tabular}

17. Dunne et al. (1988) suggest that entry and exit rates are correlated with a lag in the United States. However, even then the entry rate in a given five-year period is positively correlated with exit rates in the following five years. For an extensive discussion on this issue see Caves (1998). Caves also signals that the correlation between entry and exit reverts to negative in early and late phases of products' life cycle, 
total economy

Agriculture, Hunting, Forestry And Fishing

Mining And Quarrying

Total Manufacturing

Food Products, Beverages And Tobacco

Textiles, Textile Products, Leather And Footwear

Wood And Products Of Wood And Cork

Publishing, Printing And Reproduction Of Recorded Media

Coke, Refined Petroleum Products And Nuclear Fuel

Chemicals And Chemical Products

Rubber And Plastics Products

Other Non-Metallic Mineral Products

Basic Metals

Fabricated Metal Products, Except Machinery And Equipment

Machinery And Equipment, N.E.C.

Office, Accounting And Computing Machinery

Electrical Machinery And Apparatus, Nec

Radio, Television And Communication Equipment

Medical, Precision And Optical Instruments

Motor Vehicles, Trailers And Semi-Trailers

Other Transport Equipment

Manufacturing Nec; Recycling

Electricity, Gas And Water Supply

Construction

Services

Market Services

Wholesale And Retail Trade; Restaurants And Hotels

Transport And Storage And Communication

Finance, Insurance, Real Estate And Business Services

Community Social And Personal Services

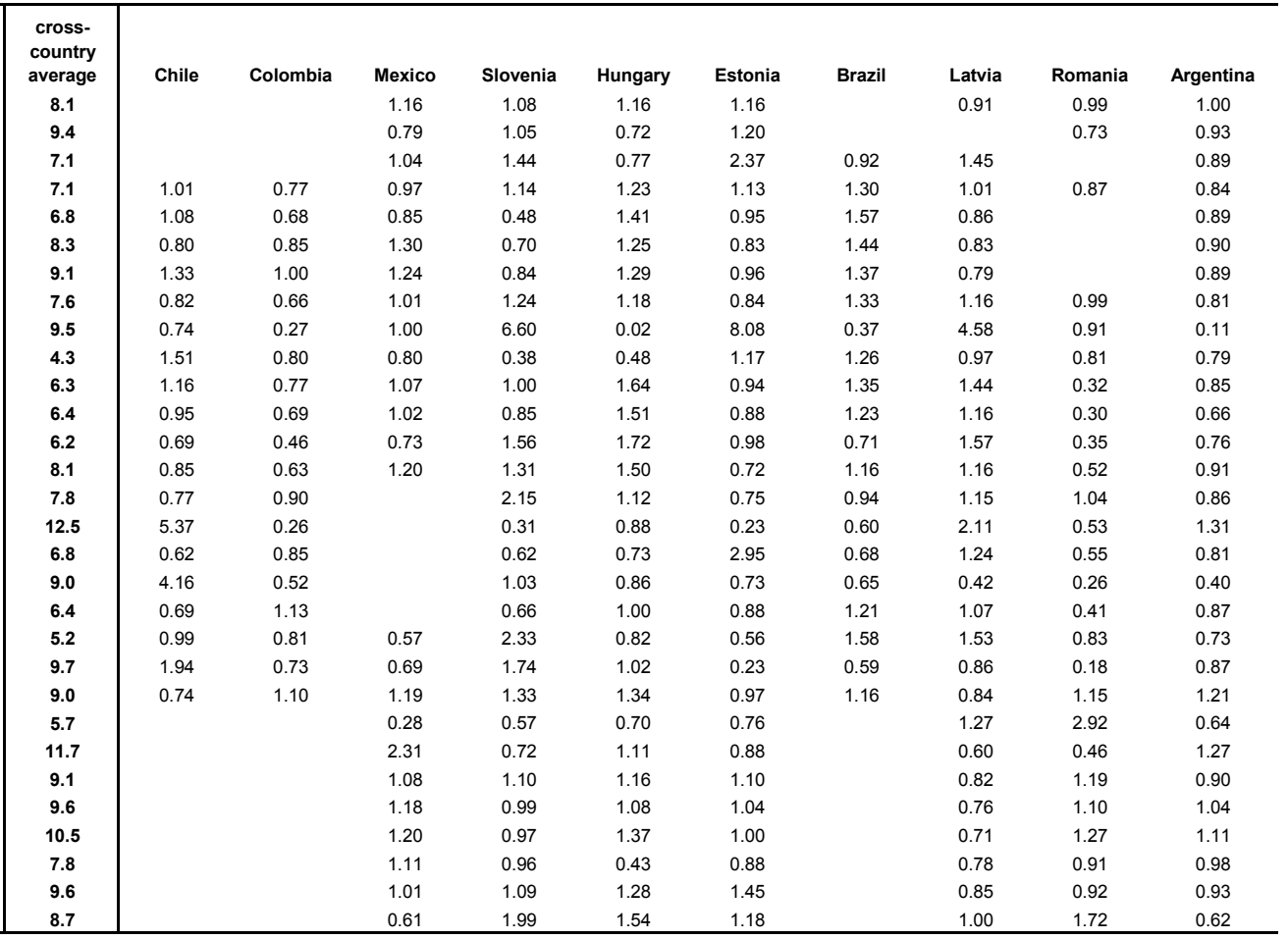

Table 6. Correlation between entry and exit rates across industries, 1990s

\begin{tabular}{|c|c|c|c|c|c|c|}
\hline \multirow[b]{3}{*}{ Denmark } & \multicolumn{3}{|c|}{ Annual correlations } & \multicolumn{3}{|c|}{ Correlations on time averages } \\
\hline & $\begin{array}{c}\text { Observations = } \\
\text { industry*year }\end{array}$ & $\begin{array}{l}\text { Entry/Exit } \\
\text { Correlation }\end{array}$ & $\begin{array}{l}\text { Entry/Exit } \\
\text { Correlation } \\
\text { (Weighted) }\end{array}$ & $\begin{array}{c}\text { Observations = } \\
\text { industry }\end{array}$ & $\begin{array}{l}\text { Entry/Exit } \\
\text { Correlation }\end{array}$ & $\begin{array}{l}\text { Entry/Exit } \\
\text { Correlation } \\
\text { (Weighted) }\end{array}$ \\
\hline & 85 & $0.3731^{*}$ & $0.6687^{*}$ & 17 & $0.5681^{*}$ & $0.8739^{*}$ \\
\hline France & 132 & $-0.2449^{*}$ & -0.1025 & 22 & $-0.5250^{*}$ & -0.2986 \\
\hline Italy & 125 & 0.0976 & $0.7999^{\star}$ & 25 & 0.1011 & $0.6894^{*}$ \\
\hline Netherlands & 175 & $0.3131^{*}$ & & 25 & $0.6702^{*}$ & \\
\hline Finland & 175 & $0.2717^{*}$ & $0.4084^{*}$ & 23 & 0.2675 & 0.2413 \\
\hline West Germany & 130 & $0.6880^{*}$ & $0.6242^{*}$ & 13 & $0.7510^{*}$ & $0.7702^{*}$ \\
\hline East Germany & 56 & 0.0385 & $0.5599^{*}$ & 14 & 0.1855 & $0.7181^{*}$ \\
\hline Portugal & 124 & -0.1239 & $0.5671^{*}$ & 25 & 0.3526 & 0.0331 \\
\hline UK & 105 & $0.2845^{\star}$ & $0.6412^{*}$ & 15 & 0.4709 & $0.7389^{*}$ \\
\hline USA & 199 & $0.8801^{*}$ & $0.8167^{*}$ & 25 & $0.8132^{*}$ & $0.9513^{*}$ \\
\hline Canada & 168 & $0.5782^{*}$ & $0.7683^{*}$ & 21 & $0.8252^{*}$ & $0.9301^{*}$ \\
\hline Venezuela & & & & 16 & -0.3306 & -0.1726 \\
\hline Chile & 128 & $0.6323^{*}$ & $0.5504^{*}$ & 18 & 0.0947 & 0.3741 \\
\hline Colombia & 129 & 0.0319 & 0.1595 & 18 & 0.4385 & $0.5527^{*}$ \\
\hline Brazil & 38 & $0.3472^{*}$ & $0.5068^{*}$ & 19 & 0.395 & $0.7880^{*}$ \\
\hline Mexico & 220 & $0.1882^{*}$ & $0.5441^{*}$ & 20 & $0.7756^{\star}$ & $0.9159^{*}$ \\
\hline Argentina & 100 & 0.0582 & $0.4971^{*}$ & 25 & $0.3973^{*}$ & $0.7432^{*}$ \\
\hline Slovenia & 178 & -0.05 & $0.7680^{*}$ & 25 & -0.1602 & $0.4373^{*}$ \\
\hline Hungary & 145 & $0.2445^{\star}$ & $0.5651^{*}$ & 25 & 0.1917 & $0.7793^{*}$ \\
\hline Estonia & 59 & $0.4977^{*}$ & $0.2874^{*}$ & 24 & 0.3344 & $0.4621^{*}$ \\
\hline Latvia & 98 & -0.0609 & 0.1511 & 24 & 0.294 & 0.1772 \\
\hline Romania & 119 & 0.0826 & 0.1209 & 21 & $0.6098^{*}$ & 0.4066 \\
\hline
\end{tabular}

Correlations are based on a maximum of 25 industries in the business sector.

${ }^{*}=$ Significant at $10 \%$ level. 


\section{The post-entry performance of firms}

The evidence provided in the previous section clearly indicates that firm dynamics (the entry and exit of firms) is not necessarily associated with changes in the size of the population of firms or in the number of products in the market but rather with continuous changes in the characteristics of firms in each market. In this context, what happens to firms subsequent to their entry seems at least as important as the entry process itself. Understanding the post-entry performance sheds light on the market selection process that separates successful entrant firms that survive and prosper from others that stagnate and eventually exit. We examine the post-entry performance of firms sequentially: we start by presenting simple survivor functions across countries and main sectors and then move to non-parametric and semi-parametric analyses of survival.

Figure 4 presents non-parametric (graphic) estimates of survivor rates for firms that entered the market in the late 1980s and1990s. The survivor rate specifies the proportion of firms from a cohort of entrants that still exist at a given age In the figure, the survival rates are averaged over different entry cohorts and do not take into account differences in the industry composition across countries.

Figure 4. Firm survival at different lifetimes, 1990s

Panel A: Manufacturing

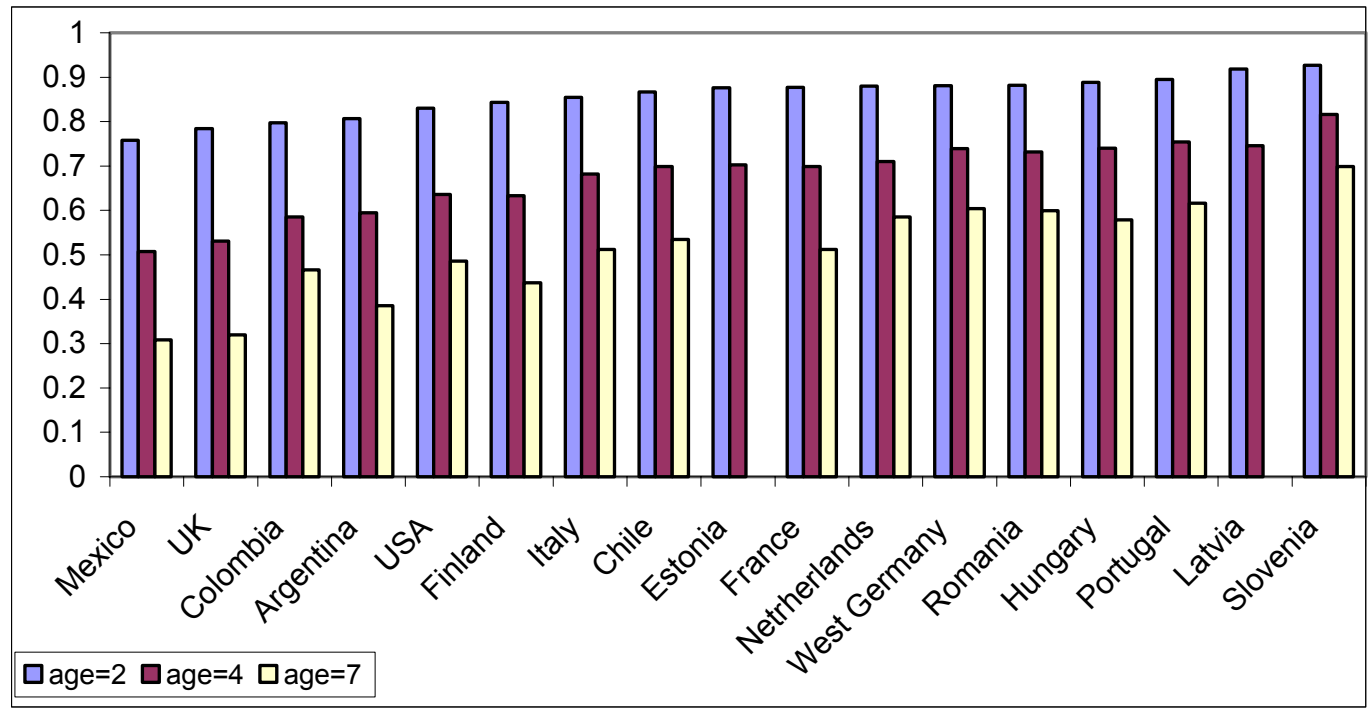


Panel B: Total business sector

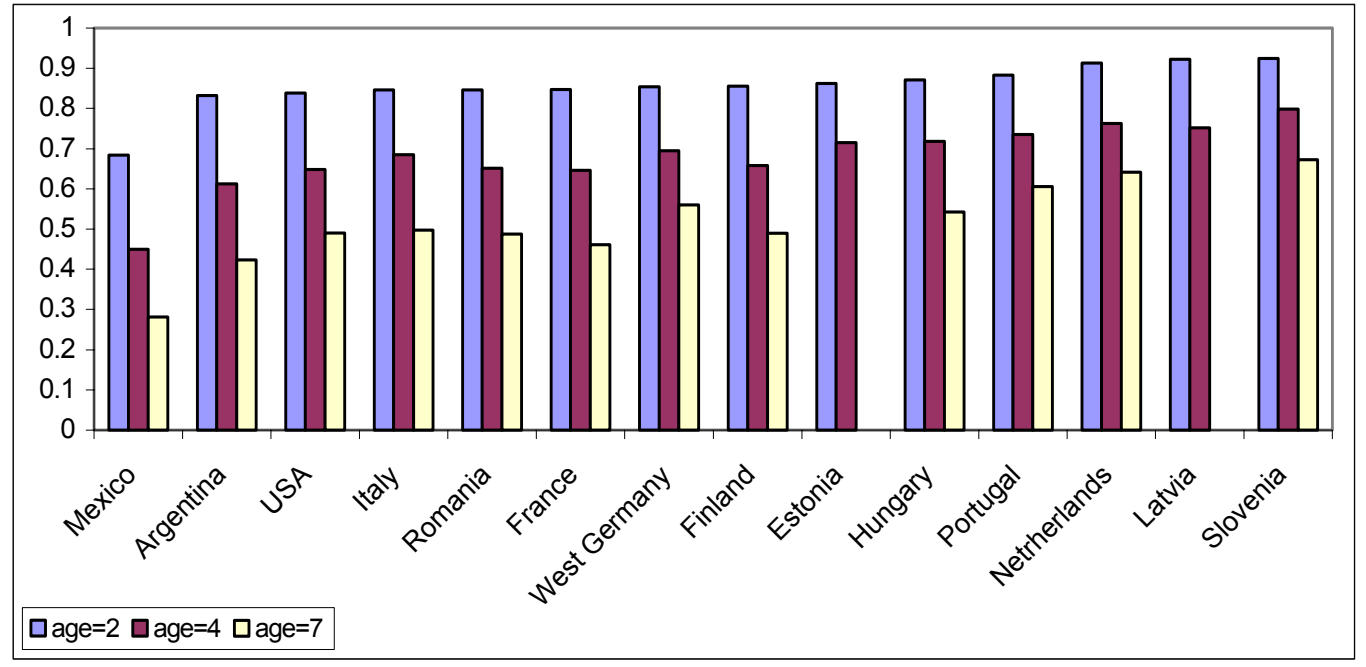

Looking at cross-country differences in survivor rates, about 10 percent (Slovenia) to more than 30 percent (in Mexico) of entering firms fail within the first two years (Figure 4). Conditional on overcoming the initial years, the prospect of firms improves in the subsequent period: firms that remain in the business after the first two years have a 40 to 80 percent chance of surviving for five more years. Nevertheless, only about 30-50 percent of total entering firms in a given year survive beyond the seventh year in industrial and Latin American countries, while higher survival rates are found in transition economies.

For most countries, the rank ordering of survival is similar whether using a 2-year, 4-year or 7-year horizon suggesting that there is an important country effect that impacts the survival function. However, there are a few interesting exceptions. The U.S. has relatively low survival rates at the 2-year horizon but relatively higher survival rates at the 7-year horizon. This pattern might reflect the relatively rapid cleansing of poorly performing firms in the U.S. In the next section, we explore the productivity implications of the turnover patterns that we observe across countries and industries.

Table 7 provides details on the survival rates at age four across industries and countries. The structure of the Table is similar to that in Table 4 above: the first column presents the cross-country average survival rate for each industry; the second and third columns report the deviations from this average for industrial and other countries respectively; while the other columns present the deviations for each country individually. Notably, the variation across countries is more systematic than that across industries. Across industries, after four years between 60 and 80 percent of firms survive, while for example the survival rate in office and computing equipment deviates from 40 percent below to 40 percent above the cross-country average of 70 percent. We will return to this in the parametric analysis of survival. 
Table 7. Survival rate (4 years of age) across countries and industries

Mining And Quarrying

Total Manufacturing

Food Products, Beverages And Tobacco

Textiles, Textile Products, Leather And Footwear

Wood And Products Of Wood And Cork

Publishing, Printing And Reproduction Of Recorded Media

Coke, Refined Petroleum Products And Nuclear Fuel

Chemicals And Chemical Products

Rubber And Plastics Products

Other Non-Metallic Mineral Products

Basic Metals

Fabricated Metal Products, Except Machinery And Equipment

Machinery And Equipment, N.E.C.

Office, Accounting And Computing Machinery

Electrical Machinery And Apparatus, Nec

Radio, Television And Communication Equipment

Medical, Precision And Optical Instruments

Motor Vehicles, Trailers And Semi-Trailers

Other Transport Equipment

Manufacturing Nec; Recycling

Electricity, Gas And Water Supply

Construction

Market Services

Wholesale And Retail Trade; Restaurants And Hotels

Transport And Storage And Communication

Finance, Insurance, Real Estate And Business Services

Total non-agricultural business sector

\begin{tabular}{|c|c|c|c|c|c|c|c|c|c|c|}
\hline $\begin{array}{l}\text { cross- } \\
\text { country } \\
\text { average }\end{array}$ & Industrial & $\begin{array}{c}\text { Other } \\
\text { countries }\end{array}$ & Finland & France & UK & $\begin{array}{c}\text { West } \\
\text { Germany }\end{array}$ & Italy & Netherlands & Portugal & USA \\
\hline 0.69 & 1.05 & 0.94 & 1.07 & 0.91 & & 1.14 & 1.10 & 1.15 & 1.11 & 0.85 \\
\hline 0.67 & 1.00 & 1.00 & 0.94 & 1.02 & 0.79 & 1.10 & 1.04 & 1.07 & 1.12 & 0.95 \\
\hline 0.69 & 1.02 & 0.98 & 0.92 & 1.10 & 0.69 & 1.10 & 1.08 & 1.01 & 1.35 & 0.91 \\
\hline 0.59 & 0.96 & 1.03 & 0.95 & 0.98 & 0.75 & 0.99 & 1.04 & 1.02 & 1.14 & 0.81 \\
\hline 0.64 & 1.04 & 0.97 & 0.95 & 1.10 & 0.86 & 1.12 & 1.09 & 1.19 & 1.04 & 0.99 \\
\hline 0.69 & 0.98 & 1.01 & 0.97 & 0.92 & 0.82 & 1.04 & 1.03 & 1.03 & 1.13 & 0.94 \\
\hline 0.73 & 1.05 & 0.96 & 1.05 & 1.05 & 0.67 & 1.20 & 1.23 & 1.13 & 1.37 & 0.79 \\
\hline 0.69 & 1.02 & 0.99 & 0.89 & 0.96 & 0.88 & 1.09 & 1.11 & 1.04 & 1.14 & 1.01 \\
\hline 0.73 & 0.98 & 1.01 & 0.91 & 0.97 & 0.96 & 1.00 & 1.00 & 1.06 & 1.06 & 0.90 \\
\hline 0.68 & 1.02 & 0.98 & 0.96 & 1.08 & 0.76 & 1.11 & 1.10 & 1.08 & 1.16 & 0.97 \\
\hline 0.69 & 0.99 & 1.01 & 0.94 & & 0.85 & & 1.08 & 1.15 & 1.01 & 0.93 \\
\hline 0.69 & 1.01 & 0.99 & 0.95 & & 0.90 & & 1.05 & 1.08 & 1.12 & 1.00 \\
\hline 0.73 & 1.01 & 0.99 & 0.96 & 1.03 & 0.70 & & 1.00 & 1.09 & 1.29 & 0.99 \\
\hline 0.70 & 0.88 & 1.10 & 0.92 & & 0.61 & & 1.05 & 1.03 & 1.13 & 0.80 \\
\hline 0.74 & 0.93 & 1.06 & 0.90 & 1.01 & 0.71 & & 1.00 & 1.00 & 0.99 & 0.91 \\
\hline 0.71 & 0.92 & 1.08 & 0.99 & 0.86 & 0.73 & & 1.00 & 0.91 & 1.00 & 0.95 \\
\hline 0.77 & 0.96 & 1.04 & 1.03 & 0.88 & 0.70 & & 0.92 & 1.08 & 1.15 & 0.95 \\
\hline 0.70 & 0.99 & 1.01 & 0.87 & 1.03 & 0.72 & & 1.08 & 1.05 & 1.29 & 0.92 \\
\hline 0.65 & 0.98 & 1.01 & 0.78 & 1.00 & 0.77 & & 1.05 & 1.14 & 1.25 & 0.95 \\
\hline 0.66 & 1.02 & 0.98 & 0.93 & 0.99 & 0.78 & 1.14 & 1.04 & 1.11 & 1.29 & 0.92 \\
\hline 0.82 & 1.01 & 0.99 & 1.14 & 0.98 & & 1.01 & 1.00 & 0.99 & 1.01 & 0.95 \\
\hline 0.64 & 1.07 & 0.94 & 1.00 & 1.00 & & 1.10 & 1.03 & 1.18 & 1.18 & 0.98 \\
\hline 0.66 & 1.02 & 0.98 & 0.99 & 0.96 & & 1.01 & 1.02 & 1.14 & 1.09 & 0.96 \\
\hline 0.64 & 1.02 & 0.98 & 0.91 & 1.01 & & 1.02 & 1.03 & 1.07 & 1.12 & 0.96 \\
\hline 0.66 & 0.98 & 1.02 & 1.22 & 1.05 & & 1.00 & 1.04 & 1.07 & 0.45 & 0.94 \\
\hline 0.70 & 1.01 & 0.99 & 1.01 & 0.85 & & 1.00 & 1.01 & 1.16 & 1.10 & 0.95 \\
\hline 0.65 & 1.02 & 0.99 & 1.00 & 0.99 & 0.82 & 1.05 & 1.04 & 1.16 & 1.13 & 0.97 \\
\hline
\end{tabular}

(as a ratio to cross-country sectoral average)

Mining And Quarrying

Total Manufacturing

Food Products, Beverages And Tobacco

Textiles, Textile Products, Leather And Footwear

Wood And Products Of Wood And Cork

Publishing, Printing And Reproduction Of Recorded Media

Coke, Refined Petroleum Products And Nuclear Fuel

Chemicals And Chemical Products

Rubber And Plastics Products

Other Non-Metallic Mineral Products

Basic Metals

Fabricated Metal Products, Except Machinery And Equipment

Machinery And Equipment, N.E.C.

Office, Accounting And Computing Machinery

Electrical Machinery And Apparatus, Nec

Radio, Television And Communication Equipment

Medical, Precision And Optical Instruments

Motor Vehicles, Trailers And Semi-Trailers

Other Transport Equipment

Manufacturing Nec; Recycling

Electricity, Gas And Water Supply

Construction

Market Services

Wholesale And Retail Trade; Restaurants And Hotels

Transport And Storage And Communication

Finance, Insurance, Real Estate And Business Services

Total non-agricultural business sector

\begin{tabular}{|c|c|c|c|c|c|c|c|c|c|c|c|}
\hline $\begin{array}{c}\text { cross- } \\
\text { country } \\
\text { average }\end{array}$ & Industrial & $\begin{array}{c}\text { Other } \\
\text { countries }\end{array}$ & Estonia & Hungary & Latvia & Romania & Slovenia & Argentina & Chile & Colombia & Mexico \\
\hline 0.69 & 1.05 & 0.94 & 0.49 & 1.11 & 0.98 & & 1.40 & 0.84 & & & 0.69 \\
\hline 0.67 & 1.00 & 1.00 & 1.05 & 1.10 & 1.11 & 1.09 & 1.22 & 0.89 & 1.04 & 0.87 & 0.76 \\
\hline 0.69 & 1.02 & 0.98 & 1.02 & 1.03 & 1.09 & & 1.15 & 0.86 & 1.03 & 0.95 & 0.80 \\
\hline 0.59 & 0.96 & 1.03 & 1.19 & 1.21 & 1.30 & & 1.20 & 0.91 & 1.08 & 0.87 & 0.80 \\
\hline 0.64 & 1.04 & 0.97 & 1.01 & 1.08 & 1.04 & & 1.26 & 0.83 & 1.13 & 0.77 & 0.69 \\
\hline 0.69 & 0.98 & 1.01 & 0.95 & 1.04 & 1.08 & 1.06 & 1.23 & 0.93 & 1.09 & 1.02 & 0.77 \\
\hline 0.73 & 1.05 & 0.96 & & 0.97 & 1.14 & 1.37 & 1.37 & 0.83 & 0.93 & 1.11 & 0.92 \\
\hline 0.69 & 1.02 & 0.99 & 0.95 & 1.04 & 1.07 & 1.09 & 0.95 & 1.02 & 1.00 & 1.00 & 0.86 \\
\hline 0.73 & 0.98 & 1.01 & 1.14 & 1.10 & 1.12 & 1.05 & 1.20 & 0.94 & 1.02 & 0.90 & 0.81 \\
\hline 0.68 & 1.02 & 0.98 & 1.11 & 1.04 & 1.17 & 1.09 & 1.22 & 0.89 & 0.98 & 0.83 & 0.74 \\
\hline 0.69 & 0.99 & 1.01 & & 0.97 & 1.35 & 1.03 & 1.32 & 0.90 & 1.13 & 0.92 & 0.78 \\
\hline 0.69 & 1.01 & 0.99 & 1.12 & 1.12 & 1.21 & 1.09 & 1.27 & 0.85 & 1.00 & 0.82 & 0.70 \\
\hline 0.73 & 1.01 & 0.99 & 1.01 & 1.09 & 0.96 & 1.03 & 1.20 & 0.86 & 0.97 & 0.75 & \\
\hline 0.70 & 0.88 & 1.10 & 1.42 & 1.16 & 1.10 & 1.02 & 1.22 & 0.60 & 1.42 & 1.42 & \\
\hline 0.74 & 0.93 & 1.06 & 1.02 & 1.06 & 1.05 & 1.10 & 1.13 & 0.93 & 1.14 & 0.98 & \\
\hline 0.71 & 0.92 & 1.08 & 0.95 & 1.07 & 1.27 & 1.07 & 1.22 & 0.86 & 1.06 & 1.04 & \\
\hline 0.77 & 0.96 & 1.04 & 1.30 & 1.07 & 1.15 & 1.01 & 1.12 & 0.99 & 1.04 & 0.81 & \\
\hline 0.70 & 0.99 & 1.01 & 1.07 & 1.14 & 1.43 & 1.14 & 1.16 & 0.95 & 0.96 & 0.83 & 0.81 \\
\hline 0.65 & 0.98 & 1.01 & 1.37 & 1.13 & 1.43 & 1.21 & 1.06 & 0.83 & 0.88 & 0.88 & 0.76 \\
\hline 0.66 & 1.02 & 0.98 & 1.05 & 1.11 & 1.20 & 1.11 & 1.17 & 0.89 & 1.07 & 0.78 & 0.70 \\
\hline 0.82 & 1.01 & 0.99 & 0.95 & 0.98 & 1.12 & 1.05 & 1.06 & 0.95 & & & 0.88 \\
\hline 0.64 & 1.07 & 0.94 & 1.16 & 1.16 & 1.21 & 1.17 & 1.31 & 0.66 & & & 0.32 \\
\hline 0.66 & 1.02 & 0.98 & 1.07 & 1.06 & 1.12 & 0.96 & 1.19 & 0.89 & & & 0.73 \\
\hline 0.64 & 1.02 & 0.98 & 1.06 & 1.07 & 1.13 & 0.98 & 1.20 & 0.87 & & & 0.74 \\
\hline 0.66 & 0.98 & 1.02 & 1.15 & 1.11 & 1.22 & 1.04 & 1.14 & 0.98 & & & 0.78 \\
\hline 0.70 & 1.01 & 0.99 & 1.06 & 1.06 & 1.13 & 1.00 & 1.20 & 0.91 & & & 0.75 \\
\hline 0.65 & 1.02 & 0.99 & 1.09 & 1.10 & 1.15 & 1.00 & 1.23 & 0.88 & 1.07 & 0.90 & 0.67 \\
\hline
\end{tabular}

Each given cohort tends to increase in the initial years because failures are highly concentrated amongst its smallest units and because of the significant growth of survivors. These facts are best presented by looking at survival rates expressed in terms of total employment of a 
given cohort and in terms of gains in average firm size amongst surviving firms (Figures 5 and 6). The time profile of the survivor function expressed in terms of employment is shifted upward and is flatter compared with the survival function of firms, due to the exit of predominantly smaller units. On average employment in a given cohort remains in the 80-120 percent range of its initial level after the first two years of its life.

Figure 6 shows the evolution in average firm size of survivors as they age, corrected for possible changes in entry size of the actual survivors by age. In the Figure the average size of survivors at different duration is compared with that at entry. ${ }^{18}$ The difference in post-entry behavior of firms in the United States ${ }^{19}$ compared with the West European countries is partially due to the larger gap between the size at entry and the average firm size of incumbents, i.e. there is a greater scope for expansion amongst young ventures in the US markets than in Europe. In turn, the smaller relative size of entrants, can be taken to indicate a greater degree of experimentation, with firms starting small and, if successful, expanding rapidly to approach the minimum efficient scale. ${ }^{20}$

Latin American countries also offer a wide range of post-entry performance of firms. Argentina has very limited post-entry expansion of successful firms in manufacturing, while in Mexico selection of small firms is stronger than in all other countries, but post-entry growth of successful firms is also very strong, pointing to a strong market selection process but also strong rewards to successful new firms.

18. Given differences in data collection, the reference average size of entrants is that at duration one for industrial countries and duration zero for other countries, but excluding firms with zero employment. The choice for the industrial countries is dictated by the fact that entrant firms include zero-employee firms. This, however, may represent an over-correction as it eliminates employment growth in firms with positive employment at registration. Earlier estimates (Bartelsman, Scarpetta and Schivardi, 2003) which did not make this correction show larger increase in surviving firms in some countries (e.g. the United States). In the United States, the time when the firm is registered and when its employment is recorded differ giving rise to the possibility that firms are recorded as having zero employees in the entry year and positive employment in the second year. However, recent work by Jarmin (2003), shows that even after correcting for the zero-employee problem, the size expansion of entrant firms in the U.S. exceeds that in other industrial countries by a wide margin. The growth in firm size in the ensuing years shows that the United States continues to perform much better than other OECD countries.

19. The results for the United States are consistent with the evidence in Audretsch (1995). He found that the four-year employment growth amongst surviving firms was about 90 percent.

20. This greater experimentation of small firms in the US market may also contribute to explain the evidence of a lower than average productivity at entry, as discussed below. 
Figure 5 Employment-based survival rates at different lifetimes, Total employment, 1990s Panel A: Manufacturing

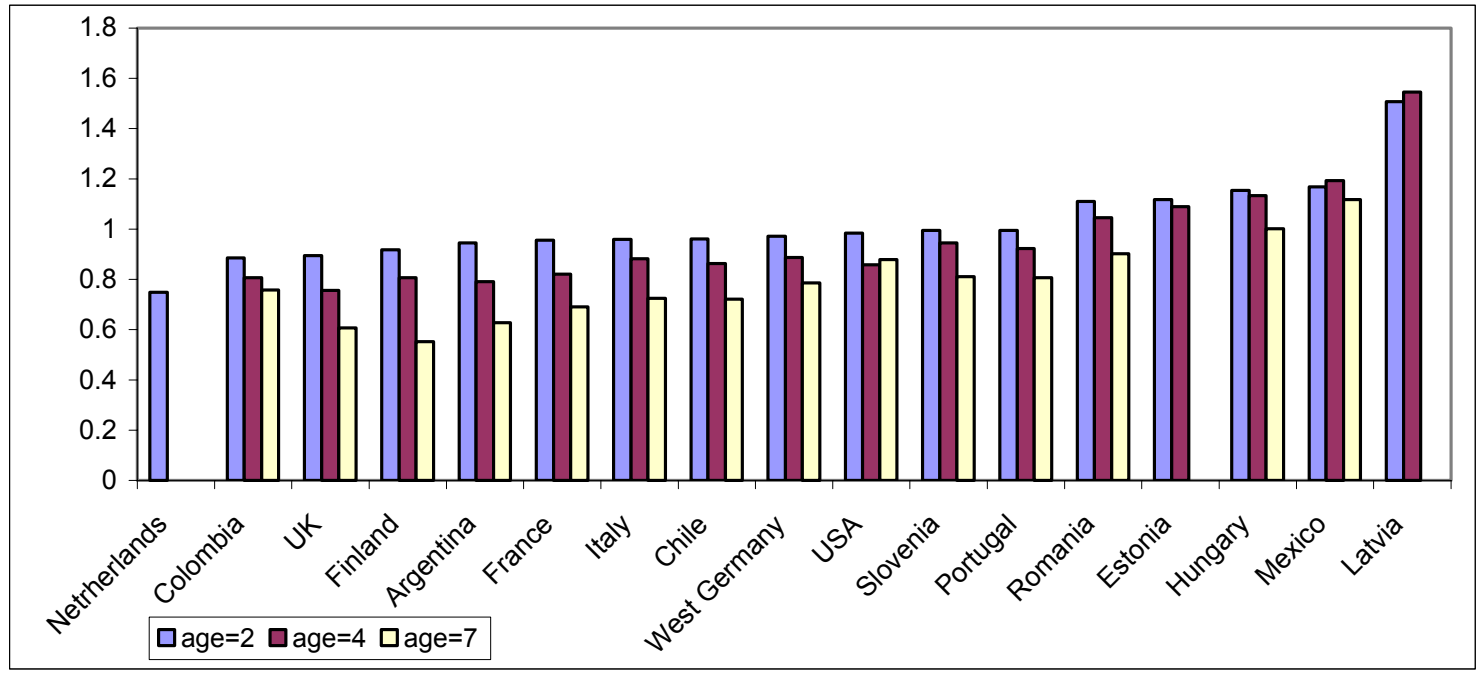

Panel B: Total Business sector

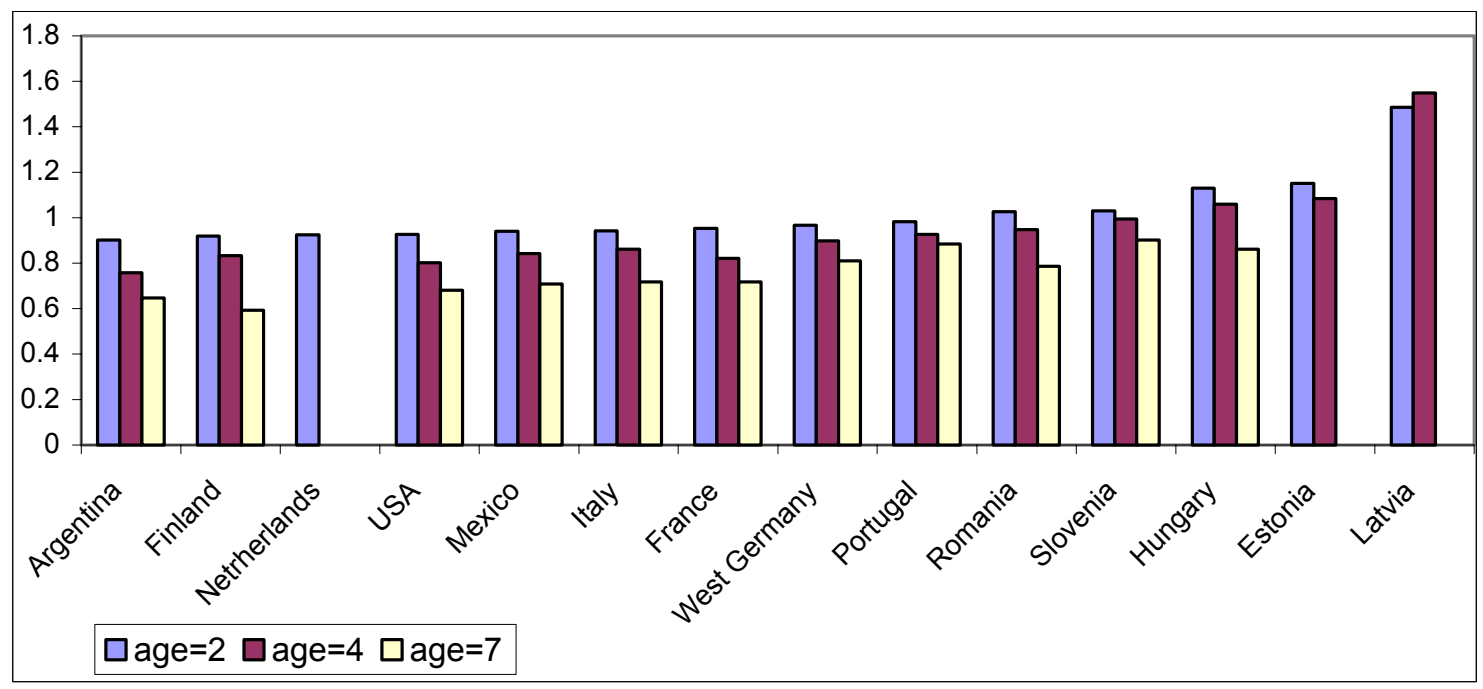

Transition economies show a different behavior from most other countries also on firm survival. They tend to show higher survivor rates and large post entry growth of successful firms which confirm the hypothesis that new firms enjoyed a period of relatively low market contestability especially in new low populated markets. Romania is obviously an outlier amongst transition economies: not only are failure rates higher than in the other countries, but even successful entrants have more limited opportunities of expanding. 
Figure 6. Average firm size relative to entry, by age

Panel A: Manufacturing

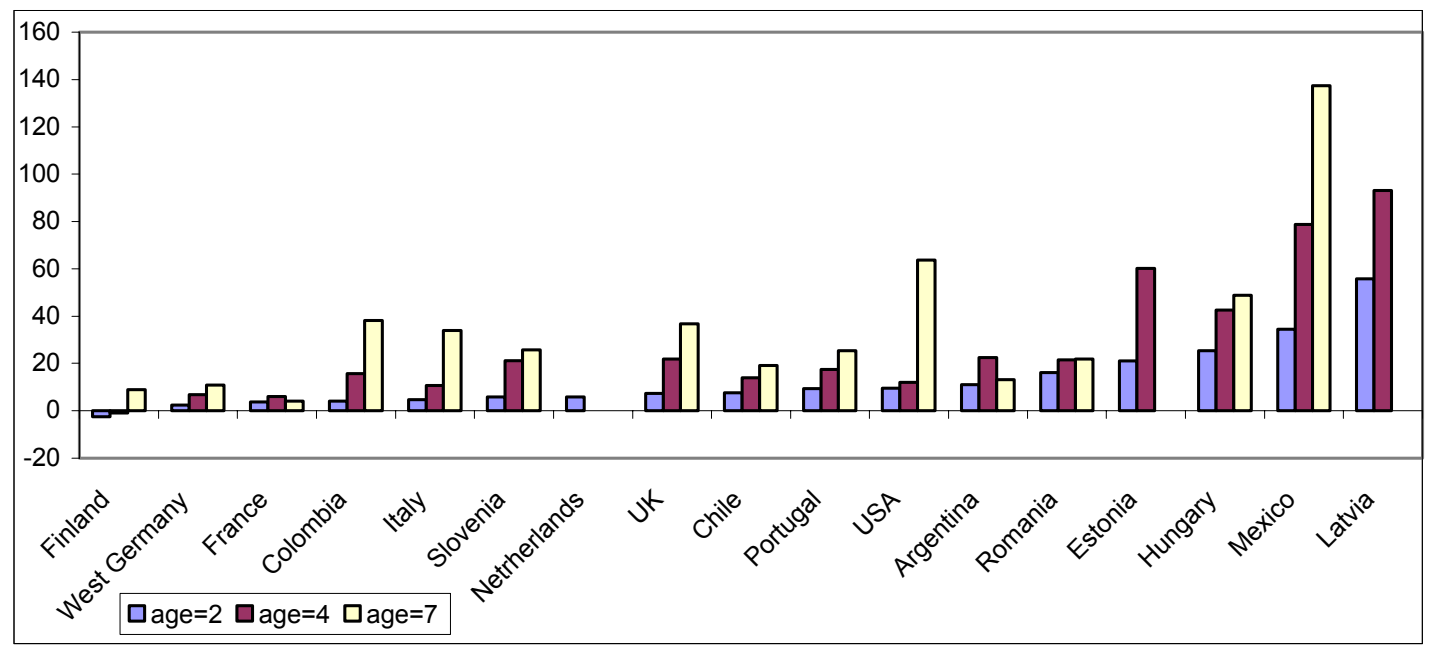

Panel B: Total Business sector

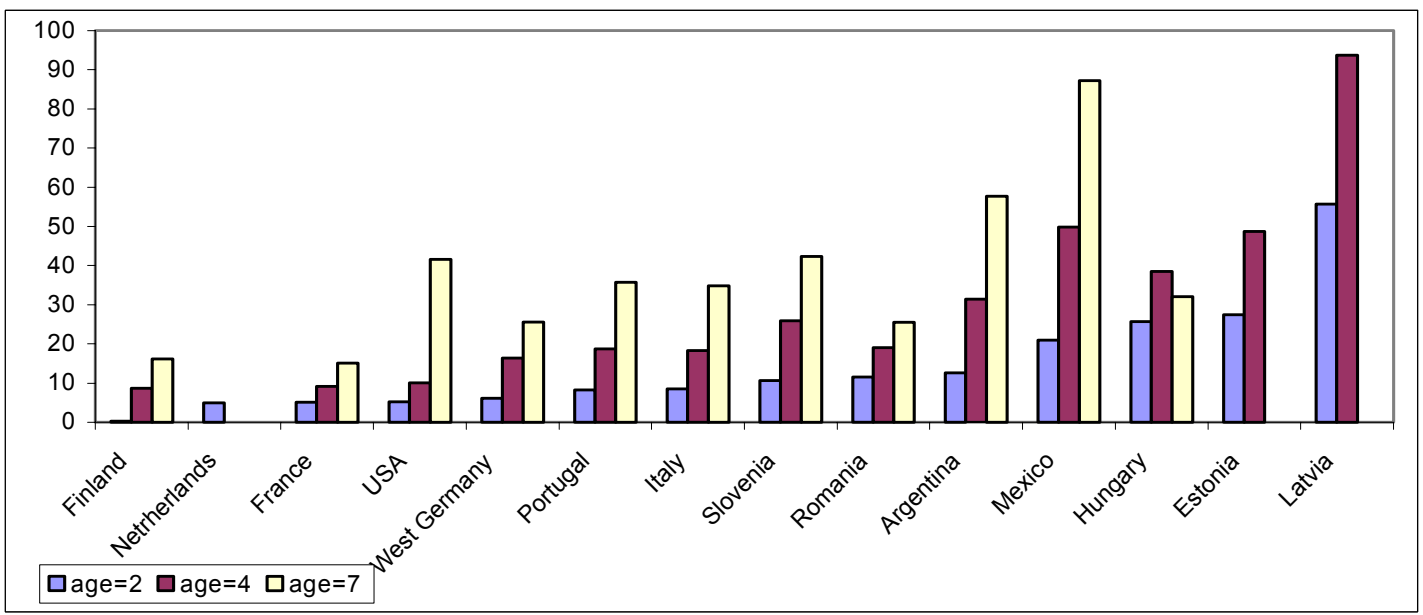

Table 8 presents the post entry growth of entrant cohorts at age seven across countries and industries. As in the previous tables, the first column shows the cross-country average for each industry, and the value for each industry and country relative to the industry average. In high tech manufacturing industries (ICT, radio and TV) and some service industries (communication and finance), successful firms have high post entry employment, while traditional manufacturing industries show only moderate size increases. 
Table 8. Post entry (employment) growth (at 7 years of age) across countries and industries

Mining And Quarrying

Total Manufacturing

Food Products, Beverages And Tobacco

Textiles, Textile Products, Leather And Footwear

Wood And Products Of Wood And Cork

Publishing, Printing And Reproduction Of Recorded Media

Coke, Refined Petroleum Products And Nuclear Fuel

Chemicals And Chemical Products

Rubber And Plastics Products

Other Non-Metallic Mineral Products

Basic Metals

Fabricated Metal Products, Except Machinery And Equipment

Machinery And Equipment, N.E.C.

Office, Accounting And Computing Machinery

Electrical Machinery And Apparatus, Nec

Radio, Television And Communication Equipment

Medical, Precision And Optical Instruments

Motor Vehicles, Trailers And Semi-Trailers

Other Transport Equipment

Manufacturing Nec; Recycling

Electricity, Gas And Water Supply

Construction

Market Services

Wholesale And Retail Trade; Restaurants And Hotels

Transport And Storage And Communication

Finance, Insurance, Real Estate And Business Services

Total non-agricultural business sector

(as a ratio to cross-country sectoral average)

\section{Mining And Quarrying}

Total Manufacturing

Food Products, Beverages And Tobacco

Textiles, Textile Products, Leather And Footwear

Wood And Products Of Wood And Cork

Publishing, Printing And Reproduction Of Recorded Media

Coke, Refined Petroleum Products And Nuclear Fuel

Chemicals And Chemical Products

Rubber And Plastics Products

Other Non-Metallic Mineral Products

Basic Metals

Fabricated Metal Products, Except Machinery And Equipment

Machinery And Equipment, N.E.C.

Office, Accounting And Computing Machinery

Electrical Machinery And Apparatus, Nec

Radio, Television And Communication Equipment

Medical, Precision And Optical Instruments

Motor Vehicles, Trailers And Semi-Trailers

Other Transport Equipment

Manufacturing Nec; Recycling

Electricity, Gas And Water Supply

Construction

Market Services

Wholesale And Retail Trade; Restaurants And Hotels

Transport And Storage And Communication

Finance, Insurance, Real Estate And Business Services

Total non-agricultural business sector

\begin{tabular}{|c|c|c|c|c|c|c|c|c|c|}
\hline $\begin{array}{l}\text { cross- } \\
\text { country } \\
\text { average }\end{array}$ & Industrial & $\begin{array}{l}\text { Other } \\
\text { countries }\end{array}$ & Finland & France & UK & $\begin{array}{c}\text { West } \\
\text { Germany }\end{array}$ & Italy & Portugal & USA \\
\hline 43.9 & 0.1 & 1.6 & & 0.6 & & 1.0 & & 0.3 & \\
\hline 34.9 & 0.8 & 1.4 & 0.3 & 0.1 & 1.1 & 0.3 & 1.0 & 0.7 & 1.8 \\
\hline 30.6 & 0.5 & 1.5 & & 0.0 & 1.7 & 0.7 & 0.7 & 0.4 & 0.7 \\
\hline 38.1 & 0.4 & 1.8 & & & 1.4 & & 0.8 & 0.7 & 1.1 \\
\hline 28.2 & 0.8 & 1.4 & 0.4 & 1.3 & 1.3 & 0.8 & 1.6 & 0.3 & 0.2 \\
\hline 35.8 & 0.7 & 1.4 & & 0.2 & 1.2 & 1.0 & & 0.9 & 2.0 \\
\hline 70.6 & 1.6 & 0.5 & 0.2 & 0.1 & & & 1.6 & & 6.0 \\
\hline 68.7 & 0.7 & 1.1 & 1.7 & 0.4 & & 0.2 & 1.3 & 0.2 & 0.4 \\
\hline 59.3 & 0.6 & 1.4 & 0.2 & 0.5 & & 0.4 & 1.0 & 0.5 & 1.2 \\
\hline 30.0 & 0.9 & 1.2 & & 0.9 & 1.0 & 0.9 & 1.6 & 1.3 & 1.0 \\
\hline 36.7 & 0.6 & 1.4 & 0.3 & & 0.6 & & & 0.9 & 2.0 \\
\hline 38.4 & 1.2 & 0.9 & 1.6 & & 0.7 & & 1.4 & 0.3 & 2.2 \\
\hline 37.2 & 1.0 & 1.0 & 1.2 & 0.4 & 0.5 & & 1.1 & 1.1 & 1.7 \\
\hline 93.1 & 0.8 & 1.3 & 0.4 & & 0.8 & & 1.0 & 0.8 & 0.9 \\
\hline 73.7 & 1.1 & 1.0 & 2.4 & 0.2 & 0.5 & & 0.7 & 2.1 & 0.8 \\
\hline 93.4 & 0.6 & 1.4 & 0.5 & 0.3 & 0.6 & & 0.1 & 0.8 & 1.5 \\
\hline 66.1 & 0.7 & 1.5 & 1.1 & 0.8 & 0.3 & & 0.9 & & 0.9 \\
\hline 77.5 & 0.9 & 1.4 & 1.8 & 0.1 & 0.7 & & 0.4 & 0.8 & 1.4 \\
\hline 34.0 & 1.3 & 0.9 & 0.3 & 0.8 & & & 1.4 & & 6.4 \\
\hline 46.3 & 0.8 & 1.1 & 0.1 & 0.3 & 1.2 & 0.7 & 1.0 & 0.7 & 1.6 \\
\hline 19.1 & 1.5 & 0.8 & & 2.6 & & 2.0 & 0.1 & 7.2 & \\
\hline 32.5 & 0.8 & 1.1 & 1.2 & 0.4 & & 1.0 & 0.8 & 0.6 & 1.0 \\
\hline 49.1 & 0.7 & 1.2 & 0.4 & 0.5 & & 0.7 & 0.8 & 1.1 & 0.9 \\
\hline 44.9 & 0.6 & 1.4 & 0.1 & 0.5 & & 0.5 & 1.0 & 0.9 & 0.3 \\
\hline 57.5 & 1.2 & 0.7 & 0.7 & 0.6 & & 0.6 & 0.4 & 4.2 & 1.0 \\
\hline 67.4 & 0.9 & 1.0 & 0.7 & 0.4 & & 0.7 & 0.6 & 1.2 & 1.5 \\
\hline 36.3 & 0.8 & 1.1 & 0.4 & 0.4 & 1.0 & 0.7 & 1.0 & 1.0 & 1.1 \\
\hline
\end{tabular}

0.4

\begin{tabular}{|c|c|c|c|c|c|c|c|c|c|}
\hline $\begin{array}{l}\text { cross- } \\
\text { country } \\
\text { average }\end{array}$ & Industrial & $\begin{array}{c}\text { Other } \\
\text { countries }\end{array}$ & Hungary & Romania & Slovenia & Argentina & Chile & Colombia & Mexico \\
\hline 43.9 & 0.1 & 1.6 & & & 5.1 & 4.2 & & & 1.2 \\
\hline 34.9 & 0.8 & 1.4 & 1.4 & 0.6 & 0.7 & 0.4 & 0.5 & 1.1 & 3.9 \\
\hline 30.6 & 0.5 & 1.5 & 0.7 & & 2.0 & 2.2 & 0.9 & 1.1 & 2.8 \\
\hline 38.1 & 0.4 & 1.8 & 1.2 & & 2.2 & 0.9 & 0.3 & 1.3 & 4.1 \\
\hline 28.2 & 0.8 & 1.4 & 1.8 & & 0.9 & 0.1 & 0.9 & 0.3 & 3.1 \\
\hline 35.8 & 0.7 & 1.4 & 0.4 & 0.7 & 2.5 & 0.4 & 0.6 & 1.9 & 2.6 \\
\hline 70.6 & 1.6 & 0.5 & & & & 1.1 & 0.5 & 2.5 & 0.9 \\
\hline 68.7 & 0.7 & 1.1 & 0.4 & 1.6 & 1.8 & 2.4 & 0.6 & 0.6 & 1.6 \\
\hline 59.3 & 0.6 & 1.4 & 1.3 & 1.9 & 0.7 & 0.9 & 0.7 & 0.8 & 2.9 \\
\hline 30.0 & 0.9 & 1.2 & 0.8 & 1.4 & 0.5 & 0.1 & 0.6 & 1.3 & 2.9 \\
\hline 36.7 & 0.6 & 1.4 & 1.0 & 0.6 & 0.7 & 0.5 & 2.0 & 0.4 & 4.2 \\
\hline 38.4 & 1.2 & 0.9 & 1.4 & & 1.1 & 0.4 & 0.8 & 0.3 & 2.0 \\
\hline 37.2 & 1.0 & 1.0 & 1.9 & 0.6 & 1.3 & 1.0 & 0.3 & 0.8 & \\
\hline 93.1 & 0.8 & 1.3 & 1.8 & 2.3 & 1.1 & 0.8 & & 0.1 & \\
\hline 73.7 & 1.1 & 1.0 & 2.4 & 1.3 & 0.5 & 0.1 & 0.9 & 0.1 & \\
\hline 93.4 & 0.6 & 1.4 & 3.0 & 0.3 & 3.1 & 1.4 & 1.0 & & \\
\hline 66.1 & 0.7 & 1.5 & 0.4 & 2.9 & 2.0 & 0.6 & 1.7 & 0.5 & \\
\hline 77.5 & 0.9 & 1.4 & 2.4 & 1.1 & 0.5 & & 0.8 & 0.4 & 3.2 \\
\hline 34.0 & 1.3 & 0.9 & 0.3 & 0.9 & & & & 2.7 & 3.0 \\
\hline 46.3 & 0.8 & 1.1 & 1.6 & 0.7 & 0.7 & 1.4 & 0.8 & 0.2 & 2.9 \\
\hline 19.1 & 1.5 & 0.8 & & & 1.6 & & & & 3.8 \\
\hline 32.5 & 0.8 & 1.1 & 0.2 & & 1.8 & 1.6 & & & 2.6 \\
\hline 49.1 & 0.7 & 1.2 & 0.7 & 1.2 & 1.6 & 1.8 & & & 1.3 \\
\hline 44.9 & 0.6 & 1.4 & 1.4 & 1.4 & 1.8 & 1.9 & & & 1.2 \\
\hline 57.5 & 1.2 & 0.7 & & 0.6 & 0.7 & 0.9 & & & 1.4 \\
\hline 67.4 & 0.9 & 1.0 & 0.6 & 0.5 & 1.6 & 1.8 & & & 1.4 \\
\hline 36.3 & 0.8 & 1.1 & 0.9 & 0.7 & 1.2 & 1.6 & 0.5 & 1.1 & 2.4 \\
\hline
\end{tabular}




\section{Controlling for sectoral composition and right-censoring}

The survival analysis discussed so far suffers from two problems: i) as in the case of firm size and firm turnover, differences in sectoral composition are likely to influence the observed cross-country differences in survival rates; and ii) right censoring makes comparisons problematic especially for countries for which we have short longitudinal series. In order to compare survival and exit hazards across countries and sectors, and to cope with the rightcensoring and other problems in the data (in some countries, non-monotonic survival rates), we complement non-parametric counts with a statistical survival analysis. The survival distribution function (SDF) is used to describe the lifespan of the population of interest. The SDF evaluated at $t$ is the probability that an experimental unit from the population will have a lifetime, $\mathrm{T}$, of at least $t$, that is:

$$
S(t)=\operatorname{Pr}(T \geq t)
$$

where $S(t)$ denotes the survival function and $T$ is the lifetime of a randomly selected experimental unit.

Some functions closely related to the SDF are the cumulative distribution function $(\mathrm{CDF})$, the probability density function (PDF) and the hazard function (HF). These are defined as:

$$
\begin{aligned}
& C D F: F(t)=1-S(t) \\
& P D F: f(t)=\frac{\partial F(t)}{\partial t} \\
& H F: h(t)=\frac{f(t)}{S(t)}
\end{aligned}
$$

We have used the Cox' proportional hazard model to study firm survival. This model assumes a $p$ parametric form of the effects of the explanatory variables on syurvival, but it allows an unspecified form for the underlying survival function. The survival time of each member of a population is assumed to follow its own hazard function:

$$
h_{i}(t)=h\left(t ; z_{i}\right)=h_{0}(t) e^{z_{i}^{\prime} \beta}
$$

with $h_{0}(t)$ an arbitrary and unspecified baseline hazard function, $z_{i}$ the vector of measured explanatory variables for the $i$ th individual and $\beta$ the vector of unknown regressions parameters associated with the explanatory variables (this vector is assumed to be the same for all individuals).

The survival function can be expressed as:

$$
\begin{aligned}
& S\left(t ; z_{i}\right)=S_{0}(t) e^{z_{i}^{\prime} \beta} \\
& S_{0}(t)=e^{-\int_{0}^{t} h_{0}(u) d u} \text { the baseline survival function }
\end{aligned}
$$

$\beta$ is estimated using the partial likelihood function, which eliminates the unknown baseline hazard $h_{0}(t)$ and accounts for censored survival times. 
The population under study may consist of a number of subpopulations, each of which has its own baseline hazard function. To adjust for such subpopulation differences a stratified analysis can be performed. Under the stratified model, the hazard function for the $j$ th individual in the $i$ th stratum is expressed as:

$$
h_{i j}(t)=h_{i 0}(t) e^{z_{i j}^{\prime} \beta}
$$

with hi0(t) the baseline hazard function for the ith stratum, zij the vector of measured explanatory variables for the jth individual, and $\beta$ the vector of unknown regressions parameters associated with the explanatory variables (this vector is assumed to be the same for all individuals).

The hazard ratios, computed by calculating the exponential of the parameter coefficients, are useful in interpreting the results of the analysis. If the hazard ratio of a prognostic factor is larger than 1, an increment in the factor increases the hazard rate. If the hazard ratio is less than 1, an increment in the factor decreases the hazard rate.

One of the main assumptions of the Cox proportional hazard model is proportionality. We checked for this by including time-dependent covariates in the model (interactions of the variables with age). If a time-dependent covariate is significant this indicates a violation of the proportionality assumption for that variable. If one of the variables is not proportional there are various solutions to consider: (1) change from using a semi-parametric Cox regression model to using a parametric regression model; (2) include the time-dependent variable for the nonproportional variables; (3) use a model, which stratifies on the non-proportional variables. The last option assumes that we are fitting separate models for each stratum under the constraint that the coefficients are equal, but the baseline hazard functions are not equal.

The explanatory variables included in the model are: (1) dummies for country; (2) dummies for industry (the lowest level available). The tests of all the time-dependent variables were not significant either individually or collectively so we do not have enough evidence to reject proportionality and will assume that we have satisfied the assumption of proportionality for this model.

By aggregating the survival probabilities over the industries, the survival function for each country can be computed: these are shown in figure 7 below. 
Figure 7. Semi-parametric survivor function by duration, 1990s
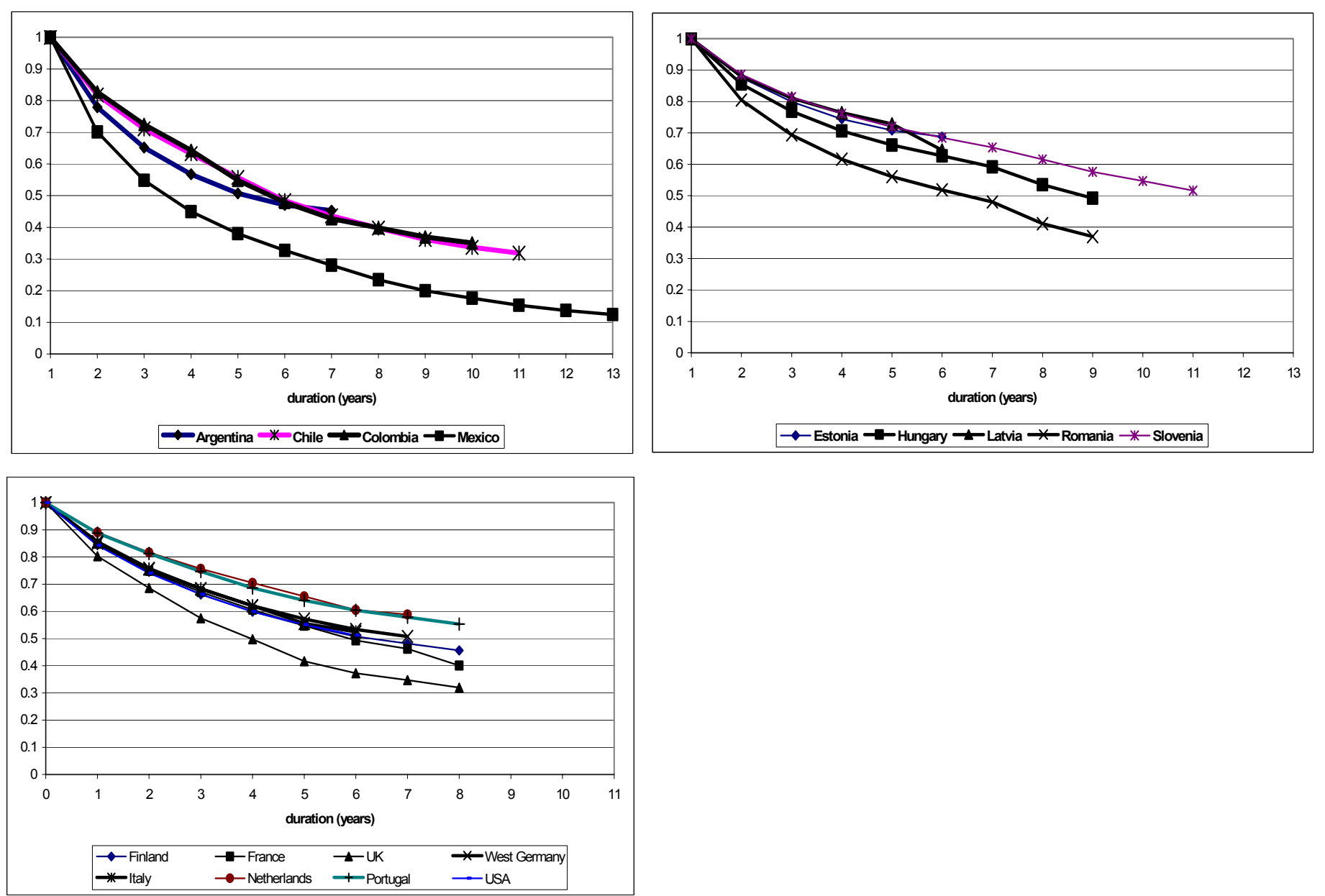

Controlling for industry composition and for right-censoring reduces the country differences in survivor rates. Amongst industrial countries, the United Kingdom shows lower survivor rates, while Netherlands and Portugal show the highest survivor rates. In Latin America, Mexico stands as the country with the lowest survivor rate, while both Colombia and Chile have higher rates. The survivor rates in transition countries seem to be shifted up-ward but Romania stands with relatively low rates compared with other countries in the group.

Another pattern of interest reflects countries with more convex survival functions so that exit rates are especially high for young businesses but decrease for older businesses so that the rank ordering of the country in terms of survival rates changes over the horizon. Countries that exhibit more convex survival functions include the U.S., Hungary and Argentina. Without more analysis, it is difficult to interpret these patterns as reflecting a more efficient "cleansing process" for poorly performing entrants. The analysis in the next section takes us in the direction of such analysis. 


\section{The effects of creative destruction on productivity}

\section{Reallocation and Productivity: Growth vs. Level Comparisons}

In the previous two sections we have presented evidence of significant cross-country differences in firm characteristics, their market dynamics and post-entry performance which cannot be fully explained by differences in sectoral composition of the economy but rather points to salient differences in market characteristics and in business environment. The next obvious question is: do these differences matter for aggregate performance? We address this question in a number of ways. First, we examine the connection between productivity growth and the reallocation dynamics that we have documented in the prior sections. We are particularly interested in the contribution of entering and exiting businesses as well as the contribution of the reallocation of activity amongst continuing businesses. However, such analysis of the contribution of reallocation to productivity growth across countries, while inherently interesting, is fraught with interpretational difficulties given our discussion in section 2 and also potentially problematic due to measurement difficulties given our discussion in section 3. We attempt to overcome some aspects of these difficulties by exploiting sectoral variation within countries in this analysis and then in turn comparing such sectoral differences between countries (i.e., a difference-in-difference approach). In addition, we explore a cross sectional decomposition of productivity that turns out to be simpler and more robust in terms of theoretical predictions and measurement.

\section{Reallocation and Productivity Growth}

Using as building blocks productivity at the firm level, as well as the inputs used in production, productivity for each industry can be decomposed into the contribution of continuing firms, entrants and exiting firms ${ }^{21}$

Let's define the sector-wide productivity level in year $t, P_{t}$ as:

$$
P_{t}=\sum_{i} \theta_{i t} p_{i t}
$$

where $\theta_{i}$ is the employment share of firm $i$ and $P_{t}$ and $p_{i t}$ are a productivity measure (in this analysis, labor productivity).

We have used three different methods for the decomposition of productivity growth. The first by Foster, Haltiwanger and Krizan (FHK henceforth, 2001) ${ }^{22}$ decomposes aggregate productivity growth into five components, commonly called the 'within effect', 'between effect', 'cross effect', 'entry effect', and 'exit effect', as follows:

21. Besides the industry decompositions of productivity, data also are collected on aggregate industry productivity levels and growth rates, un-weighted average productivity of continuing firms, entrants and exiters, and on the standard deviation of the distribution of productivity of continuers, entrants and exiters.

22. Bartelsman and Doms (2000) also use this equation but date the exiters productivity in $t$; this is an unfortunate typographical error. 


$$
\begin{gathered}
\Delta P_{t}=\sum_{i \in C} \theta_{i t-k} \Delta p_{i t}+\sum_{i \in C} \Delta \theta_{i t}\left(p_{i t-k}-P_{t-k}\right)+\sum_{i \in C} \Delta \theta_{i t} \Delta p_{i t} \\
+\sum_{i \in N} \theta_{i t}\left(p_{i t}-P_{t-k}\right)-\sum_{i \in X} \theta_{i t-k}\left(p_{i t-k}-P_{t-k}\right)
\end{gathered}
$$

where $\Delta$ means changes over the $k$-years' interval between the first year $(t-k)$ and the last year $(t) ; \theta_{i t}$ is as before; $\mathrm{C}, \mathrm{N}$, and $\mathrm{X}$ are sets of continuing, entering, and exiting firms, respectively; and $P_{t-k}$ is the aggregate (i.e., weighted average) productivity level of the sector as of the first year $(t-k){ }^{23}$

The components of the FHK decomposition are defined as follows:

- The within-firm effect is within-firm productivity growth weighted by initial output shares.

- The between-firm effect captures the gains in aggregate productivity coming from the expanding market of high productivity firms, or from low-productivity firms' shrinking shares weighted by initial shares.

- The 'cross effect' reflects gains in productivity from high-productivity growth firms' expanding shares or from low-productivity growth firms' shrinking shares.

- The entry effect is the sum of the differences between each entering firm's productivity and initial productivity in the industry, weighted by its market share.

- The exit effect is the sum of the differences between each exiting firm's productivity and initial productivity in the industry, weighted by its market share.

The FHK method uses the first year's values for a continuing firm's share ( $\theta$ it-k), its productivity level (pit-k) and the sector-wide average productivity level (Pt-k). One potential problem with this method is that, in the presence of measurement error in assessing market shares and relative productivity levels in the base year, the correlation between changes in productivity and changes in market share could be spurious, affecting the within- and between-firm effects.

To tackle these potential problems, we have also used a second approach proposed by Griliches and Regev (GR henceforth, 1995) which uses the time averages of the first and last years for them $\left(\bar{\theta}_{i}, \overline{p_{i}}\right.$, and $\left.\bar{P}\right)$. As a result the 'cross-effect', or 'covariance' term, disappears from the decomposition. ${ }^{24}$ The averaging of market shares in the GR method reduces the influence of possible measurement errors, but the interpretation of the different terms of the decomposition is less clear-cut as the time averaging makes the within effect term affected by changes in the firms' shares over time and the between effect term affected by changes in productivity over time.

23. The shares are usually based on employment in decompositions of labour productivity and on output in decompositions of total factor productivity.

24. Similarly, in case of total factor productivity decomposition using output shares, random measurement errors in output could yield a positive covariance between productivity changes and share changes, and hence, within effect could be spuriously low. 
The third method proposed by Baldwin and Gu (BG henceforth, 2003), uses as a reference for the calculations of the relative productivity of the different groups the average productivity of exiting firms. With this method, the contribution from exiting firms disappears and the entry component is positive if, on average, their productivity is higher than those of firms they are supposed to replace, the exiting firms.

In our analysis we focus much of our discussion on the FHK method, but also use the other two methods for sensitivity analysis and to better qualify some of the key results. As part of sensitivity analysis, we also explore, for a sub-set of countries, productivity decompositions over different time horizons. The baseline analysis is based on 5-year rolling windows for all periods and industries for which data are available. However we also present results for a three-year rolling windows and test the hypothesis that the contribution from entry changes with the time horizon considered. As discussed above, if new entrants undergo a significant process of learning and selection, moving from three to five years should lead to a stronger effect of entry to overall productivity. ${ }^{25}$ We also focus our discussion on results using labor productivity measured using real gross output per worker. While multi-factor productivity is conceptually preferred, it is also much more difficult to measure and the number of countries/sectors for which we have reliable measures of the evolution of multi-factor productivity is quite limited.

Figure 8 presents the decomposition of labor productivity growth in the total business sector and Figure 9 presents the decomposition of labor productivity for the manufacturing over the 1990s. Due to data availability the analysis for the total business sector is confined to a few countries, while data for manufacturing are available for a larger sample of countries.

A number of elements emerge from these decompositions:

- Productivity growth is largely driven by within-firm performance. In industrial and emerging economies (outside transition) productivity within each firm accounted for the bulk of overall labor productivity growth. This is particularly the case if one focuses on the three-year horizon (not reported); over the longer run (i.e. 5-year horizon) reallocation and, in particular, the entry component plays a stronger role to promote productivity growth.

- The impact on productivity via the reallocation of output across existing enterprises (the "between" effect) varies significantly across countries. It is generally positive but small. This factor should be combined with the covariance (or cross) term, which combined changes in productivity with changes in employment shares. The covariance term is negative in most countries, including the transition economies (in Latvia it is particularly large in the total business sector). This implies that firms experiencing an increase in productivity were also losing market shares, i.e. their productivity growth was associated with restructuring and downsizing rather than expansion. This negative cross term in a related way is potentially associated with adjustment costs of labor. That is, in any given cross section there are some businesses that have recently had a productivity shock but due to adjustment costs have not adjusted their labor inputs (at least fully). For businesses with a recent positive shock, the higher productivity will lead to a higher desired demand for labor and thus we will see such businesses increase employment but

25. Evidence for the United States suggests that moving from a five to a ten-year makes the entry contribution to aggregate productivity growth stronger (see Baily et al. 1996, 1997; and Haltiwanger, 1997). 
due to diminishing returns (in the presence of any fixed factors at the micro level) a decrease in productivity.

- Finally, the net contribution to overall labor productivity growth of the entry and exit of firms (net entry) is generally positive in most countries, accounting for between 20 percent and 50 percent of total productivity growth. While the exit effect is always positive, i.e. the least productive firms exit the market contributing to raise the productivity average of those that survive, the entry contribution tend to be negative in most OECD countries and in the non-transition emerging economies. In transition economies, in all but one country (Hungary over the three-year horizon) the entry of new firms makes a positive and often strong contribution to productivity. For most countries, while the contribution of net entry is positive, it is less than proportionate relative to the share of employment accounted for by firm turnover.

An open question is whether the observed differences across countries are accounted for by differences in market institutions and policies or whether they reflect different circumstances and/or problems of measurement. As discussed in section 2 and section 3, drawing such inferences from cross country evidence is difficult given that the policy environment may impact in a variety of ways and given the measurement problems. Still, there are some patterns worth noting. In the transition economies in particular, there is a very high rate of firm turnover as a share of total employment and entry accounts for a large (but less than proportionate to the share of turnover) share of productivity growth. The large contribution of entry partly reflects the large rate of firm turnover but it also reflects by construction a positive gap between entrants and incumbents productivity. In interpreting the latter finding, it is useful to put it in the context of the high pace of turnover. In general, it is difficult to interpret differences across countries in the magnitude of the gap between entering and exiting businesses. For example, it might reflect fundamentals driving market selection with new businesses adopting the latest business practices (or in transition economies, new businesses adopting market business practices relative to incumbents) or it might reflect a very high entry barrier so that only very productive new businesses enter. However, the latter explanation might suggest that firm turnover rates should be reduced which does not appear to be the case for the transition economies. Still, for the transition economies the contribution of net entry is far from proportionate suggesting that there is substantial churning of businesses via entry and exit that is not productivity enhancing in transition economies.

It is also interesting to note that the entry of new firms has variable effects on overall productivity growth in OECD countries. On the whole, data for European countries show that new firms typically make a positive contribution to overall productivity growth, although the effect is generally of small magnitude. By contrast, entries make a negative contribution in the United States for most industries and a stronger than average contribution tends to come from the exit of low productivity firms. Interpreting these findings without more information is difficult. The weak performance of entrants in the U.S. might reflect greater experimentation in the U.S. so that for each entering cohort of entrants there is more selection and potentially more learning by doing. Some evidence in favor of this interpretation is provided in Haltiwanger, Jarmin and Schank (2003), Foster, Haltiwanger and Krizan (2001, 2002) and Bartelsman and Scarpetta (2004). The former paper provides evidence of greater market experimentation in the U.S. relative to Germany. The latter shows that in the U.S. that as the horizon lengthens in the U.S., the contribution of net entry rises disproportionately. Moreover, Foster et. al. show that the increased contribution of net entry is due to both selection of the low productivity entrants and due to learning by doing to successful entrants. 
Figure 8 Firm-level labor productivity decomposition for Total Economy

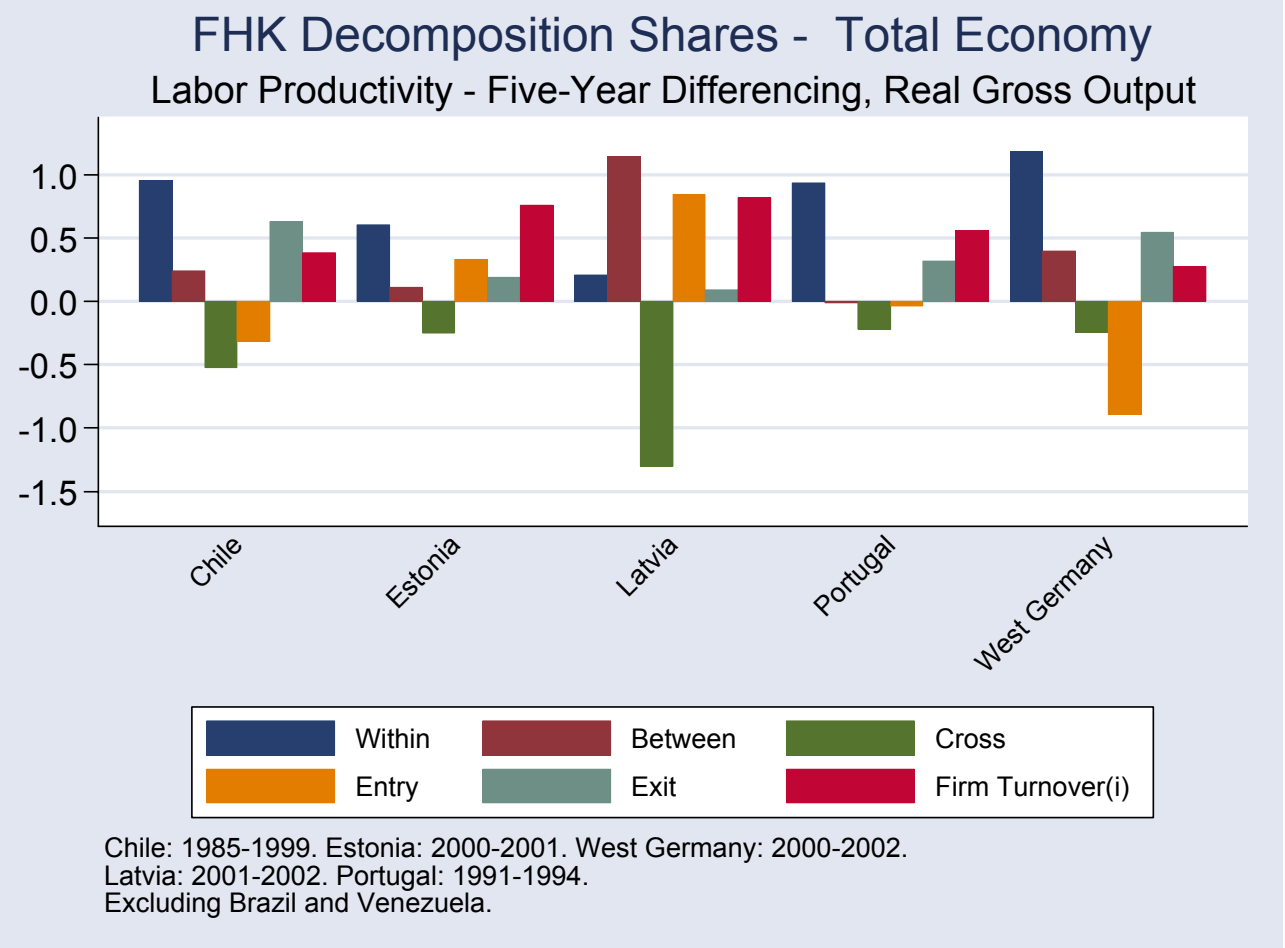

NB:

Within $=\quad$ within firm productivity growth

between $=\quad$ productivity growth due to reallocation of labor across existing firms

entry $=\quad$ productivity growth due to entry of new firms

exit $=\quad$ productivity growth due to exit of firms

Figure 9 Firm-level labor productivity decomposition for Manufacturing

FHK Decomposition Shares - Manufacturing Labor Productivity - Five-Year Differencing, Real Gross Output

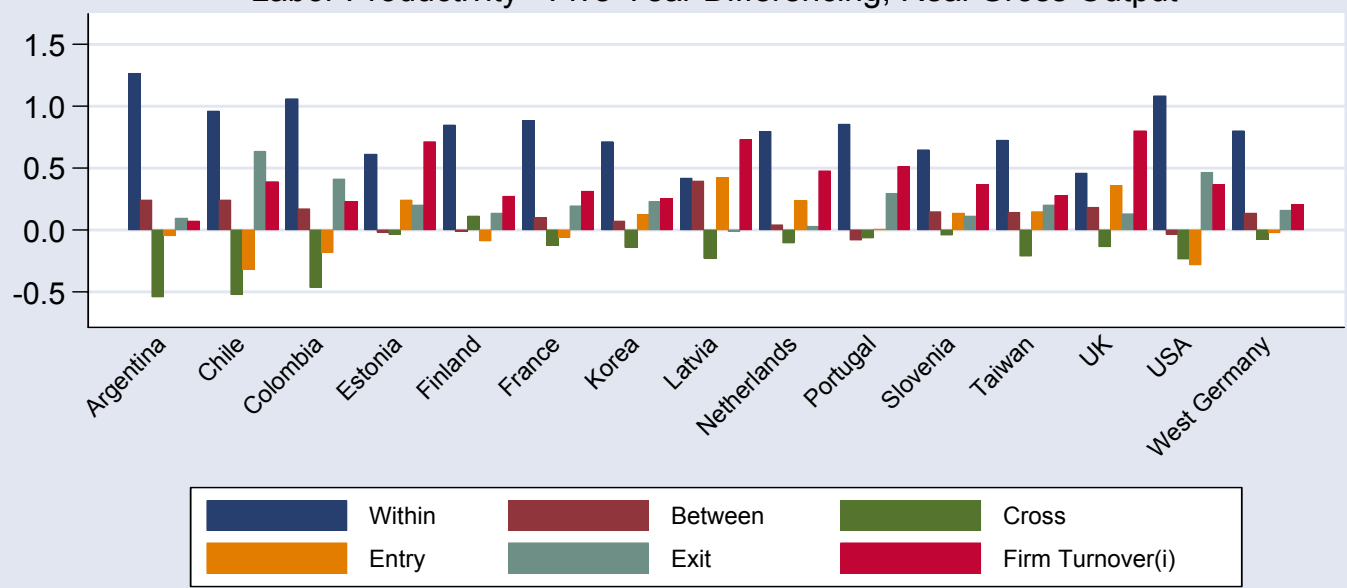

Argentina: 1995-2001. Chile: 1985-1999. Colombia: 1987-1998. Estonia: 2000-2001.

Finland: 2000-2002. France: 1990-1995. West Germany: 2000-2002. Korea: 1988 \& 1993

Latvia: 2001-2002. Netherlands: 1992-2001. Portugal: 1991-1994. Slovenia: 1997-2001.

Taiwan: 1986, 1991 \& 1996. UK: 2000-2001. USA: 1992 \& 1997

Excluding Brazil and Venezuela. 
To shed some light on the role for such horizon effects for our cross country data, Table 9 presents the difference in the components of the decomposition as the horizon increases from three to five years for selected countries (unfortunately we only have the decomposition at three and five year frequencies for a limited number of countries). To make the three and five year components comparable, the components have all been annualized. For the selected countries, increasing the horizon increases the annual contribution of net entry, decreases the annual contribution of the between component and has a mixed impact on the within component. The increase in the net entry component is largest for the transition economies with a relatively large increase of almost three percent for Estonia. For the transition economies at least, these findings are consistent with the hypothesis that learning and selection effects increase the contribution of net entry over a longer horizon. For Estonia in particular these learning and selection effects are apparently quite important.

\begin{tabular}{llrr}
\hline \multicolumn{4}{c}{ Table 9 Horizon Differences } \\
\hline \multicolumn{2}{c}{ Difference in Component from 5 to 3 Years } \\
Country & Net Entry & Between & Within \\
& & & \\
Argentina & 0.001 & -0.001 & 0.028 \\
Chile & 0.002 & -0.005 & -0.007 \\
Colombia & 0.001 & -0.005 & -0.004 \\
Estonia & 0.028 & -0.006 & -0.007 \\
Latvia & 0.019 & -0.009 & 0.027 \\
Slovenia & 0.007 & -0.001 & 0.001 \\
\hline
\end{tabular}

There is also an important sectoral dimension to the process of restructuring, reallocation and creative destruction. Figure 10 presents the productivity decompositions for two groups of industries in manufacturing: (i) the low technology industries; and (ii) the medium-high technology industries. The large negative cross-term discussed above, i.e. the fact that firms with strong productivity growth downsized, is evident in low-tech industries, while in medium high-tech industries this effect, albeit still present, seems to be smaller. Even more interestingly, the contribution of new firms to productivity growth is modest in low-tech industries, and even largely negative in a few countries including the US. But the entry effect is strongly positive in medium high-tech industries. This result suggests an important role for new firms in an area characterized by stronger technological opportunities.

One methodological issue that turns out not to be especially important in most cases is the form of the decomposition used for this analysis. To investigate the sensitivity to the decomposition methodology used, Table 10 presents the difference in the net entry component (annualized) for the FHK and BG methodologies. Recall that a key difference is that FHK use the initial average productivity of all plants as the base from which to deviate the entering and exiting plants productivity while BG use the exiters productivity. FHK motivate their approach as having desirable accounting properties - i.e., entering plants contribute positively to industry productivity growth over time if they are above the initial average while exiting plants contribute positively to industry productivity growth if they are below the initial average. BG motivate their approach as being more appropriate to the extent that entrants are displacing exiting plants so the correct reference group for entrants are the exiting businesses they are displacing. ${ }^{26}$ For most countries the difference is small and for virtually all the difference is positive. There are a couple of countries where the difference is large and positive (Korea, Slovenia and Taiwan (China)).

26. One technical limitation of this alternative is that this implies in turn that the between component uses the exiters as the base for that component and this is difficult to motivate. 
Figure 10 Productivity decomposition by technology groups
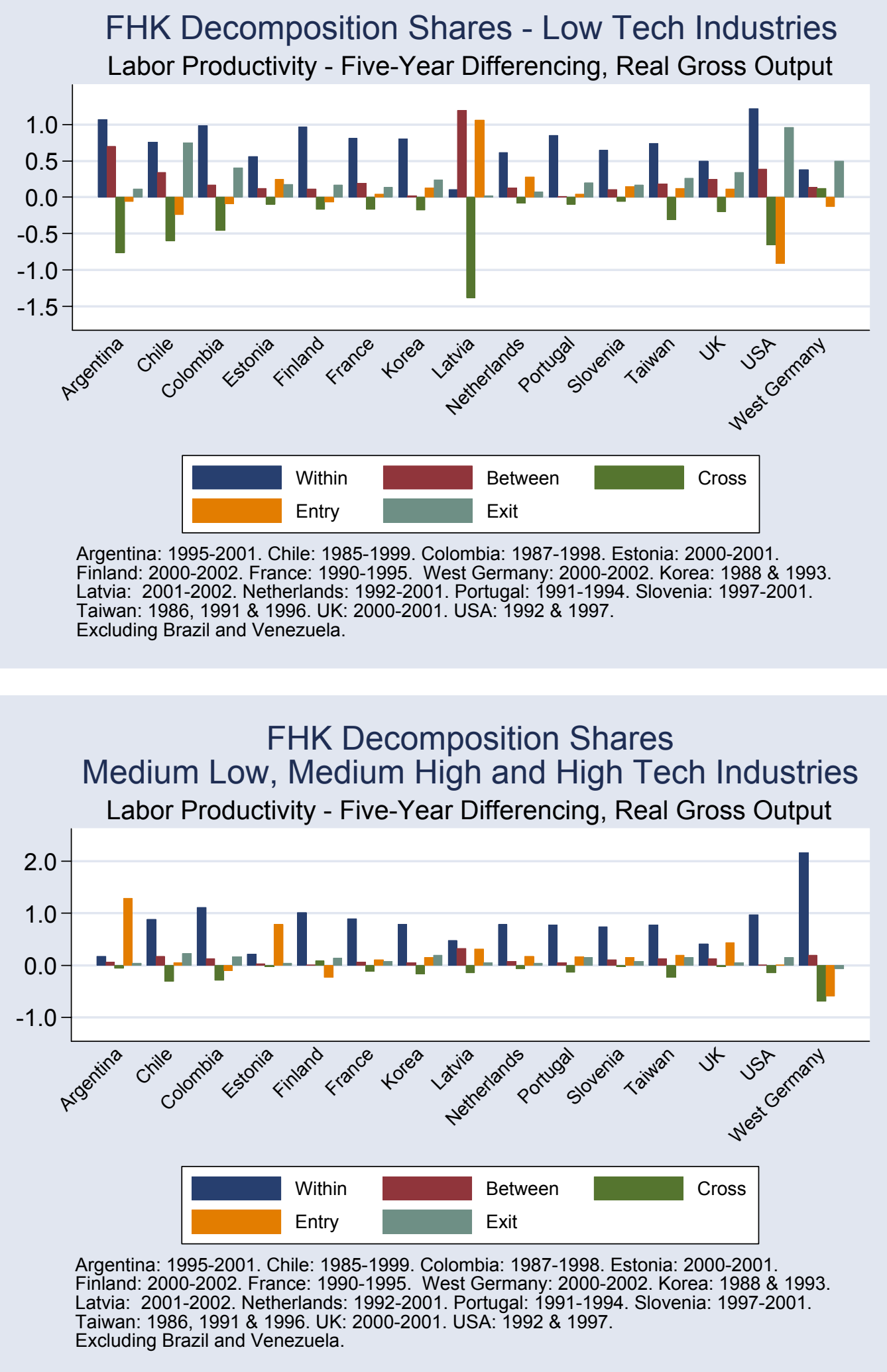
It is intuitive that the effects should in general be small because for both methods the net entry term depends critically on the difference between average productivity of entering and exiting businesses. Put differently, both the entry and the exit term subtract off whatever base is used, so at first glance it might appear that the base is irrelevant (the base term in each component cancels out in the net). Consistent with this perspective, computing the difference between the FHK and BG net entry terms yields:

$$
F H K-B G=\left(\sum_{i \in X} \theta_{i t-k}-\sum_{i \in N} \theta_{i t}\right)\left(P_{t-k}-P_{t-k}^{X}\right)
$$

where $\mathrm{P}_{\mathrm{t}-\mathrm{k}}$ is the average productivity of incumbents and $\mathrm{P}_{\mathrm{t}-\mathrm{k}}^{\mathrm{X}}$ is the average productivity of exiting businesses in the base year. Thus, if the share of activity (in this case employment) accounted for by entering and exiting businesses is the same then the difference is zero. As seen in section 4, for most countries the share of activity accounted for by entry is about the same as that for exit with the latter typically slightly larger since exiting businesses tend to be larger than entering businesses. Thus, this difference in weights does not matter for most countries. However, for Korea and to a lesser extent Portugal and Taiwan (China), the share of employment accounted for by exit is substantially less than the share of employment accounted for by entry -hence the sensitivity for these countries.

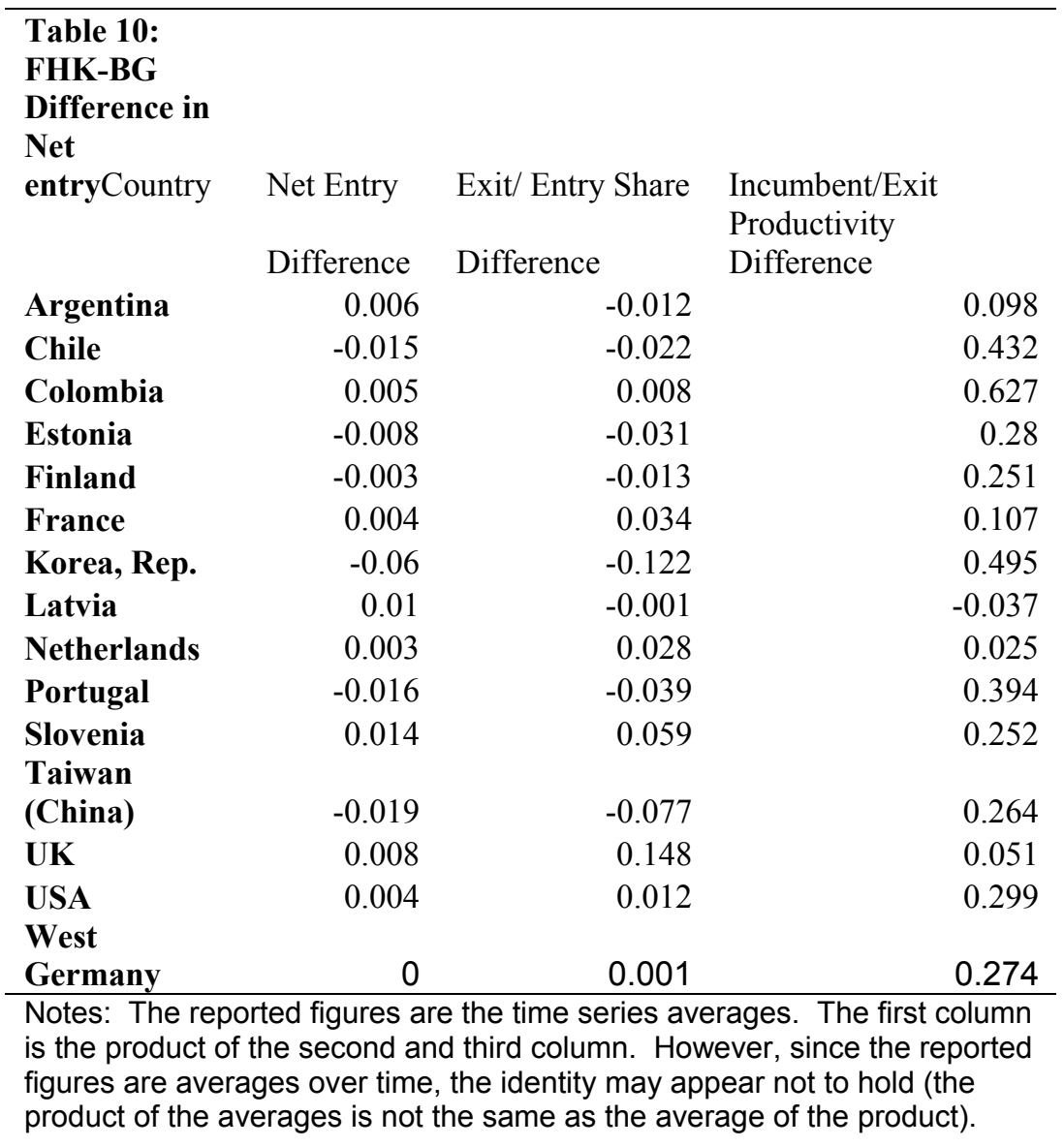




\section{The cross-sectional efficiency of the allocation of activity}

So far, the creative destruction process has been discussed mostly from the point of view of productivity growth. This is natural in this context since the creative destruction process is inherently dynamic. However, as discussed above and in section 2 at some length, distortions in market structure and institutions can distort the entry and exit margins in a variety of ways making the interpretation of the dynamic decompositions discussed above difficult. An alternative simpler and more robust approach is to ask the question - are resources allocated efficiently in a sector/country in the cross section at a given point in time. Dynamics can also be examined here to the extent that the nature of the efficiency of the cross sectional allocation of businesses can vary over time.

This approach is based upon a simple cross-sectional decomposition of productivity growth developed by Olley and Pakes (1996). They note that in the cross section, the level of productivity for a sector at a point in time can be decomposed as follows:

$P_{t}=\left(1 / N_{t}\right) \sum_{i} P_{i t}+\sum_{i} \Delta \theta_{i t} \Delta P_{i t}$

where $\mathrm{N}$ is the number of businesses in the sector and $\Delta$ is the operator that represents the cross sectional deviation of the firm-level measure from the industry simple average. The simple interpretation of this decomposition is that aggregate productivity can be decomposed into two terms involving the unweighted average of firm-level productivity plus a cross term that reflects the cross-sectional efficiency of the allocation of activity. The cross term captures allocative efficiency since it reflects the extent to which firms with greater efficiency have a greater market share.

This simple decomposition is very easy to implement and essentially involves just measuring the unweighted average productivity vs. the weighted average productivity. Measurement problems make comparisons of the levels of either of these measures across sectors or countries very problematic but taking the difference between these two measures reflects a form of a difference-in-difference approach. Beyond measurement advantages, this approach also has the related virtue that theoretical predictions are more straightforward as well. Distortions to market structure and institutions unambiguously imply that the difference between weighted and unweighted productivity (or equivalently the cross term) should be smaller.

With these remarks in mind, Figure 11 presents the measure of the gap between weighted and unweighted average productivity for a sample of countries. The Figure shows the difference between the employment-weighted (logarithm of) labor productivity and the un-weighted average (logarithm of) labor productivity, and measures how many percent higher aggregate manufacturing labor productivity is than average labor productivity of firms in manufacturing. The EU countries enjoy a 25 percent productivity boost from rational allocation of resources, but have not seen much change on balance over time. SE Asian economies are on top, followed by the U.S., while the Latin American countries, except Argentina, show higher productivity boosts through resource allocation than the EU, but lower than in SE Asia. 
Figure 11 The gap between weighted and un-weighted labor productivity, 1990s

The Gap Between Weighted and Un-Weighted

Labor Productivity, 1990s

Five-Year Differencing, Real Gross Output, Manufacturing

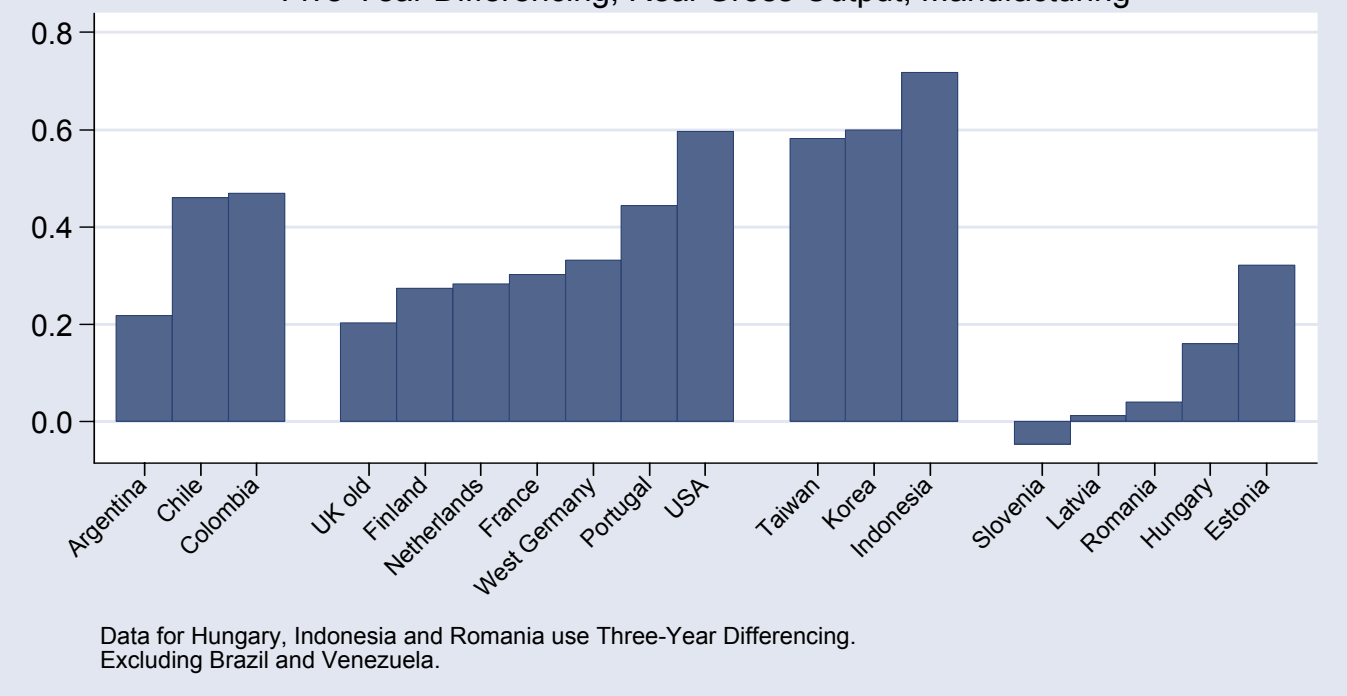

Figure 12 presents the evolution over the 1990s in the transition economies. As may be seen, the transition economies all start out at very low and sometimes negative allocation effects. A negative effect means that allocation was worse than that resulting from a toss of the dice: for some reason resources were disproportionately allocated towards poor productivity firms. However, the transition countries generally exhibit a rapid increase of this ratio over time consistent with the view that allocative efficiency improved substantially in the transition economies over this time period.

Figure 12 The evolution of the gap between weighted and un-weighted productivity in transition economies over the 1990s

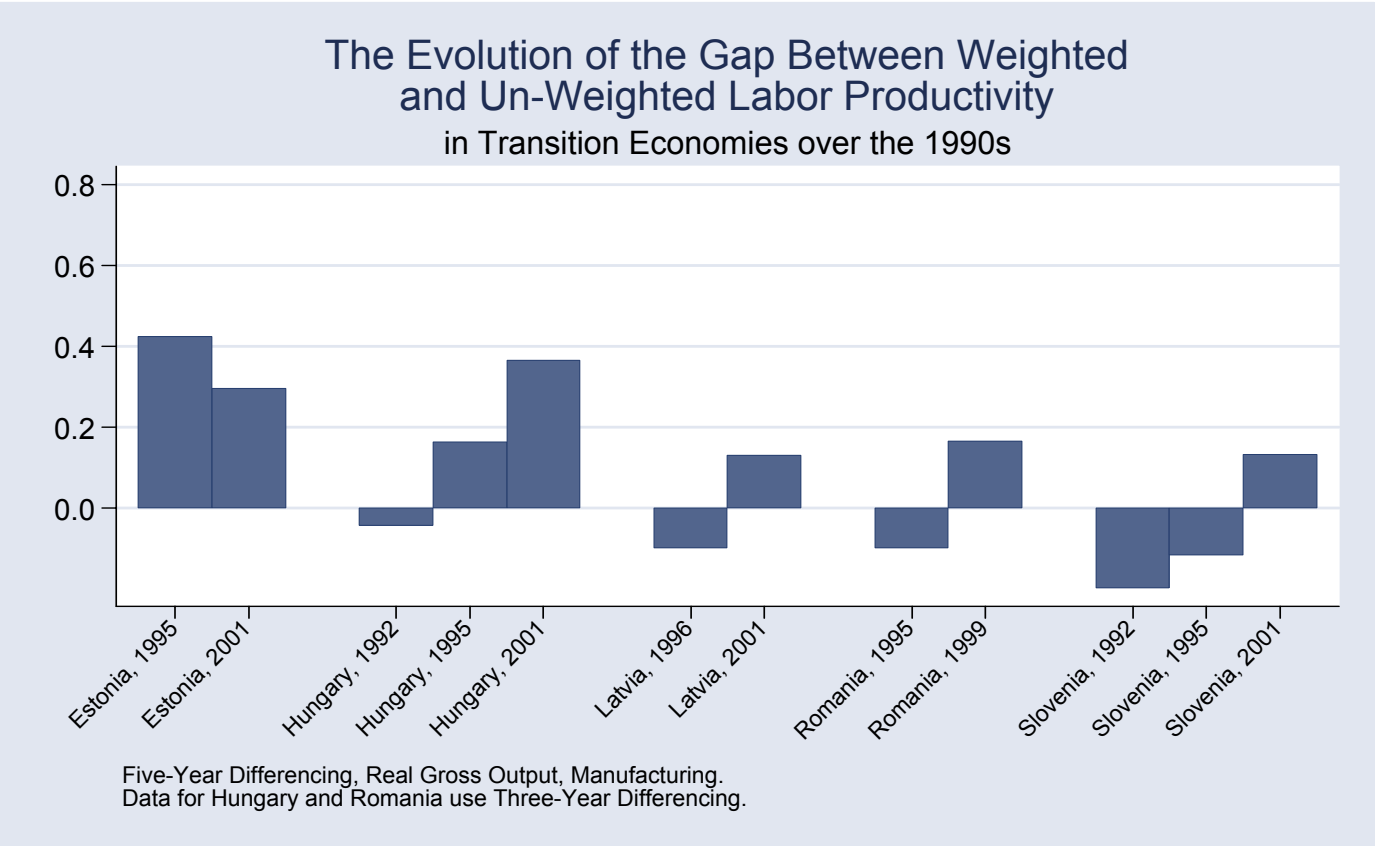




\section{Contestability Effects: The Relationship Between the Pace of Creative Destruction and Productivity Growth}

The analysis above focuses on the direct contribution of the reallocation process for productivity growth (either with the dynamic or cross sectional decomposition). These decompositions lead one to think about the reallocation contributions and the within firm contributions as being alternative explanations of productivity growth. The reallocation contributions are often interpreted in the literature as reflecting the creative destruction processes while the within firm are interpreted as reflecting more traditional sources of productivity growth (the average firm becomes more productive with advancing technology. However, rather than being alternatives, these effects (within vs. reallocation) may be closely related. That is, the pace of the creative destruction process might be interpreted as a measure of the contestability or competitive of markets. As such, greater competitive pressures may induce incumbents to perform more efficiently.

A first look at such contestability effects is provided in Figure 13. In this figure, we exploit not only the cross country variation but the variation across industries in order to be able to increase the number of observations (and since in principle the above arguments should apply across sectors as well as countries). In particular, we examine the relationship between the contribution of net entry in a country/sector (using time averages from the country/sector/year data) and the productivity growth from incumbents (the within term in the FHK decomposition). Interestingly, we find a strong positive and statistically significant correlation between the net entry contribution and the productivity growth of incumbents.

This finding is suggestive that there is a relationship between the creative destructive and within firm sources of productivity growth. If nothing else, this strong correlation suggests that these components are not orthogonal alternatives but rather closely related. It might be, however, that the correlation in Figure 13 is readily explained as reflecting the impact of technological advances for both continuing firms and for the creative destruction process. That is, it may be that with technological advances we observe incumbents who survive increase productivity and also observe entering businesses (who presumably adopt the latest advances) more productive that the exiting businesses.

To focus more on the contestability hypothesis directly, in Figure 14 we examine the relationship between the firm turnover rate and the productivity growth of incumbents. We again find a positive and statistically significant correlation. This latter finding provides more direct evidence of a connection between the competitiveness or contestability of markets and the productivity growth within incumbent firms.

A related question is whether the pace of creative destruction is also related to the productivity difference between entering and exiting businesses. Figure 15 shows the relationship between the firm turnover rate and the mean difference (unweighted) between the productivity of entering and exiting businesses. We find a strong and positive relationship here as well. ${ }^{27}$

27. Given the discussion in section 2, it is possible to justify either a positive or negative correlation. On the one hand, a higher firm turnover rate might imply greater dynamism and thus competitive forces playing a greater role in determining market selection. From this perspective, the correlation should be positive and since we found this in the data this is the interpretation we are pushing. Alternatively, greater dynamism might also be due to greater randomness in market selection and/or greater market experimentation (which adds a form of endogenous randomness). Such greater randomness in market selection would imply a negative correlation. 
These findings together suggest that greater dynamism has a strong payoff in that a higher pace of firm turnover is associated both with a higher rate of productivity growth of incumbents and a larger difference in the productivity gap between entering and exiting businesses. Appropriate caution needs to be used in drawing causal inferences as these results reflect correlations, not causality. Still, these findings suggest that understanding within firm productivity gains is closely connected with understanding the pace of turnover and the gap in productivity between entering and exiting businesses.

Figure 13 The relationship between net entry contribution and the productivity growth of incumbents.

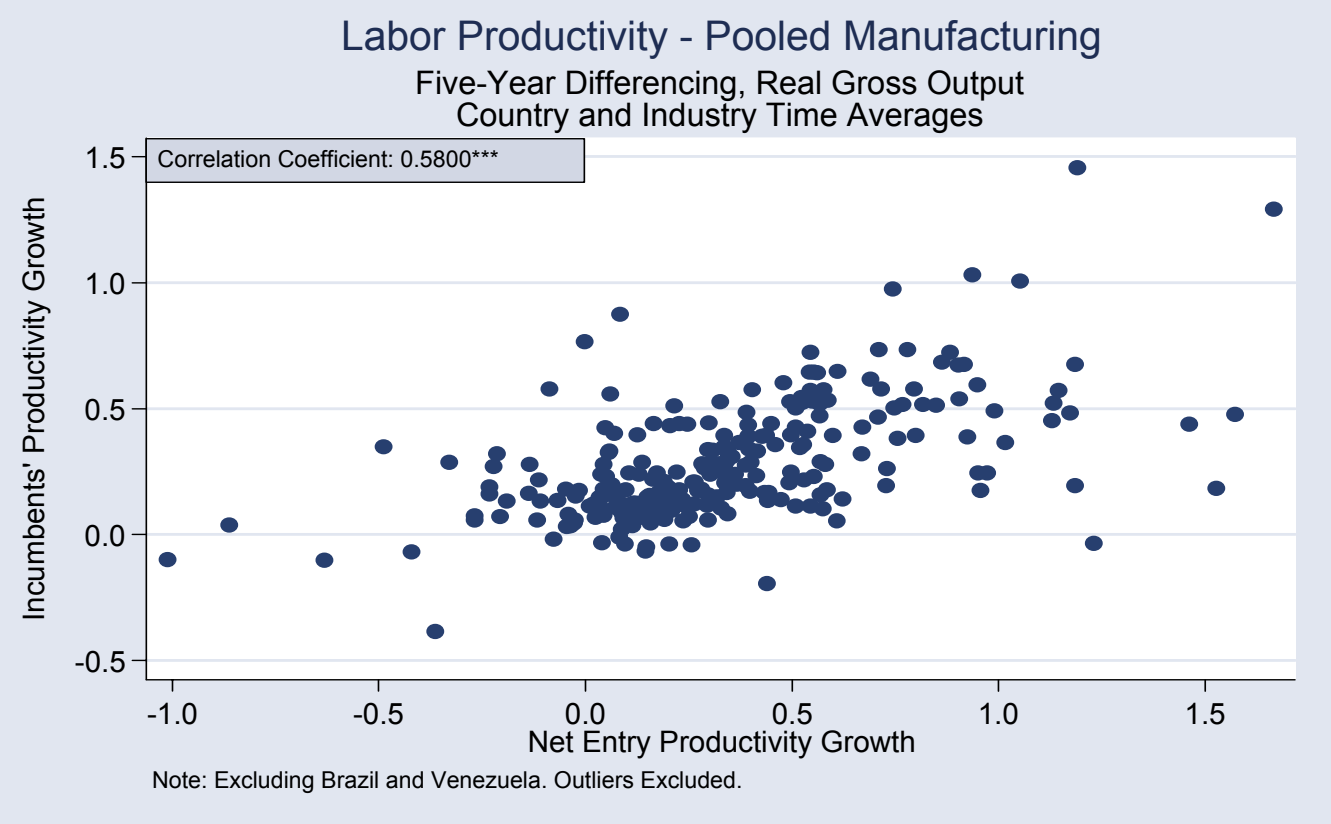

Figure 14 The relationship between the firm turnover rate and the productivity growth of incumbents

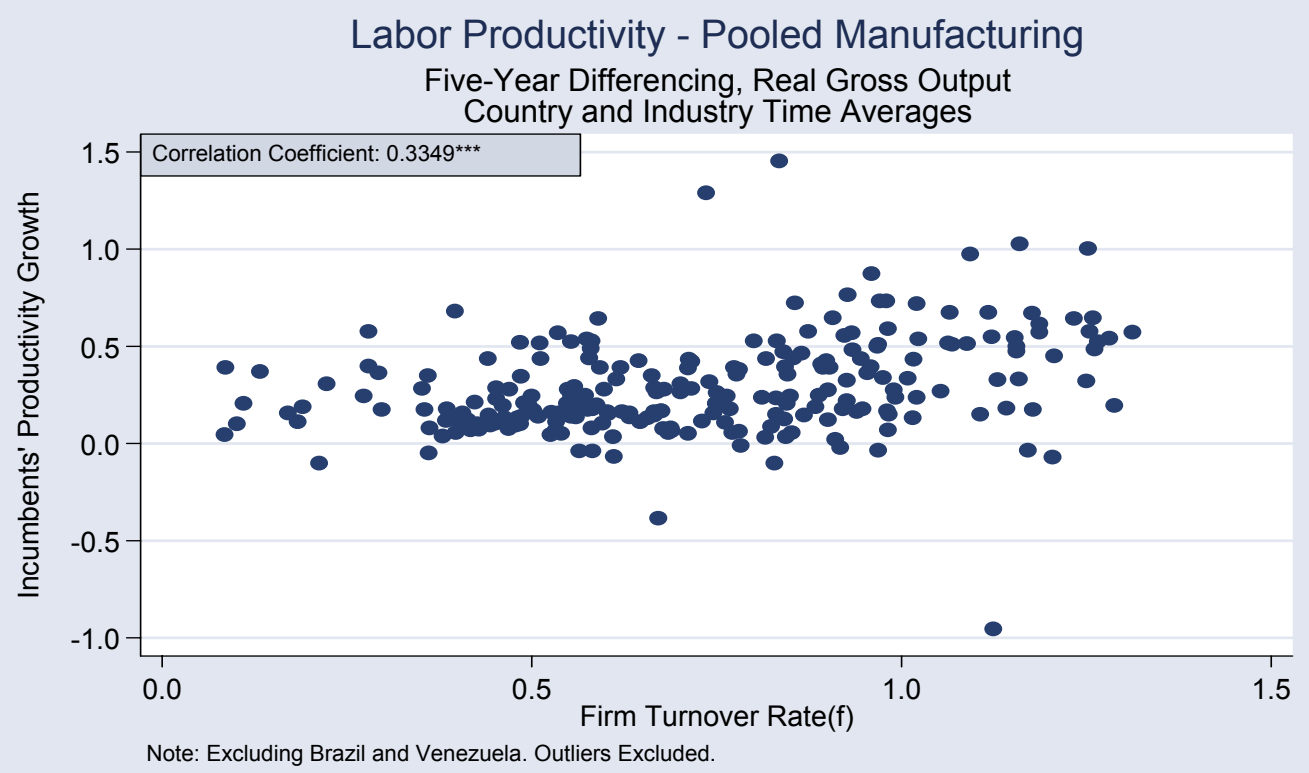


Figure 15 The relationship between the firm turnover rate and the mean productivity difference between entering and exiting businesses

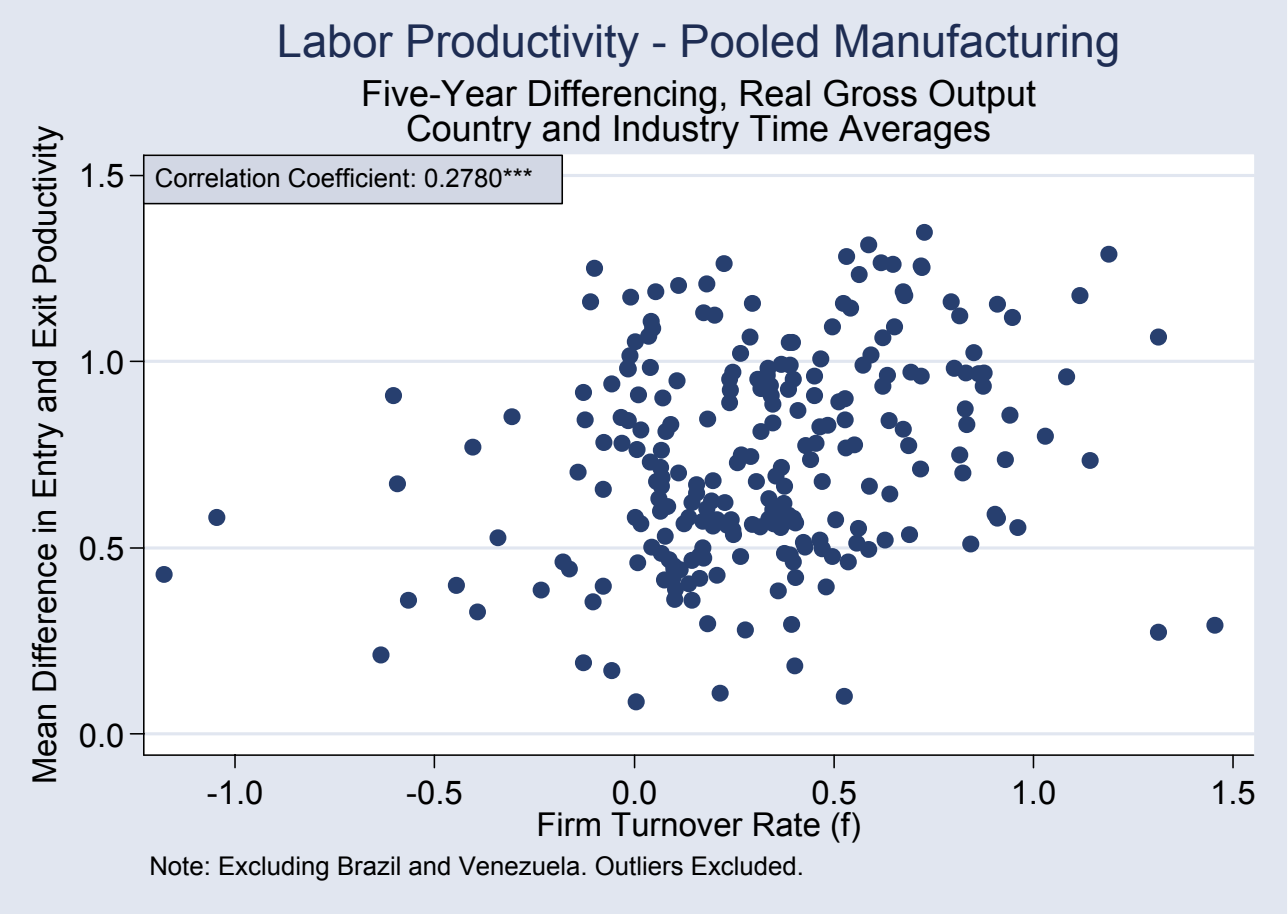

\section{Concluding remarks}

In this paper we provide an in-depth analysis of the process of creative destruction across 24 countries and 2-digit industries over the past decade. We rely on a newly assembled dataset that draws from different micro data sources (business registers, census, or representative enterprise surveys). The novelty of our approach is in the harmonization of firm-level data across countries, which enables international comparisons and the identification of country-specific factors as opposed to sectoral and time effects. Our main goal is to assess how certain stylized facts presented in the micro-economic literature of creative destruction -- largely relying on U.S. data -- are confirmed by evidence from a range of countries, characterized by different economic structures, institutions and aggregate growth performances over the period analyzed.

Overall, our data clearly suggest a significant heterogeneity of firms in each market and country. This heterogeneity is manifested in large disparities in firm size, firm growth and productivity performance. More in detail, we found:

- The average size of incumbent firms varies widely across sectors and countries. Differences in firm size are largely driven by within-sector differences, although in some countries sectoral specialization also plays a significant role. Smaller countries tend to have a size distribution skewed toward smaller firms, but the average size of firms as well as the dispersion within and across countries do not map precisely with the overall dimension of the domestic market.

- Firm churning is large: gross firm turnover involves 10-20 percent of all firms in industrial countries, and even more in transition and other emerging economies. Entering, but also exiting, firms tend to be small and thus firm flows affect only about 5-10 percent of total employment. This suggests that the entry of small firms is relatively 
easy, while larger-scale entry is more difficult, but survival among small firms is also more difficult and many small newcomers fails before reaching the efficient scale of production.

- Entry and exit rates are part of the same process. In most countries, entry and exit rates are correlated across industries. They are part of a process in which a large number of new firms displace a large number of obsolete firms (which may themselves be relatively new), without affecting significantly the total number of firms in the market at each point in time. Transition economies and some emerging countries show weaker correlations because of stronger structural changes in their economy with declining traditional sectors and expanding modern sectors.

- Market selection is pretty harsh: about 20 to 40 percent of entering firms fail within the first two years of life. Confirming previous results, failure rates decline with duration: conditional on surviving the first few years, the probability of survival becomes higher. But only about 40-50 percent of total entering firms in a given cohort survive beyond the seventh year.

- Successful entrants expand rapidly. Surviving firms are not only relatively larger but also tend to grow rapidly. The combined effect of exits being concentrated among the smallest units and the growth of survivors makes the average size of a given cohort increase rapidly toward the efficient scale.

- Creative destruction is important for promoting productivity growth. While the continuous process of restructuring and upgrading by incumbents is essential to boost aggregate productivity, the entry of new firms and the exit of obsolete units also play an important role. The contribution of firm churning to productivity is particularly important in high-tech industries -- where new technologies are often better harnessed by new firms.

- Creative destruction also promotes market contestability. A strong process of creative destruction also promotes productivity-enhancing strategies of incumbents. We have some preliminary evidence of this "contestability" effect: there is a significant correlation between firm turnover rates and incumbent productivity growth across industries and countries; and there is also a significant correlation between the net entry contribution to productivity and incumbent productivity growth. In other words, higher firm turnover is associated with stronger productivity growth of incumbents, and the more effective the process of creative destruction is for productivity, the more it stimulates growth by incumbents.

Our analysis also shows significant differences across countries along the different dimensions of our data: size, firm turnover, survival and productivity growth. These differences can be linked together to form a tentative interpretation of the nature and effectiveness of creative destruction in different contexts.

- Industrial countries. All industrial countries show a marked process of creative destruction. There are, however, some distinguishing features. There is a greater heterogeneity of firms in the United States compared with European countries, and this heterogeneity is also reflected in the composition of entrant firms. New firms tend to be smaller in relative size than incumbents and with lower productivity levels than their counterparts in Europe. But market selection and learning effects imply that successful 
surviving entrants expand rapidly, generating stronger post-entry growth, while low productivity entrants exit rapidly, freeing resources for new ventures. These features may indicate a different degree of market experimentation in the United States compared with Europe. Related to this, the European countries exhibit markedly worse static allocation of resources than the United States.

- Transition economies. Creative destruction assumes an even stronger role in the five Central and Eastern European countries in transition. The magnitude of firm creation and destruction is generally larger than that observed in industrial countries: many new smaller firms have been replacing obsolete larger units inherited from the central plan period. Moreover, new firms have filled in new market niches enjoying, especially in the early years of transition, less competition and higher survival rates. But market forces have quickly strengthened, with some stabilization and equilibration in entry and exit rates, as well as with increasing failure rates among new firms. The process of resource reallocation has become increasingly effective over the transition, shifting resources to new but also more productive firms. There are also interesting differences across countries. Hungary as well as some small open economies in transition (Estonia, Latvia and Slovenia) have all experienced a strong creative destruction process, with large post entry growth and a marked contribution of the new entry (as well as exit) to productivity growth. Romania is still dominated by some large firms; entry of new firms have increased rapidly in recent years when market reforms were advanced, but even successful new firms seem to have difficulty in expanding.

- Emerging economies of Latin America and East Asia. It is more difficult to trace common patterns for the other emerging economies. Mexico shows strong market dynamism, with large entry and exit flows, strong market selection of new entrants and strong post entry growth of successful entrants. NAFTA likely created an environment that was conducive to such growth. By contrast, Argentina resembles more some continental European countries with somewhat lower firm turnover, yet strong market selection that however is not associated with large post entry growth of successful firms. Moreover, creative destruction seems to play a relatively small role in promoting productivity growth. For the other Latin American countries, data cover only manufacturing and firms above a certain size, making comparisons more difficult. Finally, Korea, Indonesia and Taiwan (China) all show that creative destruction plays a strong role in promoting productivity growth. 


\section{References}

Ahn, S. (2000). "Firm dynamics and Productivity Growth: A Review of Micro Evidence from OECD Countries.” OECD Economics Department Working Paper No. 297, Paris.

Aw, B.Y., S. Chung and M. Roberts (2002). "Productivity, Output, and Failure: A Comparison of Taiwanese and Korean Manufacturers." NBER Working Paper 8766, forthcoming in Economic Journal.

Baily, Martin N., Charles Hulten, and David Campbell (1992). "Productivity Dynamics in Manufacturing Establishments." Brookings Papers on Economic Activity: Microeconomics, pp. 187-249.

Baldwin, J. and W. Gu (2003). "Plant turnover and productivity growth in Canadian manufacturing." Statistics Canada, April.

Baldwin, J.R. and P.K. Gorecki (1991). "Entry, Exit, and Productivity Growth", in: P.A. Geroski and J. Schwalbach, eds. Entry and Market Contestability: An International Comparison, Blackwell, Oxford.

Bartelsman Eric J. (2004). "The analysis of microdata from an international perspective." OECD Statistics Directorate, STD/CSTAT, 12.

Bartelsman, Eric and Stefano Scarpetta (2004). "Experimentation within and between firms: Any role for policy and institutions?." Paper presented at the 2004 American Economic Association Meeting, San Diego, January 3-5.

Bartelsman, Eric J. and Mark Doms (2000). "Understanding Productivity: Lessons from Longitudinal Microdata." Journal of Economic Literature 38(3), pp. 569-95.

Bartelsman, Eric J., Stefano Scarpetta and John Halitwanger (2004). "Distributed Analysis of Firm-level data from Industrial and Developing Countries." mimeo.

Bastos, F. and J. Nasir (2004). "Productivity and the Investment Climate: What Matters Most?." Working Paper.

Brown, David J. and John S. Earle (2004). "Economic Reforms and Productivity-Enhancing Reallocation in Post-Soviet Transtion.” Upjohn Institute Staff Working Paper No. 04-98.

Caballero R.J. and M.L. Hammour (1994). "The Cleansing Effect of Creative Destruction." American Economic Review 84:5, pp. 1350-68.

Caballero R.J. and M.L. Hammour (2000). "Creative Destruction and Development: Institutions, Crises, and Restructuring." National Bureau of Economic Research, Inc, NBER Working Papers: 7849.

Cabral, Luis (1995). "Sunk Costs, Firm Size and Firm Growth.” Journal of Industrial Economics 43:2 (June), pp. 161-72.

Cabral,-Luis-M-B; Mata,-Jose (2003). "On the Evolution of the Firm Size Distribution: Facts and Theory.” American-Economic-Review 93:4 (September), pp. 1075-90.

Campbell, J. (1998). "Entry, Exit, Embodied Technology, and Business Cycles." Review of Economic Dynamics 1:2 (April), pp. 371-408.

Caves, R.E. (1998). "Industrial Organization and New Findings on the Turnover and Mobility of Firms.” Journal of Economic Literature 36:4, pp. 1947-82. 
Cooper, R., J. Haltiwanger and L. Power (1997). "Machine replacement and the business cycle: lumps and bumps.” NBER Working Paper No. 5260 (revised).

Davis, Steven and John Haltiwanger (1999). "Gross Job Flows." in David Card and Orley Ashenfelter eds. the Handbook of Labor Economics, North-Holland.

Davis, Steven, John Haltiwanger and Scott Schuh (1996). Job Creation and Destruction, MIT Press.

Davis, S.J. and Henrekson, M. (1999). "Explaining National Differences in the Size and Industry Distribution of Employment." Small Business Economics 12, pp. 59-83.

Dollar, D., M. Hallward-Driemeier, and T. Mengistae (2003). "Investment Climate and Firm Performance in Developing Economies.” World Bank, Development Research Group, Washington, D.C.

Dunne, T., M. Roberts and L. Samuelson (1989). "The Growth and Failure of U.S. Manufacturing Plants.” Quarterly Journal of Economics 104, pp. 671-98.

Dunne, T., M. Roberts and L. Samuelson (1988). "Patterns of Firm Entry and Exit in US Manufacturing Industries.” Rand Journal of Economics 19:4, pp. 495-515.

Elmeskov, Jorgen, Martin, John P. and Scarpetta, Stefano (1998). "Key Lessons for Labour Market Reforms: Evidence from OECD Countries' Experiences.” Swedish Economic Policy Review Autumn 5, iss. 2, pp. 205-52.

Ericson, Richard and Ariel Pakes (1995). "Markov-Perfect Industry Dynamics: A Framework for Empirical Work.” Review of Economic Studies 62:1, pp. 53-82.

Eslava, Marcela, John Haltiwanger, Adriana Kugler, and Maurice Kugler (2004). "The Effects of Structural Reforms on Productivity and Profitability Enhancing Reallocation." Journal of Development Economics (forthcoming).

Evans, David (1987a). "The relationship between firm growth, size and age: Estimates for 100 manufacturing industries." Journal of Industrial Economics 35:4 (June), pp. 567-581.

Evans, David (1987b). "Tests for alternative theories of firm growth.” Journal of Political Economy 95:4 August, pp. 657-674.

Foster, Lucia, Haltiwanger, John, and C.J. Krizan (2001). “Aggregate Productivity Growth: Lessons from Microeconomic Evidence." in Edward Dean, Michael Harper and Charles Hulten eds. New Developments in Productivity Analysis, Chicago: University of Chicago Press.

Foster, Lucia, John Haltiwanger, and C.J. Krizan (2002). "The Link Between Aggregate and Micro Productivity Growth: Evidence from Retail Trade.” NBER Working Paper.

Geroski, Paul (1991). "Market dynamics and entry", Oxford: Basil Blackwell.

Geroski, Paul (1995). “What do we Know about Entry?” International Journal Of Industrial Organization 13, pp. 421-440.

Griliches,-Zvi; Regev,-Haim (1995). “Firm Productivity in Israeli Industry: 1979-1988.” Journal of Econometrics 65:1 (January), pp.175-203.

Hallward-Driemeier, Mary, Scott Wallsten, Lixin Collin Xu (2004). "The Investment Climate and the Firm: Firm-Level Evidence from China." mimeo. 
Haltiwanger, John, Ron Jarmin, and Thorsten Schank, (2003) "Productivity, Investment in ICT and Market Experimentation: Micro Evidence from Germany and the U.S., Center for Economic Studies Working Paper.

Haltiwanger, J. and H. Schweiger (2004). "Firm Performance and the Business Climate: Where Does ICA Fit In?” Working Paper.

Helpman, E. M. Melitz, and S. Yeaple, (2004). "Export versus FDI with Heterogeneous Firms." American Economic Review 94 (March), n1, pp. 300-316.

Hopenhayn, Hugo A. (1992). "Entry, Exit, and Firm Dynamics in Long Run Equilibrium." Econometrica 60:5, pp. 1127-50.

Jovanovic, Boyan (1982). "Selection and the Evolution of Industry." Econometrica 50:3, pp. 64970.

Jovanovic, Boyan and Glenn MacDonald (1994). "The life cycle of a competitive industry." Journal of Political Economy 102:2, pp. 322-347.

Klepper, Steven (1996). "Entry, exit, growth, and innovation over the product cycle", American Economic Review 86:3 (June), pp. 562-83.

Klepper Steven and Elizabeth Graddy (1990). "The evolution of new industries and the determinants of of market structure." Rand J. of Economics 21:1 (Spring), pp. 27-44.

Klepper Steven and Kenneth Simons (1993). "Technological Change and Industry Shakehouts." Working Paper, Carnegie Mellon, U. Pittsburgh.

Klette, Tor Jakob and Zvi Griliches (1996). "The Inconsistency of Common Scale Estimators When Output Prices Are Unobserved and Endogenous." Journal of Applied Econometrics 11:4, pp. 343-61.

Levinsohn, J. and A.Petrin (1999). "When Industries Become More Productive, Do Firms? Investigating Productivity Dynamics." NBER Working Paper 6893.

Mortensen, D. and C. Pissarides (1994). "Job creation and destruction in the theory of unemployment.” Review of Economic Studies 61, pp. 397-416.

Olley, G. Steven and Ariel Pakes (1996). "The Dynamics of Productivity in the Telecommunications Equipment Industry." Econometrica, 64:6, pp. 1263-97.

Pakes, Ariel and Richard Ericson (1998). "Empirical Implications of Alternative Models of Firm Dynamics.” J. Econ. Theory 79:1, pp. 1-45.

Roberts, M. and J. Tybout (1997). " Producer Turnover and Productivity Growth in Developing Countries" (with James Tybout), The World Bank Research Observer (February).

Sutton, John (1997). “Gibrat's Legacy.” Journal of Economic Literature 35:1, pp. 40-59. 